Linköping Studies in Science and Technology

Dissertation No. 1893

\title{
Electronic Structure of $\pi$-Conjugated Materials and Their Effect on Organic Photovoltaics
}

\author{
Chuanfei Wang
}

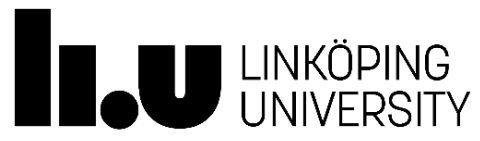

Surface Physics and Chemistry Division

Department of Physics, Chemistry and Biology (IFM)

Linköping University, SE-581 83 Linköping, Sweden 
Copyright (C) Chuanfei Wang, 2017, unless otherwise noted

Electronic Structure of $\pi$-Conjugated Materials and Their Effect on Organic Photovoltaics ISBN: 978-91-7685-393-1

ISSN: 0345-7524

Printed by LiU-Tryck, Linköping, Sweden 2017 


\begin{abstract}
The great tunability of structure and electronic properties of $\pi$-conjugated organic molecules/polymers combined with other advantages such as light weight and flexibility etc., have made organic-based electronics the focus of an exciting still-growing field of physics and chemistry for more than half a century. The application of organic electronics has led to the appearance of wide range of organic electronic devices mainly including organic light emitting diodes (OLED), organic field effect transistors (OFET) and organic solar cells (OSC). The application of the organic electronic devices mainly is limited by two dominant parameters, i.e., their performance and stability. Up to date, OLED has been successfully commercialized in the market while the OSC are still on the way to commercialization hindered by low efficiency and inferior stability. Understanding the energy levels of organic materials and energy level alignment of the devices is crucial to control the efficiency and stability of the OSC. In this thesis, energy levels measured by different methods are studied to explore their relationship with device properties, and the strategies on how to design efficient and stable OSC based on energy level diagrams are provided.
\end{abstract}

Cyclic Voltammetry (CV) is a traditional and widely used method to probe the energy levels of organic materials, although there is little consensus on how to relate the oxidation/reduction potential ( $\left(E_{\mathrm{ox}} / E_{\mathrm{red}}\right)$ to the vacuum level. Ultraviolet Photoelectron Spectroscopy (UPS) can be used to directly detect vertical ionization potential $(I P)$ of organic materials. In this thesis, a linear relationship of $I P$ and $E_{\mathrm{ox}}$ was found, with a slope equal to unity. The relationship provides for easy conversion of values obtained by the two techniques, enabling complementarily use in designing and fabricating efficient and stable OSC. A popular rule of thumb is that the offset between the LUMO levels of donor and acceptor should be $0.3 \mathrm{eV}$, according to which a binary solar cell with the minimum voltage losses around $0.49 \mathrm{~V}$ was designed here.

Introduction of the ternary blend as active layer is an efficient way to improve both efficiency and stability of the OSC. Based on our studied energy-level diagram within the integer charge transfer (ICT) model, we designed ternary solar cells with enhanced open circuit voltage for the first time and improved thermal stability compared to reference binary ones. The ternary solar cell with minimum voltage losses was developed by combining two donor materials with same ionization potential and positive ICT energy while featuring complementary optical absorption. Furthermore, 
the fullerene acceptor was chosen so that the energy of the positive ICT state of the two donor polymers is equal to the energy of negative ICT state of the fullerene, which can enhance dissociation of all polymer donor and fullerene acceptor excitons and suppress bimolecular and trap-assistant recombination.

Rapid development of non-fullerene acceptors in the last two years affords more recipes of designing both efficient and stabile OSC. We show in this thesis how non-fullerene acceptors successfully can be used to design ternary solar cells with both enhanced efficiency and thermal stability. Besides improving the efficiency of the devices, understanding of the stability and degradation mechanism is another key issue. The degradation of conjugated molecules/polymers often follow many complicated pathways and at the same time many factors for degradation are coupled with each other. Therefore, the degradation of non-fullerene acceptors was investigated in darkness by photoelectron spectroscopy in this thesis with the in-situ method of controlling exposure of $\mathrm{O}_{2}$ and water vapor separately. 


\section{Populärvetenskaplig Sammanfattning}

Stor mångfald i kemisk struktur, stor frihet i att styra elektroniska egenskaper hos $\pi$-konjugerade organiska molekyler/polymerer kombinerat med andra fördelar, såsom flexibilitet och låg vikt, har gjort organiska elektronik till ett spännande snabbväxande fält inom fysik och kemi i mer än ett halvt sekel. Tillämpningen av organisk elektronik har lett till ett brett spektrum av organiska elektroniska komponenter, främst organiska ljusdioder, organiska fält-effekt transistorer och organiska solceller. Var och hur de organiska elektroniska komponenterna används bestäms av två dominerande parametrar: deras prestanda och stabilitet. Organiska ljusdioder har framgångsrikt införts på marknaden och finns idag i TV-apparater, mobiltelefoner och surfplattor, medan de organiska solcellerna fortfarande väntar på storskalig kommersialisering på grund av låg effektivitet och sämre stabilitet. Att förstå energinivåerna hos organiska material och energinivåupplinjering i enheterna är nödvändigt för att styra effektiviteten och stabiliteten hos de organiska solcellerna. I denna avhandling undersöks energinivåerna med en rad olika metoder för att utforska deras förhållande till de optoelektroniska fenomenen i komponenterna, och strategierna för hur man konstruerar effektiva och stabila organiska solceller tillhandahålls utifrån energinivådiagrammen.

Cyklisk voltammetri är en traditionell och allmänt använd metod för att undersöka energinivåerna av organiska material, även om det finns ringa konsensus om hur man relaterar oxidations/reduktions potentialen till vakuumnivån. Fotoelektronspektroskopi kan användas för direkt detektering av vertikal joniseringspotential av organiska material. I denna avhandling hittades ett linjärt förhållande med vertikal joniseringspotential och oxidationspotential, med en lutning lika med enhet. Relationen möjliggör enkel omvandling av värden som erhållits med de två metoderna, vilket möjliggör kompletterande användning vid utformning och tillverkning av effektiva och stabila organiska solceller. En allmän tumregel att offset mellan LUMO-nivåerna av givare och acceptor borde vara $0,3 \mathrm{eV}$, enligt vilken en binär solcell med minsta spänningsförlusterna runt $0,49 \mathrm{~V}$ konstruerades här.

Introduktion av den ternära blandningen som aktivt lager är ett effektivt sätt att förbättra både organiska solcellers effektivitet och stabilitet. Baserat på vårt studerade energinivådiagram inom heltalsladdningsöverföringsmodellen konstruerade vi ternära solceller med ökad öppen 
kretsspänning, för första gången i litteraturen, och förbättrad termisk stabilitet jämfört med de binära referenssolcellerna. En ternära solcellen med låg spänningsförlust utvecklades genom att kombinera två donatormaterial med samma joniseringspotential och positiv heltalsladdningsöverföringsenergi samtidigt som de kompletterar optisk absorption. Vidare valdes fullerenacceptorn så att energin i det positiva heltalsladdningstillståndet för de två donatorpolymererna är lika med energin för fullerenens negativa heltalsladdningsöverföringstillstånd, vilket kan förbättra dissociationen av alla polymer-donatoroch fulleren acceptor excitoner och undertrycka bimolekylär rekombination och interaktion med laddningsfällor.

Den snabba utvecklingen av icke-fullerena acceptorer de senaste två åren utökar möjligheterna för att utforma både effektiva och stabila organiska solceller, vilket vi demonstrerar i denna avhandling genom att en icke-fulleren acceptorer framgångsrikt används för att designa ternära solceller med både förbättrad effektivitet och termisk stabilitet. Förutom att förbättra enhetens effektivitet är förståelsen för stabilitets- och nedbrytningsmekanismen en annan viktig fråga. Nedbrytningen av konjugerade molekyler/polymerer följer ofta många komplicerade vägar och samtidigt är många faktorer för nedbrytning kopplade till varandra. Därför undersöktes nedbrytningen av ickefullerena acceptorer i mörker genom fotoelektronspektroskopi i denna avhandling med in-situmetod för att kontrollera exponeringen av syre och vattenånga separat. 


\section{List of Publications}

1. Relationship of Vertical Ionization Potential and Oxidation potential of $\pi$-conjugated molecules/polymers

Chuanfei Wang, Liangqi Ouyang, Slawomir Braun, Xianjie Liu, Mats Fahlman Manuscript

2. Low band gap polymer solar cells with minimal voltage losses

Chuanfei Wang, Xiaofeng Xu, Wei Zhang, Jonas Bergqvist, Yuxin Xia, Xiangyi Meng, Kim Bini, Wei Ma, Arkady Yartsev, Koen Vandewal, Mats R Andersson, Olle Inganäs, Mats Fahlman, Ergang Wang

Advanced Energy Materials, 2016, 6, 1600148

3. Ternary organic solar cells with enhanced open circuit voltage

Chuanfei Wang, Xiaofeng Xu, Wei Zhang, Sadok Ben Dkhil, Xiangyi Meng, Xianjie Liu, Olivier Margeat, Arkady Yartsev, Wei Ma, Jörg Ackermann, Ergang Wang, Mats Fahlman Nano Energy, 2017, 37, 24

4. Ternary Organic Solar Cells with Minimum Voltage Losses

Chuanfei Wang, Wei Zhang, Xiangyi Meng, Jonas Bergqvist, Xianjie Liu, Zewdneh Genene, Xiaofeng Xu, Arkady Yartsev, Olle Inganäs, Wei Ma, Ergang Wang, Mats Fahlman

Advanced Energy Materials, 2017, 6, 1700390

5. Pyrrolo [3,4-g] quinoxaline-6, 8-dione-based conjugated copolymers for bulk heterojunction solar cells with high photovoltages

Xiaofeng Xu, $¥$ Chuanfei Wang, $¥$ Olof Bäcke, David I James, Kim Bini, Eva Olsson, Mats R Andersson, Mats Fahlman, Ergang Wang

( $\ddagger$ Co-first author)

Polymer Chemistry, 2015, 6, 4624 
6. Degradation of n-type non-fullerene small molecules

Chuanfei Wang, Shaofei Ni, Slawomir Braun, Xianjie Liu, Mats Fahlman Manuscript

\section{Author Contributions}

To paper 1, 2, 3, 4, 6: Did most of the experiments, wrote the first draft of manuscript, led the process of revising the manuscript and submitted the final manuscript.

To paper 5: Designed, fabricated and characterized solar cell and revised the manuscript 


\section{List of Abbreviations}

Photoelectron spectroscopy

PES

Ultraviolet spectroscopy

UPS

X-ray photoelectron spectroscopy

XPS

inverse photoemission spectroscopy

IPES

Cyclic voltammetry

$\mathrm{CV}$

Working electrode

WE

Reference electrode

RE

Counter electrode

CE

Highest occupied molecular orbital

HOMO

Lowest unoccupied molecular orbital

LUMO

Ionization potential

IP

Electron affinity

EA

Oxidation potential

Eox

Reduction potential

Ered

Normal Hydrogen Electrode

NHE

Standard Calomel Electrode

SCE

Fermi level

$\mathrm{EF}_{\mathrm{F}}$

Vacuum level

VL

Valence band

VB

Molecular orbital

MO

Charge transfer

CT

Integer charge transfer

ICT

Organic solar cell

OSC

Organic photovoltaics

OPV

Bulk heterojunction

BHJ

Donor/Acceptor

$\mathrm{D} / \mathrm{A}$

Power conversion efficiency

PCE

Short circuit current density

Jsc

Open circuit voltage

Voc 
Fill factor

Current density-voltage curve

Fourier transform photo current spectroscopy

Electroluminescence

Photoluminescence

Time resolved photoluminescence

External quantum efficiency

External quantum efficiency of electroluminescence
FF

$\mathrm{J}-\mathrm{V}$ curve

FTPS

EL

PL

TRPL

EQE

$\mathrm{EQE}_{\mathrm{EL}}$ 


\section{Contents}

Chapter 1 Introduction .........................................................................................................1

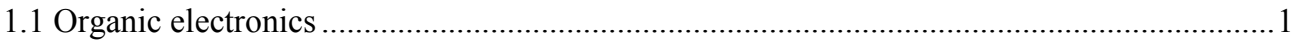

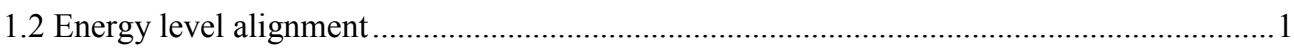

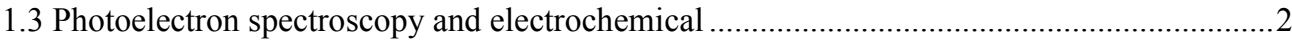

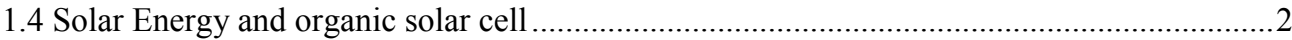

Chapter 2 Conjugated Molecules and Polymers.........................................................5

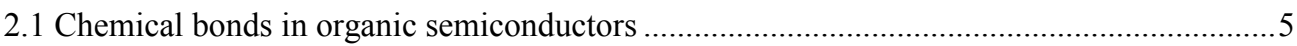

2.2 Conjugation and conjugated molecules and polymers ...................................................

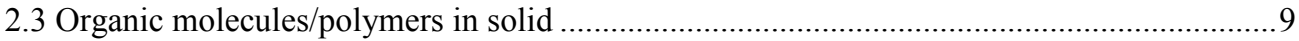

2.4 Determination of Energy levels in organic solid thin films..............................................11

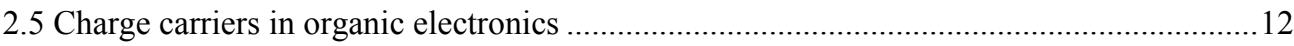

Chapter 3 Surface/Interface Properties in Organic Electronics ........................15

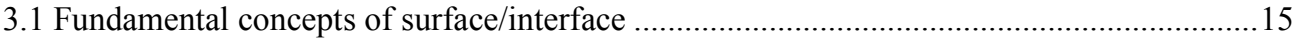

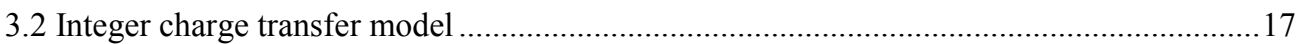

3.3 Integer charge transfer at the interface of donor and acceptor in organic solar cell.............19

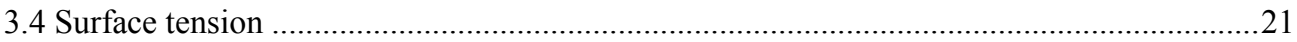

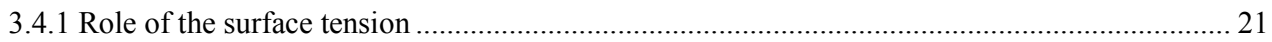

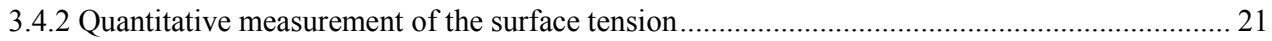

Chapter 4 Photoelectron Spectroscopy ........................................................................23

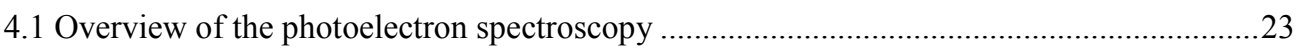

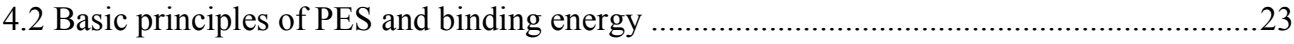

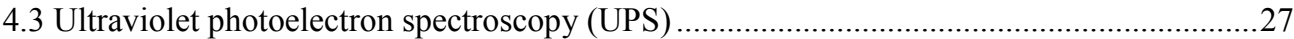

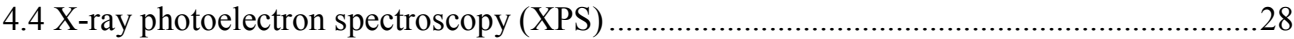

Chapter 5 Electrochemistry ............................................................................31

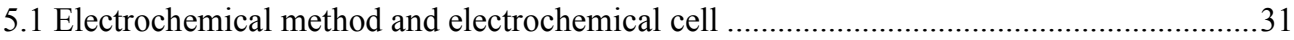

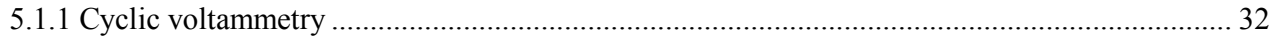

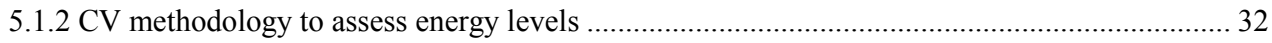

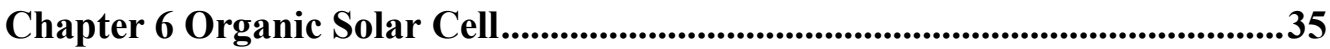

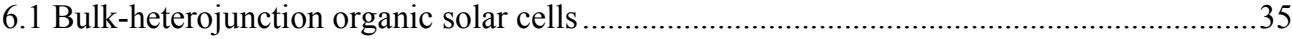

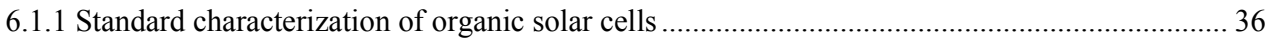

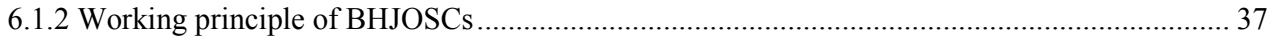




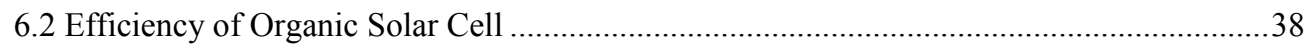

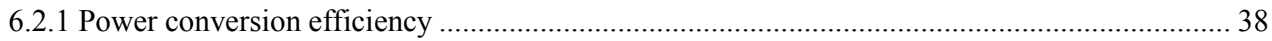

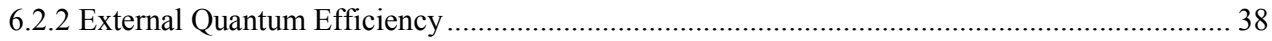

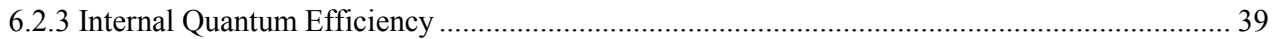

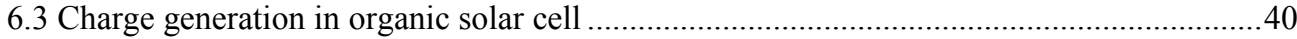

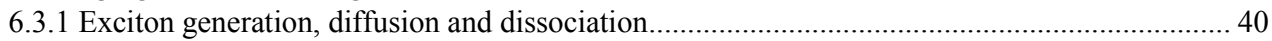

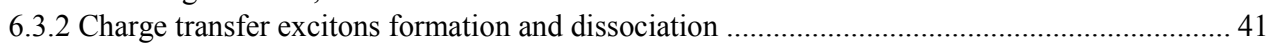

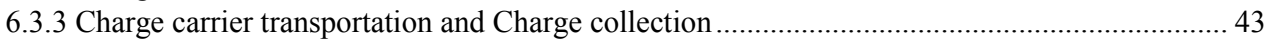

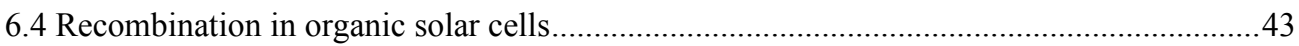

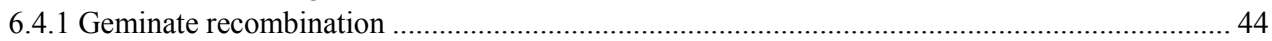

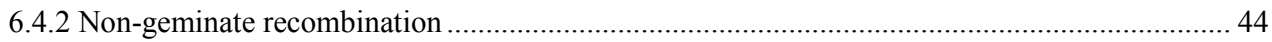

6.4.3 Distinguishing of bimolecular recombination and monomolecular recombination. .................. 45

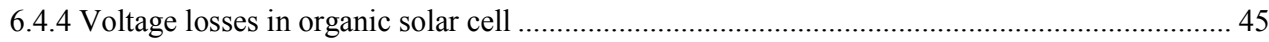

Chapter 7 Ternary Organic Solar Cell ..................................................................53

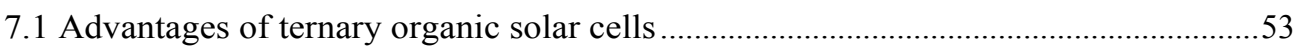

7.2 Distribution of the third component and identification methods ...............................54

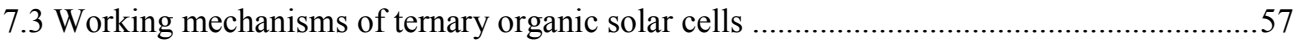

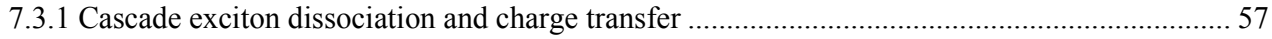

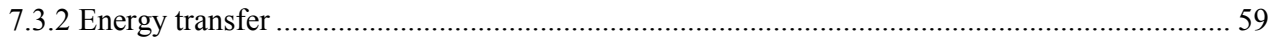

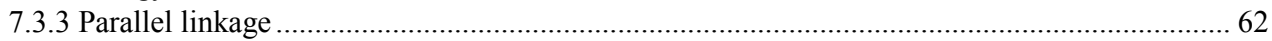

Chapter 8 Stability of Organic Solar Cell............................................................65

8.1 Parameters impacting the stability of organic solar cells ................................................65

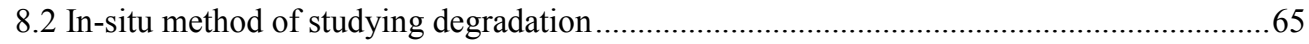

8.3 Thermal stability of the active layer containing non-fullerene acceptors..........................66

Chapter 9 Summary of Papers and Further Outlook .............................................69

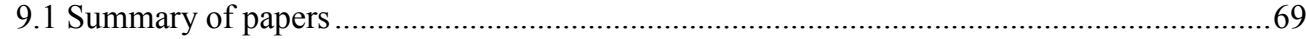

9.1.1 Paper 1

9.1.2 Paper 2 2

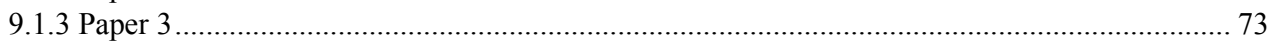

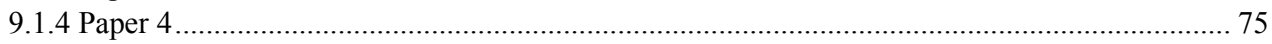

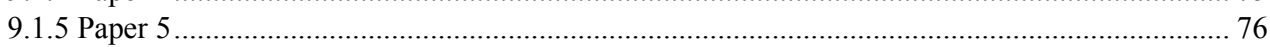

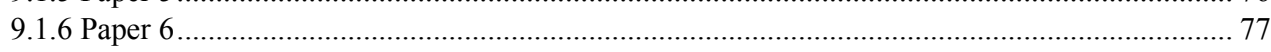

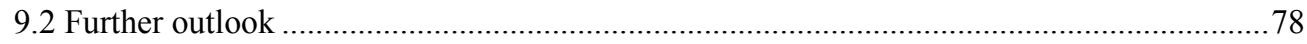

Appendix ...........................................................................................................................8

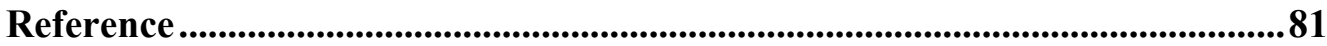




\section{Acknowledgements}

Completion of this thesis in three years was possible with the support of many people. I would like to express my appreciation to all of you who offer me support and help. Firstly, I would like to express my sincere gratitude to my supervisor Prof. Mats Fahlman. Thank you Mats for your support and for giving me the opportunity to pursue my doctoral study in the division of surface physics and chemistry. Your patience, immense knowledge and guidance in our weekly individual discussion help my project goes well. Your tutorial deepened my understanding of photoelectron spectroscopy and organic electronics. It's enjoyable working in your group and I learnt a lot from

your insightful comments and suggestions in all aspect of the research and life that are invaluable to my personal and career development.

Then I would like to thank my two co-supervisors, Dr. Xianjie Liu and Dr. Ergang Wang. Thank you Xianjie for our tremendous discussing and sharing your abundant scientific knowledge to me. I appreciate for all your instructions in the photoelectron spectroscopy and I enjoy the time working with you. Thank you Ergang for introducing me to the field of the organic electronics and giving me a lot of help in various ways. I appreciate that you would like to spend time on discussing with me and sharing me so much knowledge. Besides my supervisors, I would like to thank the past and present members in the Surface Physics and Chemistry. Thank you Slawomir for your help in the lab equipment. Thank you Karina and Kerstin for all the help with practical things. Thanks Qinye, Qian, Qi, Zhengyi, Shengwei, Jiquan, Yong Yu for your help in the lab.

My sincere thanks also goes to collaborators and stuffs in IFM. I would like to thank Prof. Olle Inganäs, Prof. Fengling Zhang, and Dr. Feng Gao. Thank you for your help and useful discussion. The sharing of the instrument in your lab promotes the progress of my project. Thanks Jonas Bergqvist for ellipsometry measurement and discussion. Than you Liangqi for help and discussing in electrochemical experiment. Thank you Yuxin, Zaifei, Zheng, Wanzhu and Xingxing for our useful discussion. I would like to thanks Chunxia and Thomas Ederth for helping me with the instrument. Thanks my mentor Lars-Göran Mårtensson. Thanks all my Chinese fiends at IFM, not explicitly mentioned here, and all other stuffs afforded help for my study and research in past three years. 
Furthermore, I would like to extend my sincere thanks to my collaborators and co-authors to the paper from other institutions. Thanks Xiaofeng in Chamers University of Technology for affording me materials and many useful discussion. Thanks Mats Anderson. Thanks Sadok Ben Dkhil, Olivier Margeat and Jörg Ackermann for hosting me in CNRS, and thank you for all your help and discussion. Thanks Wei Zhang and Arkady Yartsev in Lund University for help in TRPL measurement. Thanks Xiangyi and Wei Ma in Xi'an jiaotong University for help in GIWAXS measurement. Thanks Koen Vandewal in Dresden for checking the experiment data related to energy losses. Last but not least I would like to thank the guys in Org500 and SUSTC for your help and encouragement. Thank you Dr. Aie Wang and Prof. Peiqiang Huang. Thank you Prof. Wei Lu and Prof. Wei Jiang. I appreciate that you try your best on helping me get the scholarship. Thank you Wei Lu for all your help in various ways. Thank you Dr. Chao for all your help and visiting. Thanks prof. Bintan and prof. Xinyuan Liu. Thank you Dr. Chunyan, Yutang, Lu Yu, Shaofei, Jiang He, Ying Chen for your help. Thanks Prof. Qingshi Zhu for your recommendation and thanks China Scholarship council for a stipend.

Finally, a special gratitude goes to my family, especially my parents and my sister, for your support and encouragement for all these years. 


\section{Chapter 1 Introduction}

\subsection{Organic electronics}

Organic electronics is an interdisciplinary subject. It has been the focus of a growing body of investigation in the fields of physics and chemistry for more than half century, involving synthesis and characterization of the organic molecules/polymers and design, preparation and characterization of the devices. Since the first demonstration of a low voltage and efficient organic thin film light emitting diode (OLED), ${ }^{[1]}$ organic thin film has been proven useful in many applications, including organic thin film transistors (OFET), organic photovoltaics (OPV), organic photodetectors and organic spintronics. All these organic electronic devices with the properties of light weight, flexibility and easy solution-based processing for mass production show tremendous advantages over inorganic devices. OLED has been successful used in long lived and efficiency color displays, not far behind the OLEDs are OFET and OPV. With the property of converting solar energy to electric energy, OPV is attracting researcher's attention. It has been made great progress in the recent decade via new materials designing including low band gap donors and nonfullerene acceptors and electrode development. So-called tandem and ternary device structures also have been deployed to enhance the performance and improve the stability of OPV.

\subsection{Energy level alignment}

The preparation of any organic electronic devices typically involves the deposition of various conjugated molecules/polymers on the metal substrates to form the film, or visa verse, implying that there are would be several interfaces formation in the devices. All these interfaces can be mainly classified into metal/organic interface and organic/organic interface. During working process of the devices, all charge injection, extraction, generation and recombination mainly occur at these interfaces, all of which are crucial for the device performance enhancement. In bulk heterojunction organic solar cells, the energy level of the active layer will affect the photo absorption and stability, and the energy level alignment will affect both the voltage losses and the charge transfer exciton dissociation efficiency. When turn to the ternary solar cells, the optimization of the energy level alignment will affect the working mechanisms of the ternary solar 
cells. Thus understanding and optimization of the energetic properties is a crucial basic scientific issue.

The interactions between the interfaces involved in organic electronics are weak. Integer charge transfer (ICT) model is well developed to interpret and predict the interactions between these weakly interacting interfaces formed in the devices. ${ }^{[2]}$ According to the values of the fermi level of the substrates and the pinning energy of the conjugated molecules/polymers, there are three kinds of regime to describe the energy level alignment. (1) Fermi level pinning to the positive ICT state. (2) Vacuum level alignment (3) Fermi level pinning to the negative ICT state. In BHJOSCs, we can predict if there are spontaneous charge transfer or not between donor and acceptor in the dark ground state via comparing the $E_{\mathrm{ICT}+}$ of the donor and $E_{\mathrm{ICT}-}$ of the acceptor.

\subsection{Photoelectron spectroscopy and electrochemical}

Photoelectron spectroscopy (PES), including both traditional X-ray photoelectron spectroscopy (XPS) and ultraviolet photoelectron spectroscopy (UPS), is a powerful tool for charactering the bulk and surface chemical and electronic structure of condensed matter and is the experimental base of molecular orbital theory. In particular, the method is very useful for studying of the chemical and electronic structure of surface and interfaces. UPS has relatively high sensitivity and high resolution. It is advantageously used to study valence band. The work function (WF), vertical ionization potential (IP) and energy level alignment could be deduced from the UPS spectra. Core level electron could be detected via XPS. So the change of the chemical state could be monitored via XPS spectra. Cyclic voltammetry is a simple electrochemical technology, in the community of organic electronics, it can be used to measure the oxidation or reduction potential of the organic films, from which the absolute frontier orbital energy levels could be deduced. Different from the PES measurement, the IP deduced from the CV method in different labs are usually different from each other due to different experiment conditions and the different values of the formal potential of the reference redox couple. ${ }^{[3,4,5,6]}$

\subsection{Solar Energy and organic solar cell}

Solar is the Latin word for "sun" and it's a powerful source of energy. The enormous power that the sun continuously delivers to earth, 120000 terawatts (TW), dwarfs every other energy source, 
renewable or nonrenewable, dramatically exceeding the rate that human civilization produces and uses energy, currently about $20 \mathrm{TW} \cdot{ }^{[7]}$ Despite abundance of solar energy, we use very little of it especially in terms of electricity as shown in Figure 1.1.
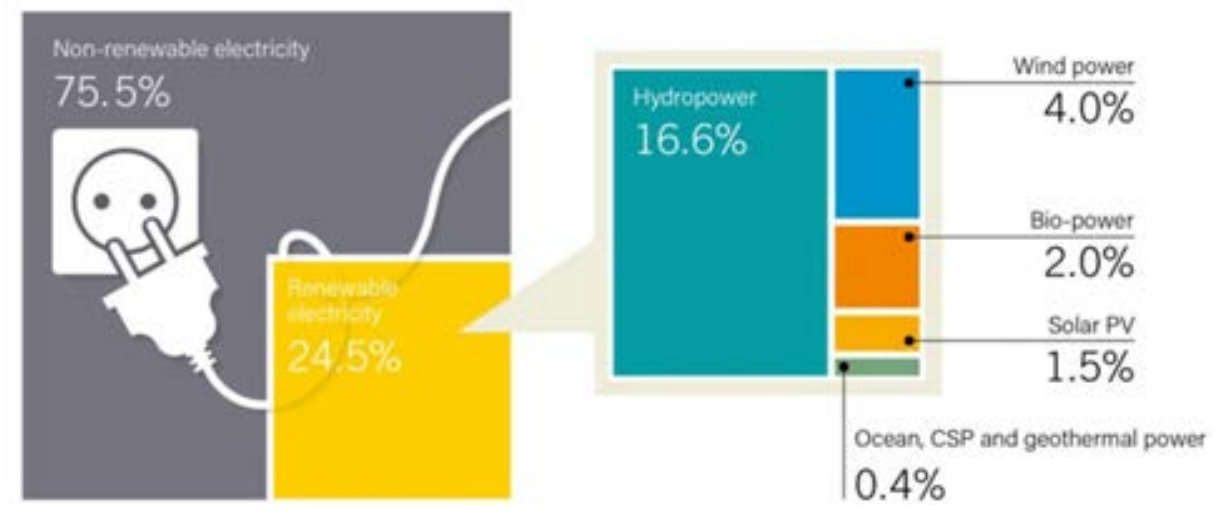

Figure 1.1 Renewables 2017 Global status report-Estimated renewable energy share of global electricity production, End 2016 ${ }^{[8]}$

Solar energy can be converted to electric energy by solar cells. At present, the market is dominated by silicon solar cells due to the high conversion efficiency as shown in Figure 1.2 and high stability. The huge success and maturity of silicon industry means there is little urgency to develop alternatives. ${ }^{[7]}$ However, the manufacturing process of the silicon solar cell is complicated and use a lot of energy.

Organic solar cells with featuring properties of light weight, flexibility and easy solution-based processing for mass production have the potential of being inexpensive in high volumes for application. Yet there are two main obstacles that need to be overcome. One is the low power conversion efficiency as shown in the Figure 1.2 and another one is the stability. The synthesis of new materials and new device structures are improving the efficiency and stability of the organic solar cell. The recent reported efficiency of single junction organic solar cell has been pushed to over $12 \%$ and the stability has also been improved, ${ }^{[9]}$ moving the field further forward to commercialization of OSCs. 


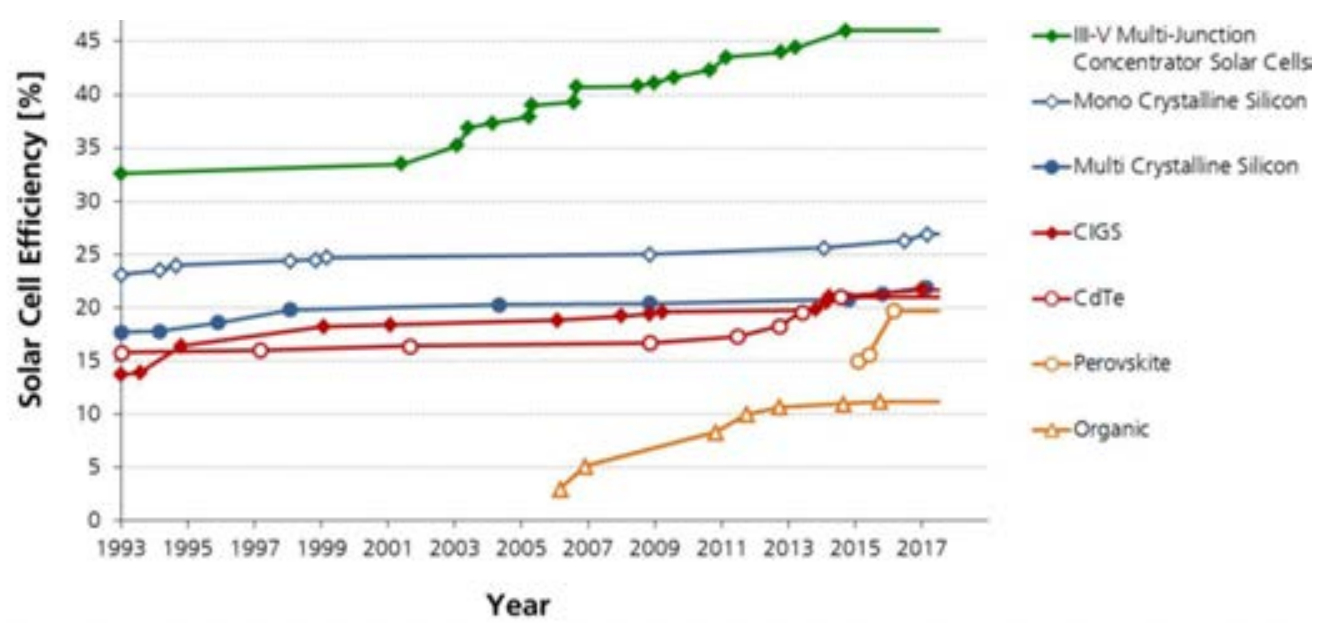

Figure 1.2 Development of Laboratory Solar Cell Efficiencies (adapted from reference). ${ }^{[10]}$

Upon the issues mentioned above, this thesis provides a comprehensive study and understanding on organic electronics, especially organic solar cells, from molecule/polymer level to the integrated devices and from the efficiency to stability. The thesis illustrates how the energy levels are determined by different technologies, UPS and CV methods, and explore what is the relationship between the values measured by different methods. How the energy level alignment affect the performance of the organic solar cells and how to control the photo voltage in binary and ternary organic solar cell according to energy level alignment at interface also is explored. The stability and degradation of n-type non-fullerene materials is studied via in situ method (PES) and we demonstrate how this kind of materials interact with oxygen and water. 


\section{Chapter 2 Conjugated Molecules and Polymers}

\subsection{Chemical bonds in organic semiconductors}

A chemical bond is an attraction between atoms and there are mainly three kinds of chemical bonds, corresponding to ionic, metallic and covalent bond. Most bonds in organic molecules/polymers are covalent bonds, which is determined by the electronic configuration of the carbon atom $\left(1 \mathrm{~s}^{2} 2 \mathrm{~s}^{2} 2 \mathrm{p}^{2}\right)$ comprising the organic molecules/polymers skeleton. In quantum chemistry, the distribution and movement state of the electrons around the nucleus can be described by the solution of the Schrödinger equation-wave function $\phi(x, y, z) . \phi$ is called atomic orbital. The distribution of the electrons around the nucleus should following the Pauli Exclusion Principle, principle of lowest energy and the Hund's rule. There are 4 valence electrons in carbon atom and it tends to lose or obtain 4 electrons to get the stable conformation, which is obvious difficult. So the carbon atoms share the electrons with other atoms to form molecules/polymers via covalent bonds. Valence bond (VB) theory is the earliest theory developed to illustrate the chemical bonds in molecules. The VB theory indicates that the covalent bond is formed between two atoms by overlapping of half-filled valence atomic orbitals of each atom containing one unpaired electron, and the covalent bond with the character of saturation that once the unpaired electrons form the covalent bond, they cannot interact with other unpaired electrons, and with the character of direction to form the most stable conformation, and the orbital with similar energy could hybridize to form the hybridization orbital with same energy. Such as the carbon atom with the valence electron configuration of $(2 \mathrm{~s})^{2}\left(2 p_{\mathrm{x}}\right)^{1}\left(2 \mathrm{p}_{\mathrm{y}}\right)^{1}\left(2 \mathrm{p}_{\mathrm{z}}\right)^{0}$ could be excited to the configuration of $(2 \mathrm{~s})^{1}\left(2 \mathrm{p}_{\mathrm{x}}\right)^{1}\left(2 \mathrm{p}_{\mathrm{y}}\right)^{1}\left(2 \mathrm{p}_{\mathrm{z}}\right)^{1}$, then hybridize to 4 equivalent $\left(\mathrm{sp}^{3}\right)^{1}$ orbitals. Except $\mathrm{sp}^{3}$ hybridization, carbon atom also can have $\mathrm{sp}^{2}$ and sp hybridization as shown in the Figure 2.1. The driving force for hybridization is that the total energy of the hybridized orbital would be lower than that of the originals orbitals. The VB theory can illustrate the formation of a bond between two atoms and explain the relationship between the structure and characteristic of molecules/polymers, but a limitation of the VB theory is that the valence electrons are localized between two atoms and cannot describe the alternating double and single bonds in conjugated organic molecules/polymers exactly. Neither can it illustrate other phenomena, such as the hydrogenation heat of butadiene is less than two times the hydrogenation heat of the ethene. 


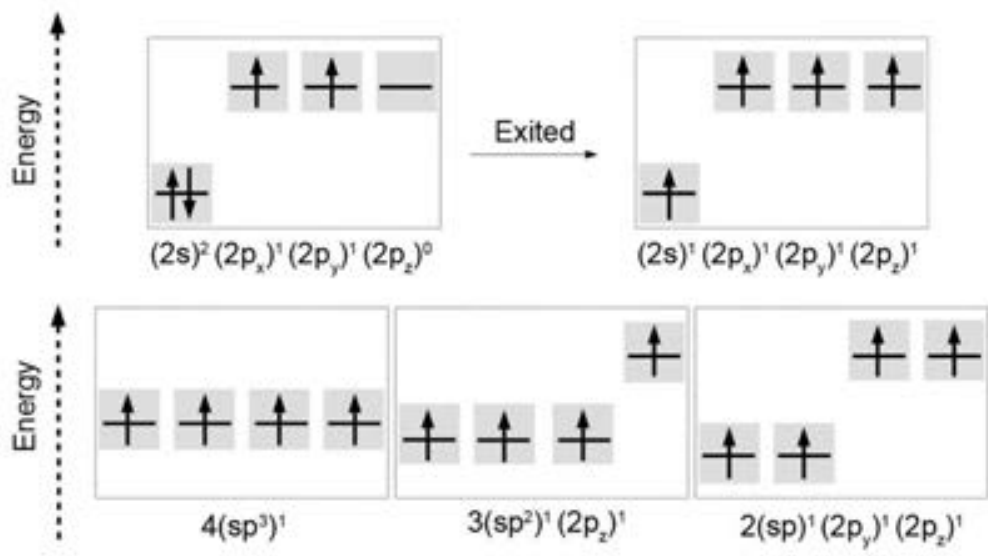

Figure 2.1 Electron configuration of the carbon atom and hybridization state.

Complementing the VB theory, the molecular orbital (MO) theory was developed later to describe the covalent bond. MO theory states that electrons are distributed in sets of MOs and can extend over entire molecule. Like VB theory, the formation of molecular orbitals obeys minimum energy principle, Hund's rules and Pauli Exclusion Principle. In quantum mechanics, molecular orbitals can also be described by the solution of the Schrödinger equation-wave function $\Psi 1$ and the most popular application of the molecular orbital method is the linear combination of atomic orbitals (LCAO), including two kinds of molecular orbital, bonding orbital, $\Psi 1=\phi_{1}+\phi_{2}$, and anti-bonding orbital, $\Psi 2=\phi_{1}-\phi_{2}$, showing in Figure 2.2.

(a)
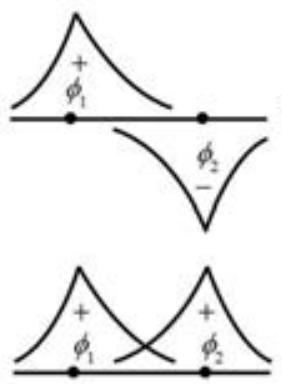
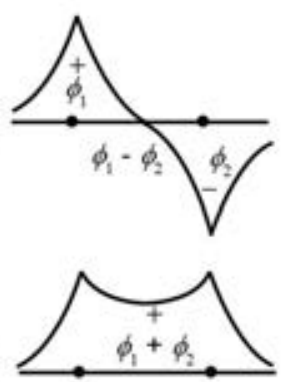

(b)

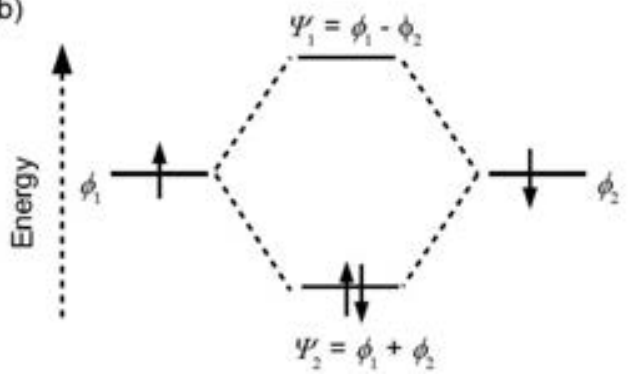

Figure 2.2 Linear combination of the atomic orbitals to form bonding orbital and anti-bonding orbital. 
In MO theory, the head on overlapping of the two atomic orbitals form the $\sigma / \sigma^{*}$ molecular orbital. The side by side overlapping of the two atomic orbitals could form $\pi / \pi^{*}$ molecular orbital. As shown in Figure 2.3, for the simple ethylene, the two carbon atoms adopt $\mathrm{sp}^{2}$ hybridization and two $\mathrm{sp}^{2}$ atomic orbitals form $\sigma / \sigma^{*}$ molecular orbital by head on overlapping, while the residual $\mathrm{p}$ orbitals overlap side by side to form $\pi / \pi^{*}$ molecular orbital. The formation of the $\pi$ molecular orbitals make the length of double bond in ethylene shorter than single bond. The formation of the $\pi$ molecular orbitals can also make the molecule more planar because the free rotation is limited.

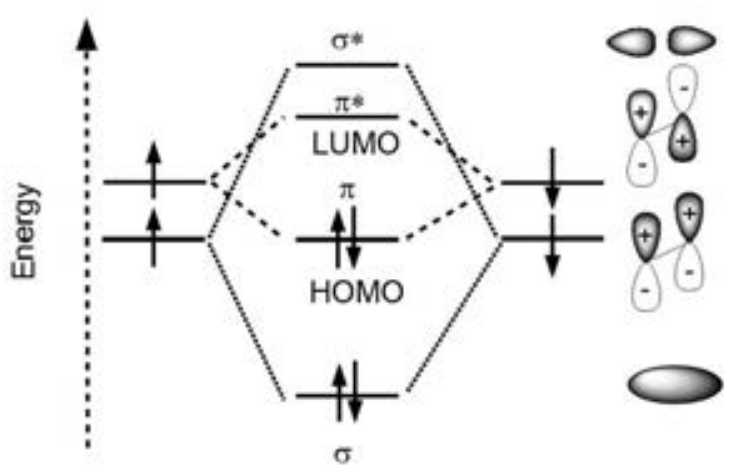

Figure 2.3 Formation of the $\sigma$ molecular orbital and $\pi$ molecular orbital

\subsection{Conjugation and conjugated molecules and polymers}

There are mainly three types of conjugation in organic molecules/polymers. They are $\pi-\pi, p-\pi$ conjugation and $\sigma-\pi$ hyper conjugation respectively (Figure 2.4 ). p- $\pi$ conjugation could be usually found between the adjacent $\pi$ orbital and p-orbital with paired electrons. The weak $\sigma-\pi$ hyper conjugation exist in the system with the $\pi$ orbital and adjacent $\mathrm{C}-\mathrm{H} \sigma$ bond. The main conjugation effect in conjugated molecules/polymers with alternating single and double bonds is $\pi-\pi$ conjugation. One simple example is butadiene as shown in Figure 2.4c, the butadiene could be considered as the connection of the two ethylene by the elimination of one hydrogen in each molecule and the unoccupied two $\mathrm{sp}^{2}$ form additional $\sigma$ bond between two carbon atoms. Usually, we only care about the $\pi$-orbitals in conjugated molecules/polymers. There are should be four $\pi$ MO in butadiene and the energy would increase with the increasing of the nodes. 
(a)

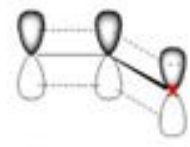

$\mathrm{X}=\mathrm{Cl}, \mathrm{OH} \ldots$

(b)

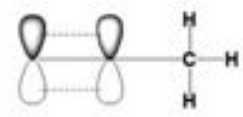

(c)
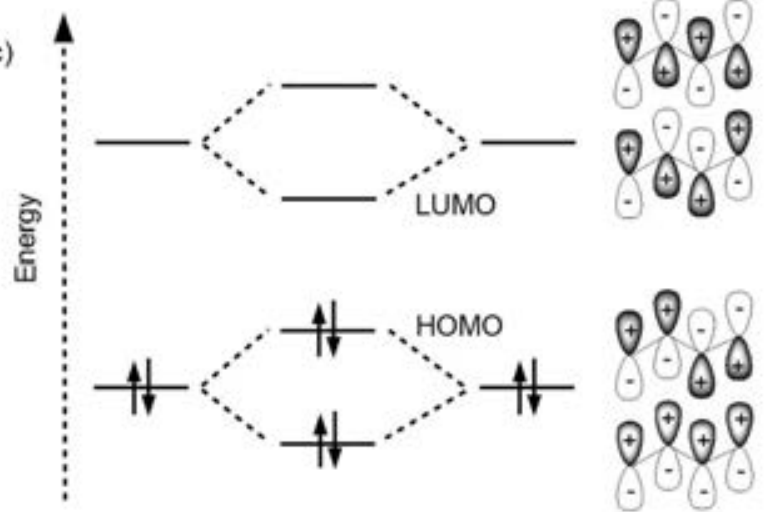

Figure 2.4, $p-\pi, \sigma-\pi$ and $\pi-\pi$ conjugation.

There are two occupied $\pi$-bonding orbitals and unoccupied $\pi$-anti-bonding orbitals in butadiene The highest occupied molecular orbital (HOMO) and The lowest unoccupied molecular orbital (LUMO) are defined as the frontier molecular orbitals. ${ }^{[11]}$ The pair of $\pi$-electrons occupying the highest orbital which are referred to as frontier electrons, playing a decisive role both in chemical activation and optoelectronic properties of the hydrocarbon molecules/polymers. The ionization potential (IP) is defined as the minimum energy needed when taking one electrons from the HOMO to the vacuum, and electronic affinity (EA) is defined as the minimum energy released when adding one electron from the vacuum level to the LUMO. The energy difference between the HOMO and the LUMO is defined as energy gap. It is well known now that the energy and energy difference between two orbitals is quantized, so the optical properties are determined by the energy of the MO and electrons can be excited from occupied orbitals to unoccupied orbitals with absorption of the energy equal to the energy difference between two orbitals. The energy gap determines the minimum energy that can be absorbed by the molecules/polymers.

It is easy to imagine that with the increase of the conjugated chain, the bonding and antibonding orbitals will form a band-like distribution, named valance band and conduction band respectively as shown in Figure 2.5. With the increase of the conjugated length, the HOMO and the LUMO would become closer, i.e. The IP would be decreased and the EA would be increased, and the energy gap between LUMO and HOMO would be decreased. 


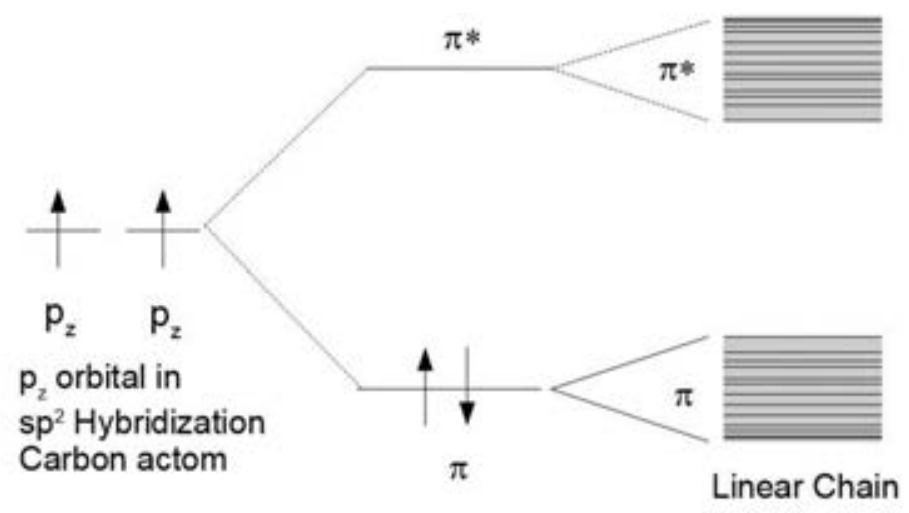

Figure 2.5 Energy level derivation in $\pi$-conjugated linear chain.

\subsection{Organic molecules/polymers in solid}

When the molecule/polymers are stacked into solid materials, the distribution of the bonding and antibonding orbitals can be further broadened as shown in Figure 2.6 due to interchain $\pi-\pi$ stacking.

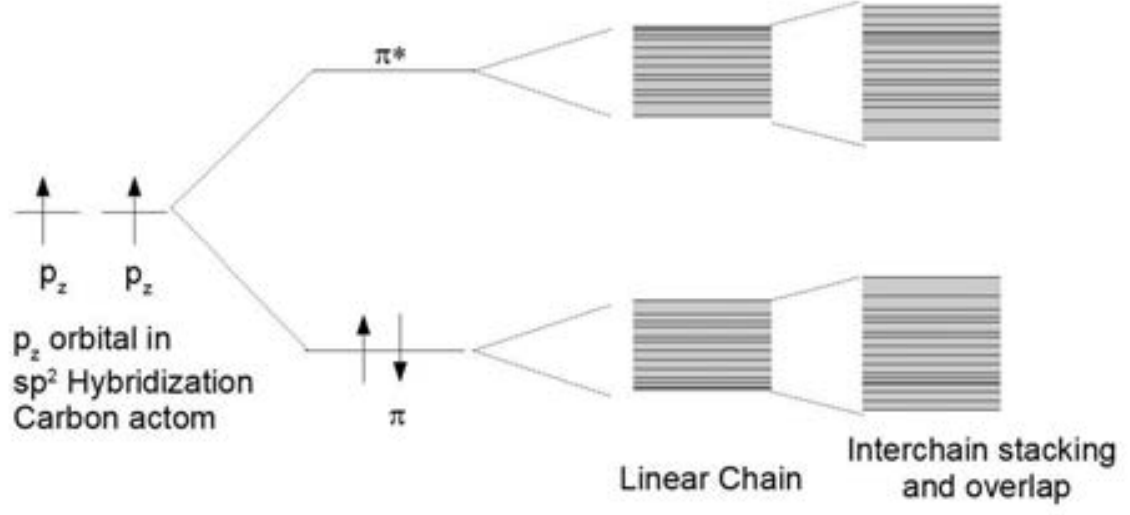

Figure 2.6 Energy level derivation in stacked solid state.

For an isolated molecules/polymer, the energy of each MO is discrete. Here we focus on IP and EA. While the energy of molecular orbitals strongly depends on the local environment, i.e. the intermolecular order and the nature of surrounding molecules/polymers. ${ }^{[12,13]}$ In amorphous or 
polycrystalline, each molecule has a unique local environment as shown in Figure 2.7, then each IP and EA will be unique. In this case, although the HOMO and LUMO is unique, and IP and EA are well defined for each isolated molecule, there will be a broad distribution of the IP and EA for solid film due to the variations in the local molecular order. The same holds true for polymers. Besides the situation in molecular solid, the different conjugation length of each polymer makes the distribution of the IP and EA broader in polymer solid. The broad distribution of the IP in molecule/polymer solid could be proved by photoelectron spectroscopy of anthracene as shown in Figure 2,8a. ${ }^{[12]}$ Compared with the gas spectra, in solid film, the spectra of frontier orbital was broaden and the onset shift to low binding energy (high kinetic energy) due to relaxation.

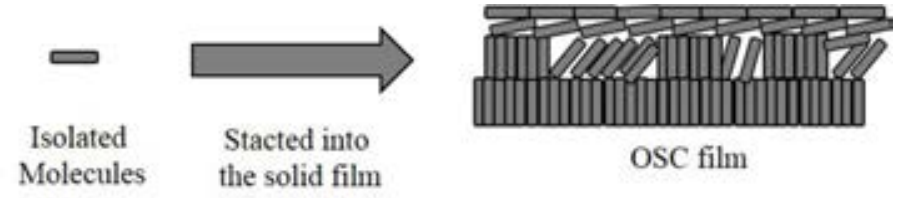

Figure 2.7 Molecular arrangement in the film

(a)

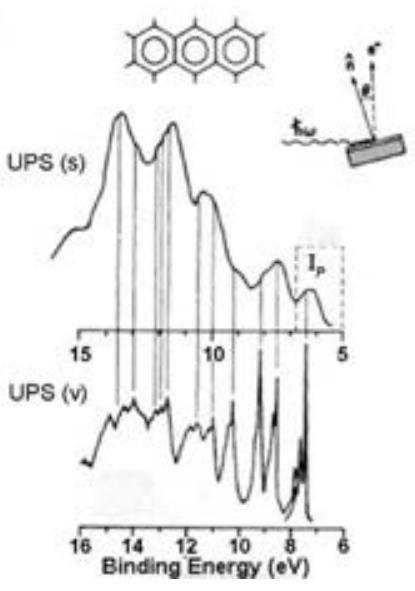

(b)

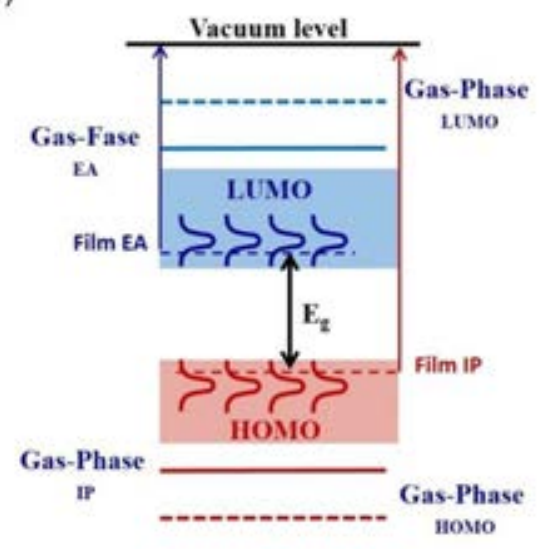

Figure 2.8 (a) Photoelectron spectroscopy of pentacene. (b) Bulk energy level in the organic semiconductor film. The figures are adapted from reference. ${ }^{[9,12,14,15]}$

Every molecule/polymer in the film has its own individual IP and EA, and the frontier part of the IP and EA distribution is often modeled as being Gaussian. The IP and EA of the film are 
represented by the smallest individual IP and largest individual EA. The actual energy gap in organic solid film is then defined by the upper edge of the IP energy distribution and the lower edge of the EA energy distribution. The energy level diagram could be summarized in Figure 2.8b. According to the definition of the actual energy gap, for the non-degenerate materials, there are consequently no gap states in absence of doping or molecular defects as the frontier IP/EA energies created by variations.

\subsection{Determination of Energy levels in organic solid thin films}

The definition of each item has been clarified and defined as described above. In the field of organic electronics, one of the most important tasks during design and fabrication of organic devices is to measure the energy levels of the organic materials appropriately and understand the energy level alignment at the interfaces involving semiconducting molecules and polymers. ${ }^{[16,17]}$ For instance, the electron affinity $(E A)$ of an electron-transporting organic material should be larger than a threshold value $(\sim 3.6 \mathrm{eV})$ so as to get electron-trap-free transport and stable devices, ${ }^{[18,19,20]}$ while the energy level alignment at interfaces will affect charge injection, free charge generation, charge transport and extraction. ${ }^{[2,9,14,16]}$ The determination of energy levels, mainly $I P$ and $E A$, hence is crucially important and constitutes an important step towards making efficient and stable devices. ${ }^{[21]}$ Commonly used methods to determine energy levels in thin film materials and energy level alignment at interfaces include ultraviolet photoelectron spectroscopy (UPS), ${ }^{[2]}$ inverse photoemission spectroscopy (IPES) ${ }^{[22,23]}$ cyclic voltammetry $(\mathrm{CV})$ and quantum chemical calculation, ${ }^{[22,24]}$ sometimes assisted by Kelvin probe (interface potential steps) ${ }^{[25]}$ and UV-vis (band gap) measurements. ${ }^{[22,26]}$ In this thesis, the value of IP and EA are deduced from the UPS spectra assistant by UV-vis absorption or voltammograms. Two kinds of spectra are shown in Figure 2.9. These two kinds of related technologies and methods will be described in detail in Chapter 4 and chapter 5 respectively. 

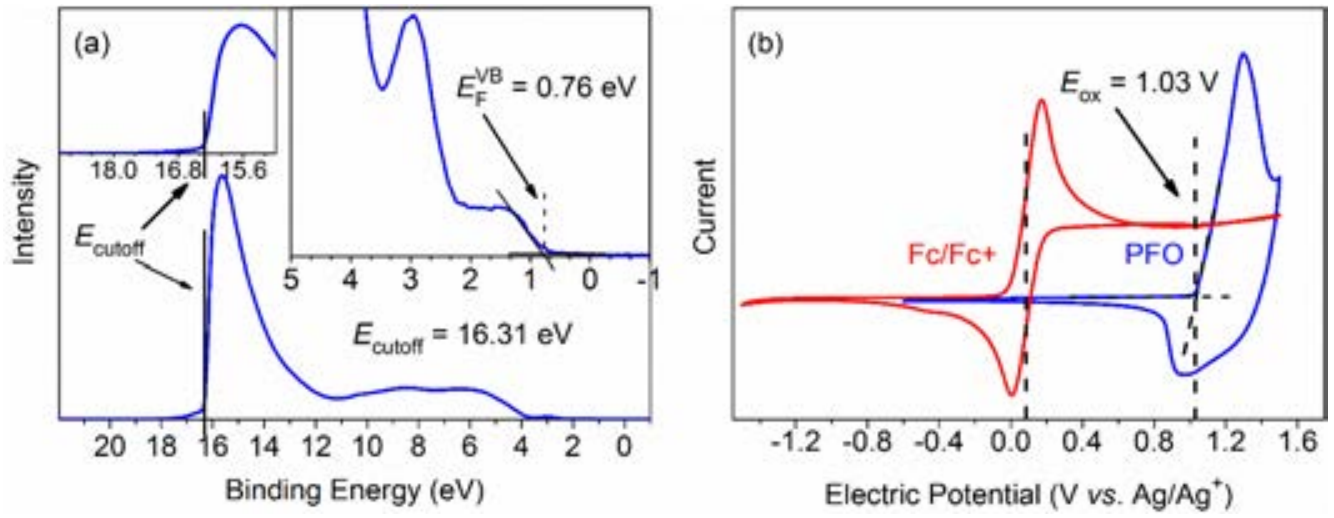

Figure 2.9 (a) UPS spectra of PFO, (b) voltammograms of the PFO.

\subsection{Charge carriers in organic electronics}

Undoped conjugated organic molecules/polymers are called organic semiconductors and the molecule/polymer is not charged without charge injection from an electrode in the electronic device and the organic semiconductors are usually used in the light emitting diode, solar cell, transistors or photodiode. The organic molecule/polymer could be charged by chemical or electrochemical reaction and be transferred to organic conductors. Doping in the context of organic films typically means integer charge transfer. Although they are used in pristine in most devices, the charge transfer doping, charge injection and optical excitations induce large modification of both electronic and the geometric structure of the materials.

Because organic molecules/polymers are soft material, there is a strong interconnection between the electronic structure and geometry. The total energy of the system can be lowered by changing the geometry of the soft molecule slightly, via so-called Peierls distortion or Jahn-Teller distortion.

The system goes in as a polaron when an electron was added or took away. The creation of the polaron is accompanied by changing both the electronic and geometry structure. The lattice distortion leads to a localization of the electron, and the LUMO containing the added electron or the HOMO containing the added hole would move down (up) to the forbidden energy gap and the "former" energy gap is slightly increased as shown in the Figure 2.10. 

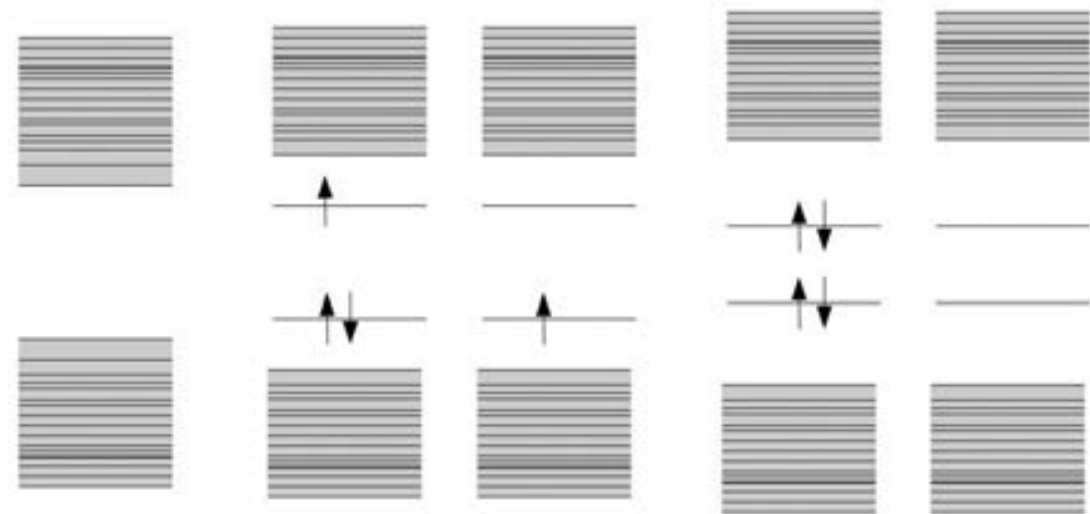

$\mathrm{P}^{-}$

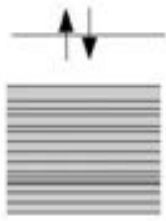

$\mathrm{BP}^{+}$

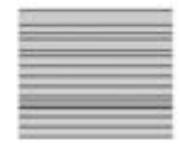

$\mathrm{BP}^{++}$

Figure 2.10 Energy level of neutral conjugated molecular/polymer polaron and bi-polaron. 


\section{Chapter 3 Surface/Interface Properties in Organic Electronics}

\subsection{Fundamental concepts of surface/interface}

An interface represents the boundary between two phases, including solid-liquid interfaces, solidgas interfaces, solid-solid interfaces, solid-vacuum interfaces, liquid-liquid interfaces and liquid gas interfaces. Solid-gas interface and liquid gas interface are also called surface due to the attendance of the gas.

In organic electronics, the devices are made of different layers with different functions via deposition of e.g. one material on the surface of the other, as shown in Figure 3.1 for the organic solar cell with conventional structure, so the interfaces between the solid would be formed when the $\pi$-conjugated molecules/polymers are brought into contact with the surface of another material. The interface involved in organic electronic devices mainly includes organic/metal and organic/organic interface, and the key electronic processes such as charge injection, extraction, charge dissociation and recombination occur at these interfaces, and all these processes play an important role in the device performance. Thus, it is important to figure out the interface properties of both organic/metal and organic/organic interface.

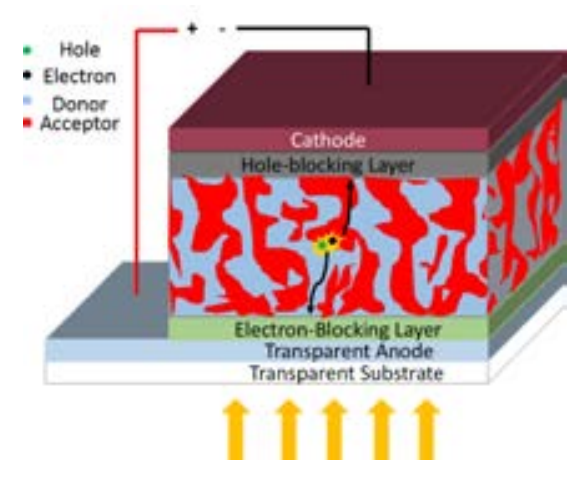

Figure 3.1 Conventional structure of organic solar cell

When a $\pi$-conjugated molecule/polymer is brought into contact with the surface of another material, the absorption process may result in a wide variety of effects at the interface and the energetic 
properties of organic molecules/polymers at interfaces typically will be different from the bulk. These interface effects including: polarization of the electron density of the organic material due to interaction with an image charge on the substrate surface, partial charge transfer through covalent organic-substrate bonds, integer charge transfer through tunneling across the organic/substrate interface, surface rearrangement by (inter) diffusion across the organic/substrate interface, adsorption-induced order or disorder. According to the interaction strength, the types of interface can be categorized to five kinds as shown in Table 3.1.

Table 3.1 Interfaces involved in organic electronics. The Table is adapted from reference. ${ }^{[2]}$

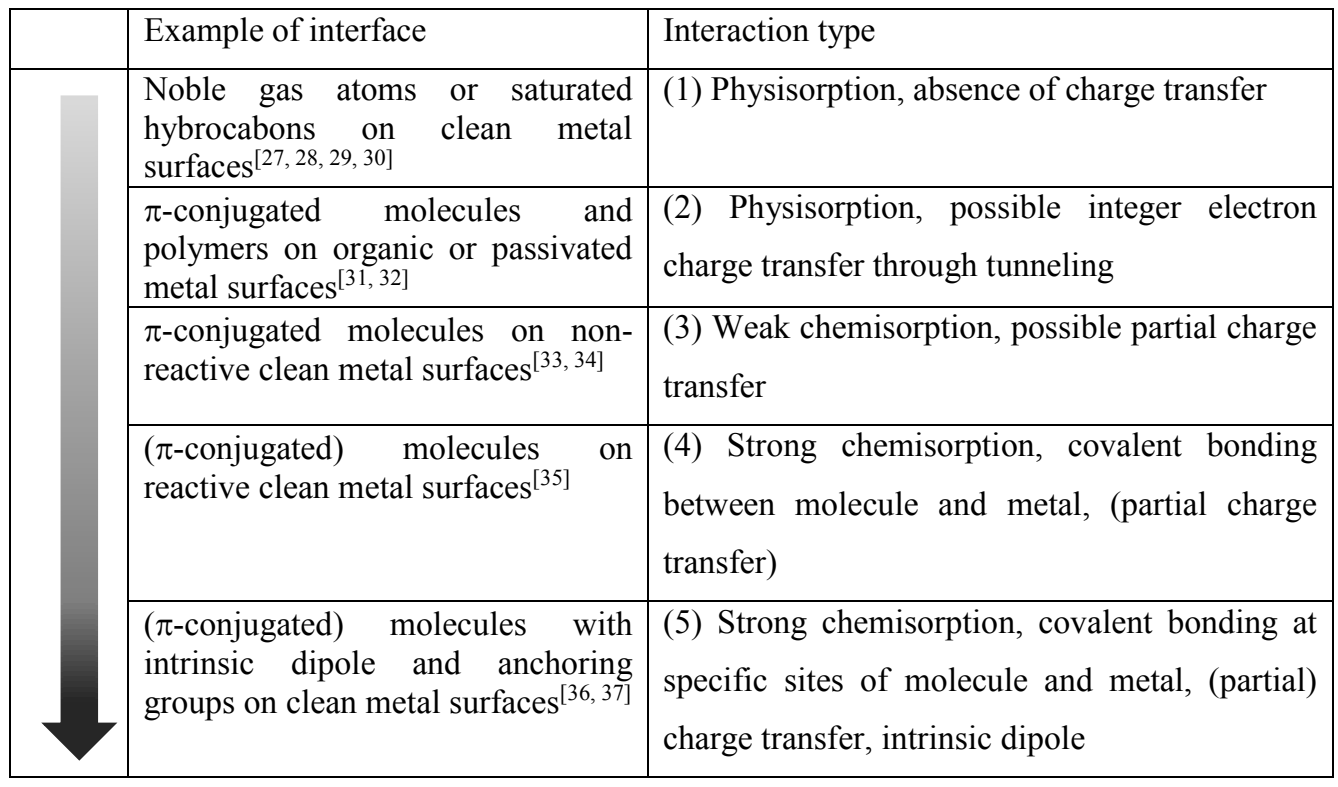

Although there is no unified model to describe all these kind of interfaces mentioned above, models exist that successfully describe subsets of different interface types. The electronic properties of the interface that are characterized by negligible hybridization of $\pi$-electronic molecular orbitals and substrate wave functions could be explained and predicted by ICT model. ${ }^{[32,38]}$ In Organic electronics, due to the processing conditions such as solution processing of molecules/polymers via spin coating or printing, the organic semiconductor films typically are physisorbed on the substrates to form such interfaces. More generally, semiconducting organic/organic interfaces and 
interfaces formed with substrates that are passivated by oxides or residual hydrocarbons also fall in this category. The residual of hydrocarbons or oxide would prevent hybridization of electronic states and thus blocking the formation of interface dipoles via partial electron charge transfer. But electron transfer can still occur by tunneling as long as the passivating layer is thin enough. The tunneling of the electrons through the interface passivating layer implies integer charge transfer.

\subsection{Integer charge transfer model}

The ICT model predicts and explains the experimentally verified abrupt transitions between a vacuum level alignment regime and Fermi-level pinning regimes upon variations of the work function of the substrate. The Fermi-level pinning regimes feature a potential step that scales with the difference between the equilibrium ionization potential or electron affinity of the organic semiconductor at the interface and the work function $\left(\Phi_{\mathrm{SUB}}\right)$ of the substrate. The origin of the potential step is explained by spontaneous charge transfer across the interface via tunneling (integer charge transfer) when the substrate work function is higher than the energy required to take away one electron (lower than the energy gained from adding one electron) from (to) the molecule at an interface producing a fully relaxed state. The most easily oxidized donor molecules (or segments on polymers) hence will be "used up" until enough charge has been transferred across the interface to create a potential step that equilibrates the Fermi level. The energy where the Fermi level is subsequently pinned is referred to as pining energy $\left(E_{\mathrm{ICT}+,-}\right)$. The energy of a positive integer charge transfer state, $\mathrm{ICT}^{+}$, is defined as the energy required to take away one electron from the molecule/polymer producing a fully relaxed state, that is, both electronic and geometrical relaxation are included as well as screening from the substrate. The energy of a negative integer charge-transfer state, $\mathrm{ICT}^{-}$, is defined as the energy gained when one electron is added to the molecule/polymer producing a fully relaxed state, that is, both electronic and geometrical relaxation are included as well as screening from the substrate. Thus, the pinning energy is similar in nature but differ from the ionization potential (IP) and electron affinity (EA) of the organic semiconductor, i.e. the polaronic transport states, such as $\mathrm{E}_{\mathrm{ICT}+}=\mathrm{IP}-\mathrm{B}^{+}$and $\mathrm{E}_{\mathrm{ICT}-}=\mathrm{EA}+\mathrm{B}^{-}$, where $\mathrm{B}^{+}\left(\mathrm{B}^{-}\right)$is the Coulomb energy associated with charging a molecule in the interface layer with an hole (electron), ${ }^{[38,39]}$ and are thus moved into the gap compared to the bulk polarons (IP/EA) 
Three distinct energy level alignment regimes are predicted by the ICT model and the detail are described as following and process are shown in Figure 3.2.

(i) $\Phi_{\mathrm{SUB}}<E_{\mathrm{ICT}}$ Fermi level pinning to a negative integer Charge transfer state; substrate independent resulting work function $\Phi_{\mathrm{ORG} / \mathrm{SUB}}$

(ii) $E_{\mathrm{ICT}-}<\Phi_{\mathrm{SUB}}<E_{\mathrm{ICT}}+$ Vacuum level alignment; substrate dependent resulting work function $\Phi_{\mathrm{ORG} / \mathrm{SUB}} ;$ slope $=1$

(iii) $\Phi_{\mathrm{SUB}}>E_{\mathrm{ICT}}+$ Fermi level pinning to a positive integer charge transfer state; substrateindependent resulting work function $\Phi_{\mathrm{ORG} / \mathrm{SUB}}$

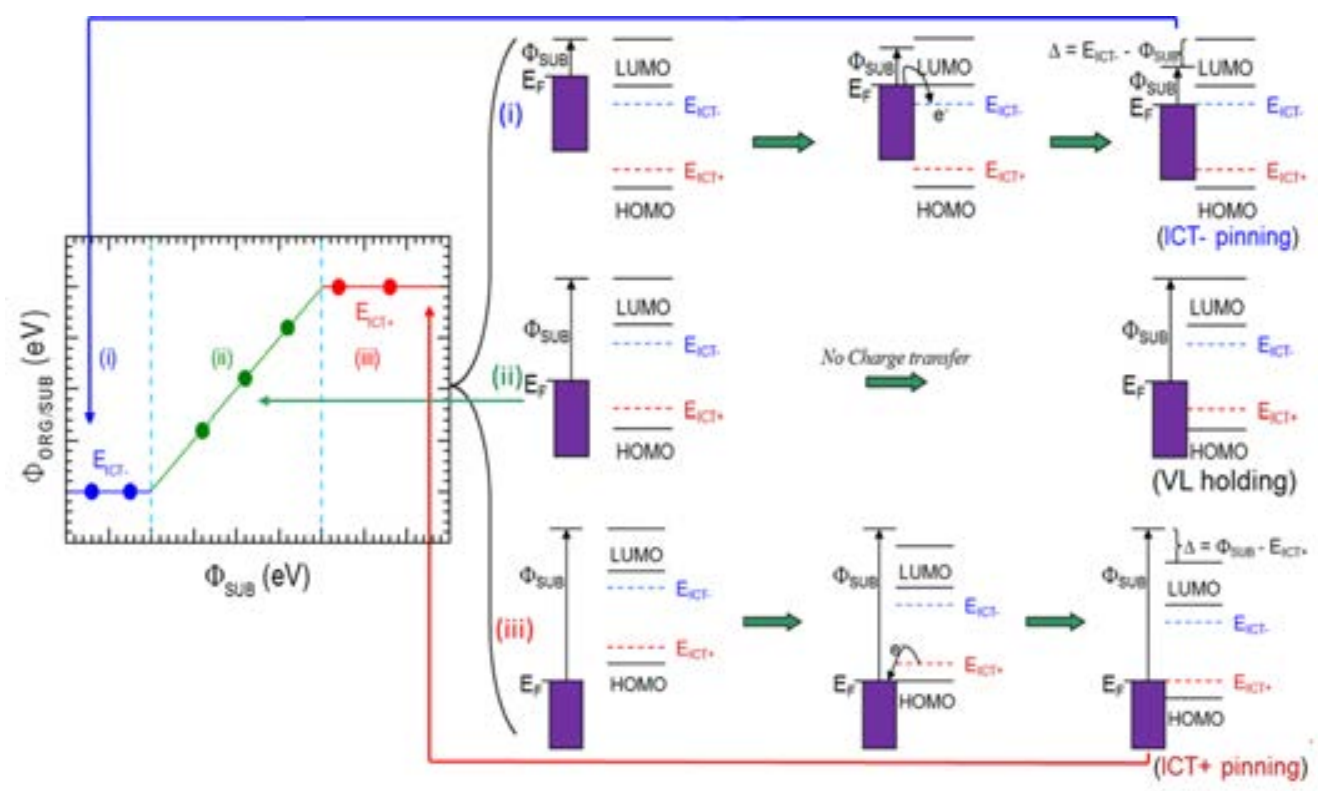

Figure 3.2 Typical energy level alignment behavior for weakly interacting organic semiconductor interfaces that follow the ICT model, where the resulting work function ( $\left.\Phi_{\mathrm{ORG} / \mathrm{SUB}}\right)$ is either independent (i, iii) or linearly dependent with a slope of $\sim 1$ (ii) of the substrate work function $\left(\Phi_{\mathrm{SUB}}\right)$ and Schematic illustration of the evolution of the energy-level alignment when a $\pi$ conjugated organic molecule or polymer is physisorbed on a substrate surface. The figure is adapted from reference. ${ }^{[2]}$

As we described in chapter 2, the frontier parts of the resulting occupied and unoccupied state distributions forming the energy gap are often modeled as being Gaussian. Now, taking 
$E_{\mathrm{ICT}+} / E_{\mathrm{ICT}+,-}$ and IP/EA together, the evolution of the energetic from interface to bulk can be summarized in Figure 3.3.

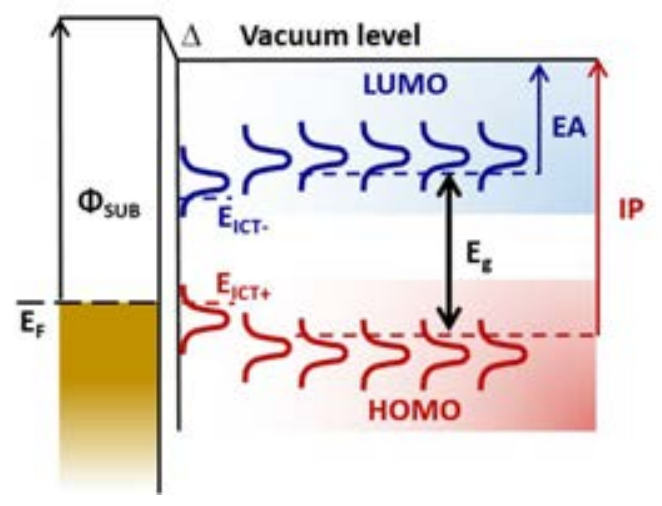

Figure 3.3 Diagram showing energy level alignment including the ICT state and bulk frontier density of state distribution. Here the Fermi level becomes pinned to the $\mathrm{E}_{\mathrm{ICT}+}$ (oxidation of molecules at the interface causing Fermi level equilibrium). The figure is adapted from reference. ${ }^{[9}$, $14,15]$

\subsection{Integer charge transfer at the interface of donor and acceptor in organic solar cell}

In organic electronic devices, besides the organic/metallic interfaces, there are organic/organic heterojunction interfaces, which are characterized by weak van der Waals intermolecular bonding and can be considered as nearly non-interactive. So the ICT model can not only explain and predict the energy level alignment at organic/metal interfaces, but also can be successfully applied to various cases of heterojunctions comprised of organic semiconductors, where the relative position between the $\pi$-conjugated organic molecules/polymers integer charge transfer states determines the energetic alignment at the organic/organic interfaces. ${ }^{[2,40,41,42]}$

The active layer of organic solar cells is composed of donor(s) and acceptor(s), implying there are organic/organic interfaces as shown in Figure 3.1. The energy level alignment diagram between an adjacent donor and acceptor are shown in the Figure 3.4. When the $E_{\mathrm{ICT}+}$ of the donor is larger than the $E_{\mathrm{ICT}}$ of the acceptor, the vacuum level would be alignment, meaning that there is not charge transfer between donor and acceptor under the dark ground state (Figure 3.4a). In contrast, when the $E_{\mathrm{ICT}+}$ of the donor is smaller than the $E_{\mathrm{ICT}-}$ of the acceptor, there would be spontaneous charge 
transfer from the donor to acceptor until the positive integer charge transfer state pins to the negative integer charge transfer state of the acceptor under the dark ground state. This kind of ground charge transfer will promote the generation of the occupied ICT state and interface potential energy gradient, resulting in a dipole with the negative pointing to the acceptor as shown in Figure $3.4 \mathrm{~b}$. When the $E_{\mathrm{ICT}+}$ of the donor is equal to the $E_{\mathrm{ICT}-}$ of the acceptor, no dipole formation occur at the donor/acceptor interface large enough to be measured by UPS. However, as the frontier edge of the respective ICT distribution likely will overlap, some integer charge transfer still can be expected (Figure 3.4b). ${ }^{[9,15,34,43]}$

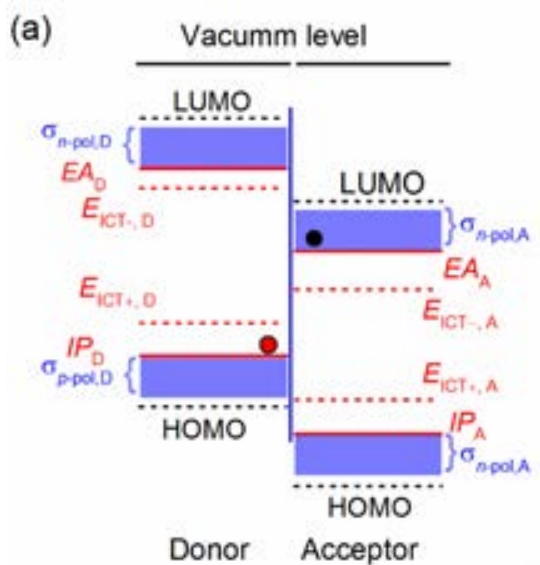

(b)

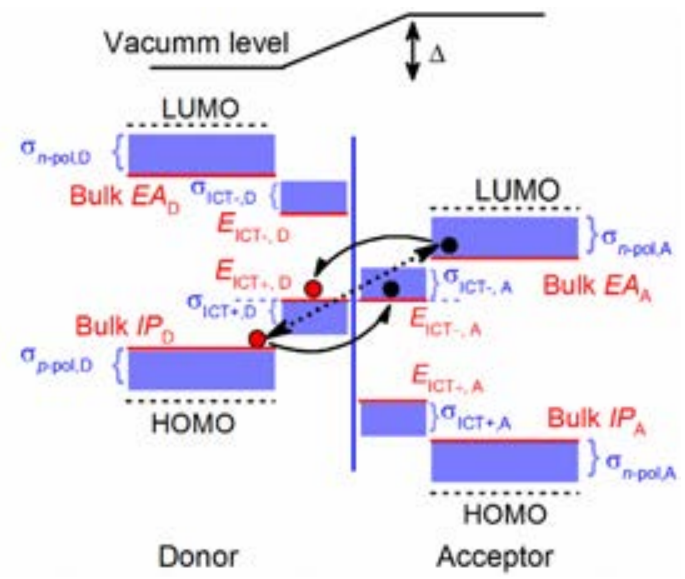

Figure 3.4 Energy level alignment between adjacent donor and acceptor in organic solar cell when

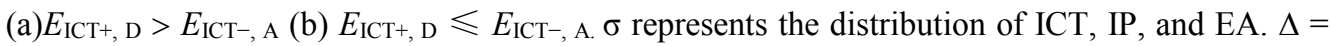
$E_{\mathrm{ICT}-, \text { A }}-E_{\mathrm{ICT}+\text {, D }}$ represents interface potential step caused by Femi level equilibrium. Dashed arrow represents direct bimolecular recombination and solid arrow represents trap-assistant recombination via ICT state. The Figure is adapted from reference. ${ }^{[9,15]}$

The ICT model can be successful used to design organic solar cells. The work function of the typically used anode such as PEDOT:PSS, and the cathode such as LiF/Al is sufficiently large and small to form pinned contact with donor and acceptor materials. In that case, the open circuit voltage mainly would be controlled by the donor/acceptor blend. Occupied ICT states at the donor/acceptor (D/A) interface, occurring when $\mathrm{E}_{\mathrm{ICT}+, \mathrm{D}} \leqslant \mathrm{E}_{\mathrm{ICT}-\text {, A }}$ (Figure 3.4b), can act as trap sites for recombination that reduce the open circuit voltage, while the generation of free charge carries at the $\mathrm{D} / \mathrm{A}$ interface is enhanced by the interface potential energy gradient generated by occupied ICT states. ${ }^{[43,44]}$ Hence, there is a trade-off in terms of occupied integer charge transfer 
state density and the sweet spot occurs at $E_{\mathrm{ICT}-, \mathrm{A}} \approx E_{\mathrm{ICT}+\text {, D. }}{ }^{[9,15,43]}$ More details will be discussed in chapter 7.

\subsection{Surface tension}

\subsubsection{Role of the surface tension}

Organic molecules/polymers are solution processable, which allows for manufacturing of organic electronic devices on various substrates by common technics such as spin-coting and printing. Thus, the structure of the film forms dynamically during it's solidification from a solution and the final structure of the film depends strongly on processing condintions and materials properties of the components, one of which is the surface tension. Both of the surface tension of the substrate and the organic molecules/polymers plays an important role in the process of electrochemical and electronic devices preparation.

The surface tension of the substrate will affect the buried interface component during the deposition of the blend film, and it can be tuned or even actively controlled via replacement or modification of the substrate. ${ }^{[45,46,47]}$ The surface tension of the organic molecules/polymers can affect the phase seggragation and determin the vertical phase separation of the blend film. ${ }^{[13,48,49]}$ The materials with lower surface energy is likely to be segregated into the air/film interface, while the materials with higher surface energy tend to segregate to the film/substrate interface. In organic solar cells, it would be beneficial to charge collection having the hole tranporting phase of the active layer adjacent to the anode and the electron transporting phase adjacent to the cathode.

Not only can the surface energy be the driving force of the vertical distribution but also it can be the driving force of the location for a third component in ternary blends. ${ }^{[9,15,50,51]}$ The later case will be discussed in Chapter 8 .

\subsubsection{Quantitative measurement of the surface tension}

The surface energy of a material $\mathrm{M}$ can be estimated from the contact angle of ultrapure water on spin coated films of material M. As shown in Figure 3.5, the angle $\theta$ between the liquid-gas interface and solid-liquid interface is defined as contact angle. The surface (interficial) tension (surfce energy) is represented by $\gamma \cdot \gamma_{\mathrm{S}-\mathrm{L}}$ represents interfacial energy between solid and liquid, $\gamma_{\mathrm{L}-\mathrm{G}}$ 
represents interfacial energy between liquid and gas, $\gamma_{S-G}$ represents interfacial energy between solid and gas. These three parameters can be connected by Young's equition. The detailed calculation process for each parameters is included in Chapter $8{ }^{[52]}$

$$
\begin{gathered}
\cos \theta=\frac{\gamma_{S-G}-\gamma_{S-L}}{\gamma_{L-G}},(3.1) \\
\gamma_{S-G}=\gamma_{S-L}+\gamma_{L-G} \cos \theta,(3.2)
\end{gathered}
$$

(a)

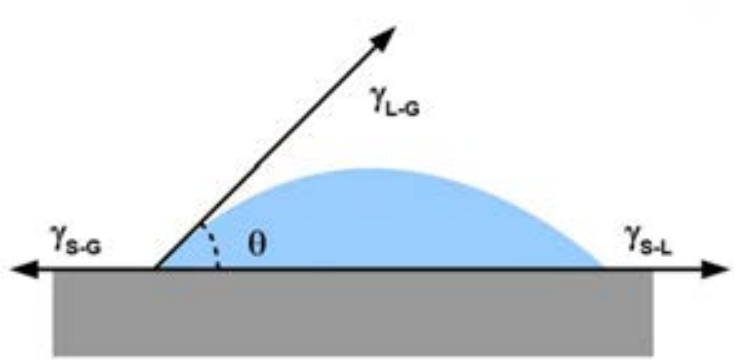

(b)

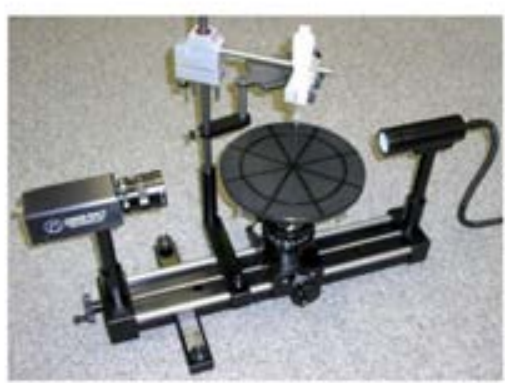

Figure 3.5 Schematic of (a) contact angle and (b) contact angle measurement instrument. 


\section{Chapter 4 Photoelectron Spectroscopy}

\subsection{Overview of the photoelectron spectroscopy}

PhotoElectron Spectroscopy (PES), also called PhotoEmission Spectroscopy (PES), is based on the photoelectric effect discovered by Hertz in 1887 and explained by Einstein in 1905 via invoking the quantum nature of the light. Different from other conventional methods of spectroscopy in that PES detects electrons rather than photons to study electronic structure of materials. Nowadays, it has been developed into powerful and widely used techniques in academic basic research as well as in industry. Not only does PES provide the experimental basis for molecular orbital theories but it is also an important tool for surface analysis. The information provided by photoelectron spectroscopy includes the following.

- Surface chemical states, including the type and the content of the elements, chemical valance states, the formation of the chemical bonds.

- Surface structure, including morphology, phase aggregation, elements distribution and atomic arrangement.

- Surface electronic state, including distribution of the surface electrons, energy level and energy level alignment at surface.

The widely application of the PES could be attributed to many advantages of this measurement, including that

- There is a maximum amount of both chemical and electronic information (listed above) within a single measurement.

- It is typically non-destructive to organic systems.

- It is surface sensitive.

\subsection{Basic principles of PES and binding energy}

PES can measure the energy, intensity and spacial distribution of the photoelectrons emitted from the materials. Starting from the isolated molecule, the physical process of photo ionization process can be expressed by the Formula 4.1 


$$
M+h v \rightarrow M^{+*}+e^{-},(4.1)
$$

The molecule $\mathrm{M}$ is excited to $\mathrm{M}^{+*}$ by a photon with the energy hv and an electron $\left(\mathrm{e}^{-}\right)$is emitted with the kinetic energy $E_{\mathrm{k}}$. As we know, the energy of the molecule is the eigenvalue of the Schrödinger equation

$$
\hat{\mathrm{H}} \Psi_{i}=E_{i} \Psi_{i},(4.2)
$$

According to energy conversation

$$
E_{i}(n)+h v=E_{f}(n-1)+E_{k},(4.3)
$$

or

$$
E_{K}=h v-\left(E_{f}(n-1)-E_{i}(n)\right),(4.4)
$$

Where $E_{\mathrm{i}}(\mathrm{n})$ is the energy of the ground state of molecules with n electrons and $E_{\mathrm{f}}(\mathrm{n}-1)$ is the energy of final state of ionized molecules with (n-1) electrons. The binding energy $\left(E_{B}\right)$ is defined as

$$
\left.E_{B}^{V}=E_{f}(n-1)-E_{i}(n)\right)=h v-E_{K},(4.5)
$$

Thus $E_{\mathrm{B}}$ represents the energy difference between the initial ground state and various final exited states and could be calculated by delta-self-consistent field ( $\triangle \mathrm{SCF}$ ) according to Koopmans rule that the wave function of other electrons do not change when an electron is taken away from the molecule. i.e. the binding energy is equal to the negative energy of the orbital from which the photoelectron is emitted. But the reality is that both of intramolecular electron relaxation and nuclear geometric relaxation will happen following the emitting of the electron to screen the core hole and to minimize the total energy of the final ionized state. The relaxation would lead to a decrease of expected binding energy defined in Formula (4.5). It should be noted that in PES measurement, the photoelectrons leave the molecule typically within about $10^{-15} \mathrm{~s}$ during the photo emitted process, while the electronic relaxation time is around $10^{-16} \mathrm{~s}$, and the nuclear geometric relaxation time is around $10^{-13} \mathrm{~S} .{ }^{[53]}$ Thus, the electrons have had time to relax, that is, the hole is fully screened, but the nuclei are frozen during the process. This means that PES measurement will 
overestimate the binding energy and the final hole-polaron formation energy in general due to that the energy of ionized final-state would be further decreased by geometric relaxation.

In the solid, the binding energy are conventionally measured with respect to the Fermi level instead of the vaccum level, and the binding energy could be expressed by

$$
E_{B}^{F}=h v-E_{K}-\Phi,(4.6)
$$

Where $\Phi$ represent the work function of the solids. In organic molecule/polymer solids, the intermolecular relaxation of the surrounding molecules provides addition screening of the hole, which will increase the kinetic energy and decrease the binding energy further compared to isolated molecule. The rigid shift caused by the intermolecular polarization effects could be observed in Figure 2.8a.

\subsection{Spectra and final states effects}

\section{Binding Energy of Electrons}

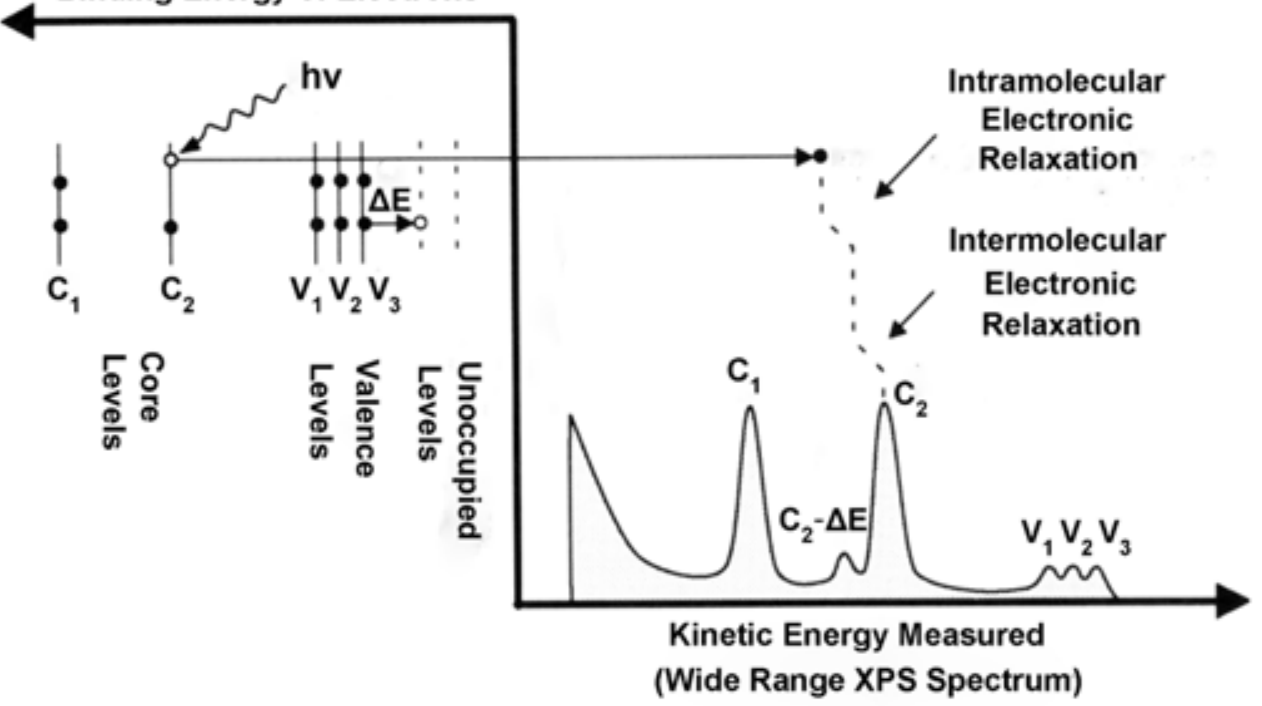

Figure 4.1 Schematic of how a PES spectra is obtained through the ionization of the various electron levels. 
For a given photo energy, recoding the number of photoelectrons as a function of their kinetic energy yields a spectra of distinct line as shown in the Figure 4.1, reflecting the energy distribution of the occupied orbital. In general, the spectra are recorded with $E_{B}$ as the abscissa according to equation (4.6). Depending on the energy of the photon source, the PES is divided into Ultraviolet photoelectron spectroscopy (UPS) and X-ray photoelectron spectroscopy (XPS). UPS can measure the electrons coming from the valence orbital and XPS can measure the electrons in the core levels as well.

PES always measure the final state energies that can be related to the initial state. As discussed above, the main photoelectron line would shift to lower binding energy rather than at the binding energy of the neutral state due to electron relaxation as shown in Figure 4.1. Thus the relaxation of the electron system in response to the creation of a hole is one of important final state effects. Another kind of the final state effects is multi-electron excitations. During the emission process of the electrons, a variety of electronically excited final states would be created in company with the core level ionization state and the satellite lines would be recorded in the spectra. According to energy conservation, the excitation energy would be missing from the kinetic energy, leading to the satellite lines shift to high binding energy $\left(\left(\mathrm{C}_{2}-\Delta E_{1}\right)\right.$ in Figure 4.1)) compared to the main line. Some most important final states are shown in Figure 4.2

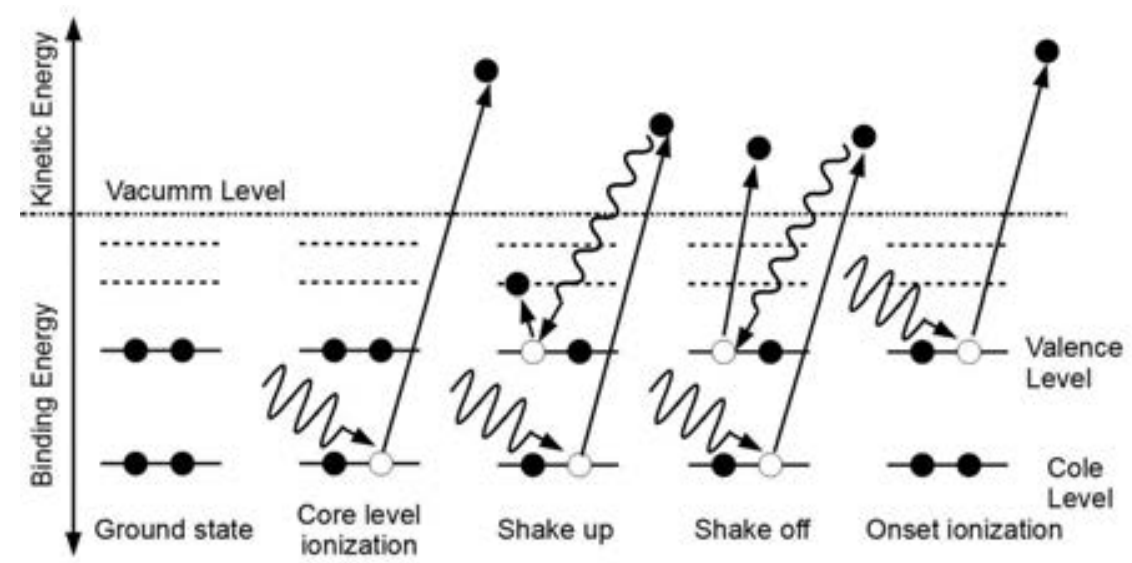

Figure 4.2 Schematic of various final states. The figure is adapted from reference. ${ }^{[54]}$ 


\subsection{Ultraviolet photoelectron spectroscopy (UPS)}

UPS refers to the measurement of kinetic energy spectra of photoelectrons emitted from the materials which is excited by a low energy ultraviolet light source. UPS technique is analogous to XPS but with orders of magnitude higher photoionization cross-section and higher resolution. The source of photons usually used are $\mathrm{HeI}(\mathrm{h} v=21.2 \mathrm{eV})$ radiation and HeII radiation $(\mathrm{h} v=40.8 \mathrm{eV})$. The valence electronic states of materials can be mapped out in the form of the spectrum with the intensity as the function of the binding energy. The full UPS spectra of both a gold substrate and a polymer over-layer on the gold substrate are shown in the Figure 4.3. The occupied electronic structure, the work function $(\Phi)$ and the change in the work function $(\Delta)$ that can occur upon coverage of the substrate surface can be derived from the UPS spectra.

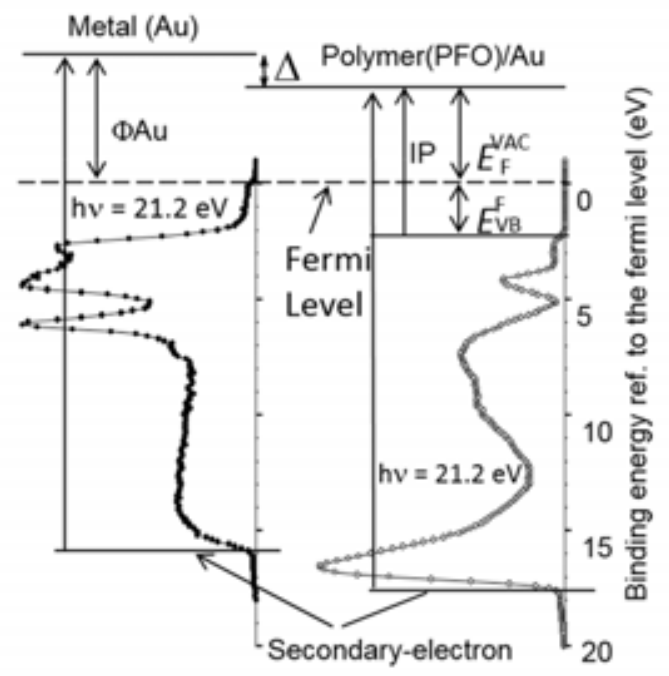

Figure 4.3 The full UPS spectra of both a gold substrate (left) and a polymer over-layer on the gold substrate (right). The figure is adapted from reference. ${ }^{[2]}$

The vacuum level of a metal substrate as measured by UPS corresponds to the energy of an electron at rest just outside the sample instead of the electron at the infinite distance and it is still affected by the potential of the solid. ${ }^{[17]}$ Work function is an important parameter that determines the minimum energy necessary to remove an electron from the material. The work function could be obtained from the measured energy of the secondary-electron cutoff ( $\left.E_{\text {cutoff }}\right)$ according to formula 
(4.6) and (4.7), and the change in work function $(\Delta)$ could be derived by measuring the $E_{\text {cutoff }}$ of the substrate with the overlayer as shown in Figure 4.3.

$$
\Phi=h v-E_{\text {cutoff }},(4.7)
$$

The offset between the valence band edge of the overlayer and the fermi energy in conducting substrate, represented by $E_{\mathrm{VB}}^{\mathrm{F}}$, determines the hole injection barriers. According to formula 4.6, the electrons with maximum kinetic energy must be emitted from the fermi level of the metal substrate or valence band edge of the polymer, represented by $\mathrm{E}_{\mathrm{K}}^{\mathrm{Max}}$ (metal) and $\mathrm{E}_{\mathrm{K}}^{\mathrm{Max}}$ (polymer) respectively. In this case, the offset represents the kinetic energy difference between the fastest photoelectrons from fermi level of the metal substrate and from the valence band edge of the polymer over-layer. The energy difference between the vacuum level of the polymer over-layer and the fermi energy in the conducting substrate $\left(E_{\mathrm{F}}^{\mathrm{Vac}}\right)$ is given by formula (4.8)

$$
E_{F}^{V a c}=h v-\left(E_{K}^{M a x}(\text { polymer })+E_{V B}^{F}\right),(4.8)
$$

The offset between the vacuum levels of the polymer-covered substrate and the clean gold substrate arises from the existence of dipole at the interface and can be expressed by formula (4.9).

$$
\Delta=E_{F}^{V a c}-\Phi_{A u},(4.9)
$$

The ionization potential (IP) for the molecule/polymer is a material constant and should not depend upon the substrate.

$$
I P=E_{V B}^{F}+E_{F}^{V a c},(4.10)
$$

EA is also materials constant, but it cannot be measured via UPS due to there are no electrons to photoemit, so inverse photoemission spectroscopy (IPES) instead can be used to obtain EA. The EA could also be obtained by adding the optical band gap to the IP measured by UPS. Another simple method to measure IP and EA is the electrochemical method that will be described in Chapter 5 .

\subsection{X-ray photoelectron spectroscopy (XPS)}

The commonly used light sources in XPS are $\mathrm{Mg}(\mathrm{Ka})$ with the photo energy of $1253.7 \mathrm{eV}$ or $\mathrm{Al}(\mathrm{Ka})$ radiation with the photo energy of $1486.6 \mathrm{eV}$. In XPS measurements, the core electronic properties 
of materials can be mapped due to the high light radiation energy. It's easy to understand that the binding energy of core electrons for each element would be different and the exact value of the binding energy of a distinct atom also depends on the chemical environment. An energy shift will occur when chemically inequivalent atoms of the same elemental species are present and these energy shifts are named chemical shifts. By comparison with the data of standard substances, the chemical shift can be used to determine the oxidation state and chemical bonds. Thus the XPS can be used to detect the distribution of each component at surface according to the ratio of each elements or the feature elements in different component. One example is that the XPS can be used to identify the vertical distribution of the blend film. The vertical distribution of the donor and acceptor is important for charge extraction in organic solar cell as mentioned in Chapter 3 . The change of the chemical environment can be recorded by XPS, so it can be used to track the process of doping, oxidation or adsorption. In this thesis, XPS are used to exam the degradation of the ntype organic electronics in air atmosphere. 


\section{Chapter 5 Electrochemistry}

\subsection{Electrochemical method and electrochemical cell}

Electrochemistry is a branch of physical chemistry and it studies the relationship between chemical changes and electrical effect. The chemical energy and electrical energy can be converted and this conversion is accomplished by ionic current flow in an electrolyte solution between two electrodes connected to each other via an external circuit with an electrical load or current source. Devices such as batteries and fuel cells can convert the energy from chemical reactions into electrical energy, while electrolysis and some electro-analysis can reverse this conversion direction.

Although there are many different kinds of instrumentation, all these electrochemical measurements are conducted in an electrochemical cell which is the basic component of various electrochemical instrument and consists of two or more electrodes and the electronic circuitry for controlling and measuring the current and the potential. Two electrode electrochemical cell consists of a working electrode and a counter electrode immersed in electrolyte solution, while there is an additional reference electrode in three electrode system as shown in Figure5.1.

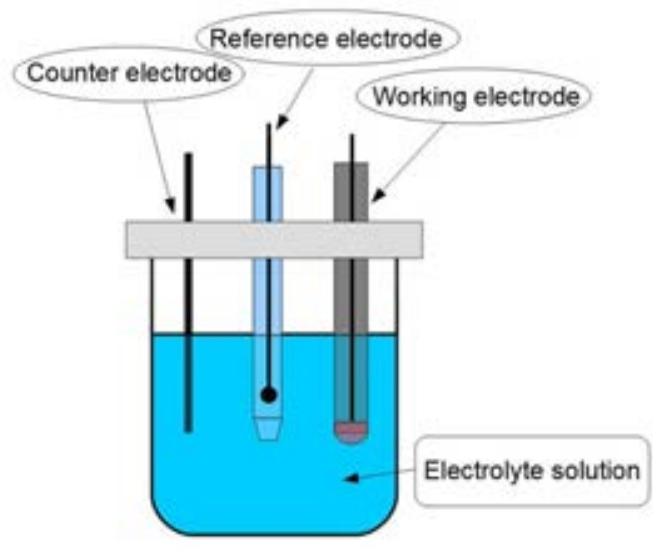

Figure5.1 Schematic of the three electrode cell configuration 


\subsubsection{Cyclic voltammetry}

Cyclic voltammetry (CV) is a simple and common used electrochemical technique. In the CV experiment process, the voltage applied to the working electrode is scanned linearly from initial value to a predetermined limit where the direction of the scan is reversed. The scan process can be halted at any point when necessary. The current is plotted as a function of potential to yield a voltammogram. Three electrode systems are used in CV experiments to make sure that the current passing between the working and counter electrode and the potential of working electrode (WE) relative the reference electrode (RE) can be measured. The classical electric circle of three electrode system is shown in the Figure 5.2. The electrolytic cell consists of a working electrode onto which the reaction takes place, a reference electrode that maintains the constant potential, and the counter electrode that supplies the reaction current. The potentiostat supplies a desired cell potential between WE and RE, and measures the reaction current between WE and CE.

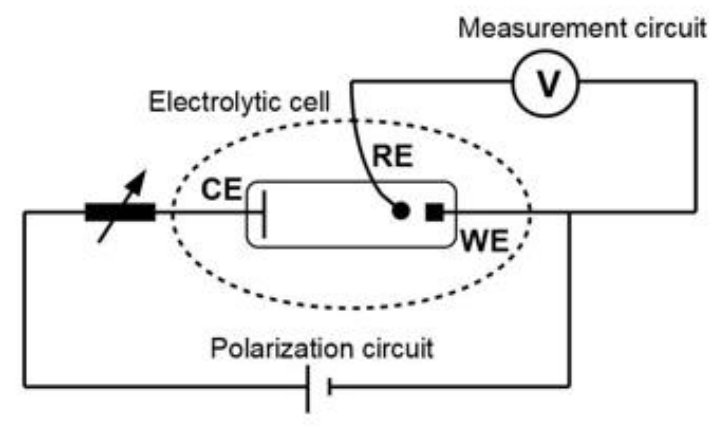

Figure5.2 Classical three electrode circuit used in CV measurement.

\subsubsection{CV methodology to assess energy levels}

Determination of the energy levels of the conjugated molecules/polymers is the prerequisite to design efficient and stable organic electronic devices, especially in organic light emitting diodes or organic solar cells. Besides photoelectron spectroscopy, $\mathrm{CV}$ is another important methodology commonly used in organic electronics to measure the energy levels of the conjugated molecules/polymers, although there is little consensus in the community on how to use this technique and how the measurements relate to the vacuum scale. ${ }^{[6,55]} \mathrm{CV}$ methods employed to 
measure the reduction and oxidation potentials of conjugated molecules/polymers involve the deposition of the organic conjugated materials onto the working electrode. The oxidation process of the conjugated molecules/polymers cannot be equal to the reverse reduction process. So the oxidation and reduction potentials are usually estimated by the onset potential, ${ }^{[56]}$ defined as the potential at which the initial injection of holes or electrons to the HOMO and LUMO, respectively. According to the IUPAC recommendations, ${ }^{[57]}$ The oxidation or reduction potential are usually measured against the potential of the $\mathrm{Fc}^{+} / \mathrm{Fc}$ redox couples because this potential show little variations. The energy of HOMO and LUMO (or IP and EA) could be deduced from equation (5.1) and (5.2) respectively (Figure 5.3).

$$
\begin{aligned}
& E_{\text {номо }}=-\left(E_{\text {onset }, \text { oХ } v \text { v. } F c^{+} / F c}+E^{0 \prime}\right)(5.1) \\
& E_{L U M O}=-\left(E_{\text {onset }, \text { red } v s . F C^{+} / F c}+E^{0 \prime}\right)(5.2)
\end{aligned}
$$

Where $\mathrm{E}^{0^{\prime}}$ is the formal potential of the $\mathrm{Fc}^{+} / \mathrm{Fc}$. When the formal potential of the NHE is $-4.456 \mathrm{eV}$, its value is approximately $-5.1 \mathrm{eV}$ in fermi scale assuming its value of $0.4 \mathrm{e} \mathrm{V}$ versus SCE in acetonitrile and the potential of SCE versus NHE is $0.2414 \mathrm{eV}$. The formal potential of the $\mathrm{Fc}^{+} / \mathrm{Fc}$ in fermi scale usually used in the community could also be $5.39 \mathrm{eV}$ or $4.8 \mathrm{eV}$. Different values of formal potential in the equation is used in different labs. Therefore, the frontier orbital energy levels obtained with different scales should not be compared directly.

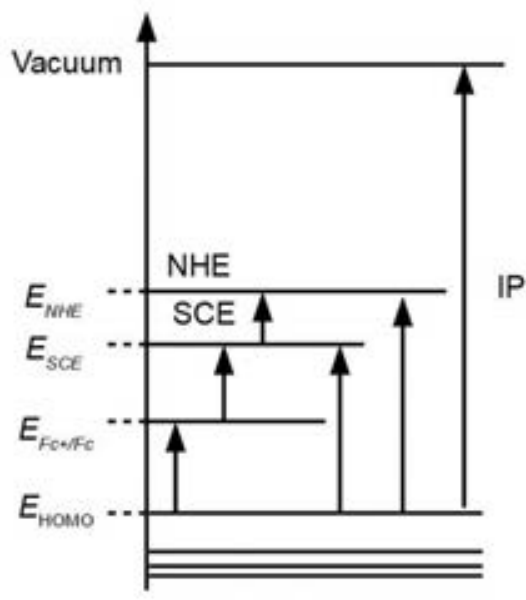

Figure 5.3 Energy level diagram in cyclic voltammetry measurement. 


\section{Chapter 6 Organic Solar Cell}

\subsection{Bulk-heterojunction organic solar cells}

Organic solar cells (OSCs) are attracting research's attention due to the advantages of cheap, light weight and flexible etc., and a lot of efforts have been devoted to understanding the working mechanism and improving the performance of the bulk heterojunction organic solar cells (BHJOSCs) during last two decades. In BHJOSCs, ${ }^{[58]}$ the active layer is composed of mixture of donor(s) and acceptor(s) that could form interpenetrating network of donor and acceptor with massive $\mathrm{D} / \mathrm{A}$ interfaces. The penetrating network can support charge transport through the active layer and the $\mathrm{D} / \mathrm{A}$ interfaces can help exciton dissociation, both of which contribute significantly to improve the performance of the OSCs. The introduction of the BHJOSCs solves the problem of large binding energy of the excitons in the first generation single layer $\mathrm{OSCs}^{[59]}$ and the problem of inefficient exciton dissociation in the second generation bilayer OSCs. ${ }^{[60]}$ According to the components of the active layer, the BHJOSCs can be divided into binary OSCs and multiplejunction OSCs. In binary organic solar cell, the active layer is just composed of one pair of donor and acceptor. In multiple-junction OSCs, the component of the active layer is more than one donor or/and one acceptor. In BHJOSCs, the active layer is sandwiched between two electrodes, and according to the function of the electrodes, the structure of the devices can be divided into conventional structure (Figure 6.a) and inverted structure (Figure 6.1b). In conventional structure, the bottom transparent electrode is the anode, while in inverted structure, the bottom transparent electrode is the cathode.
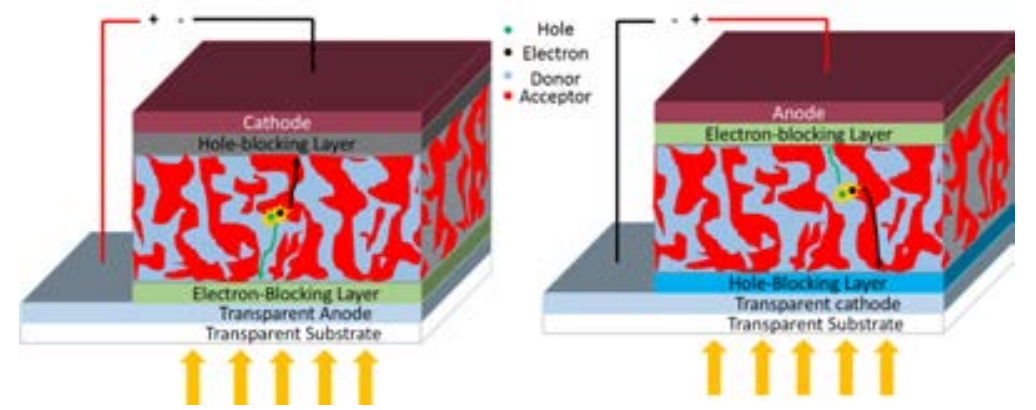

Figure 6.1 Conventional and inverted structure of BHJOSCs. 


\subsubsection{Standard characterization of organic solar cells}

The energy supply for organic solar cell is the photons coming from the sun and the actual spectrum impinging on the cell in operation can vary due to weather, season, time of day, and location. So standard illumination air Mass (AM) $1.5 \mathrm{G}$ with an intensity of $100\left(\mathrm{~mW} / \mathrm{cm}^{2}\right)$ is used. ${ }^{[61]}$ The standard spectra allows the evaluation and comparisons of solar cells performance in different laboratory. Under standard illumination, the power generates from the solar cell is a product of photocurrent and photo voltage acting on the external load. So the extraction of power depends on both the solar cell itself and the external load. The maximum power output can be obtained when the external load is optimized. The applied voltage sweep simulates different resistor and the optimum external load can be determined via recording the J-V curve (Figure 6.2).

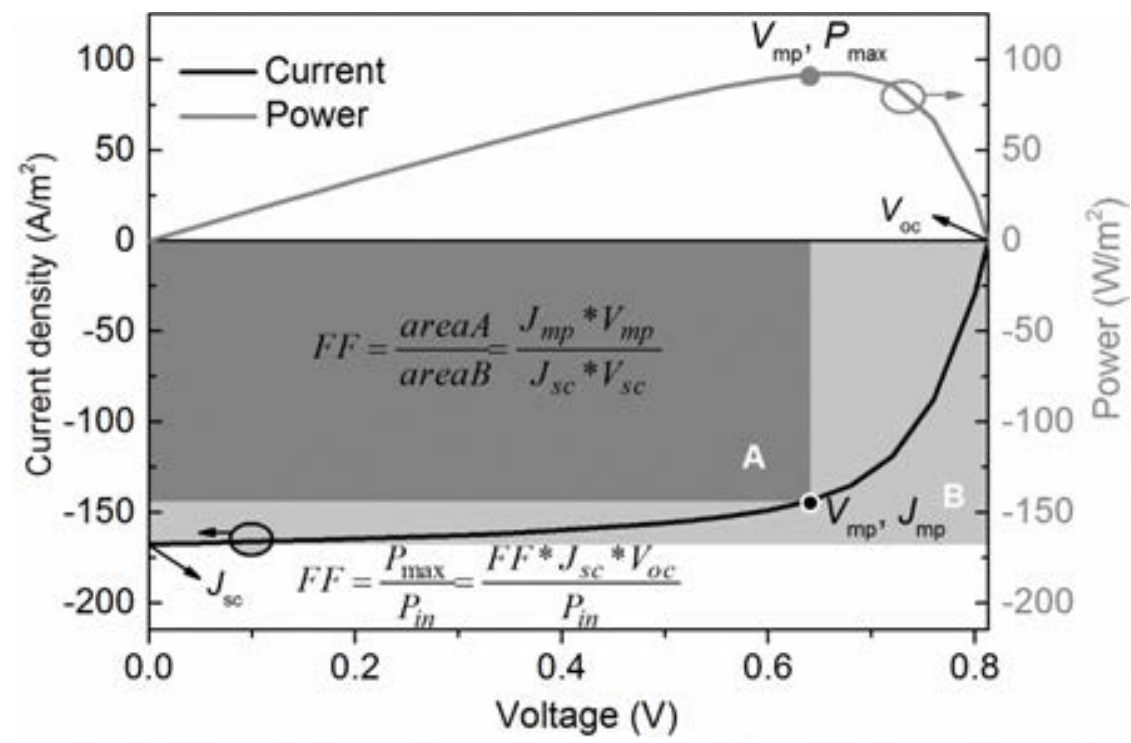

Figure6.2 Typical Current-Voltage (J-V) curve and power-voltage (P-V) curve of an organic solar cell under AM-1.5G illumination. (PTB7-Th: PBDTTS-FTAZ: $\mathrm{PC}_{71} \mathrm{BM}$ ). The figure is adapted from reference. ${ }^{[15]}$

The quantity $\mathrm{P}_{\text {out }}$ has its best value at the maximum power point $\left(\mathrm{P}_{\max }\right)$ as shown in the Figure6.2. When the photon impingement area is equal to the current generating area, the best thermodynamic efficiency of the photovoltaic energy conversion process for the solar cell can be expressed by equation 6.1 . 


$$
P C E=\frac{P_{\text {max }}}{P_{\text {in }}}=\frac{J_{m p} * V_{m p}}{P_{\text {in }}}
$$

The ideally shaped J-V characteristic would be rectangular and would deliver a constant current

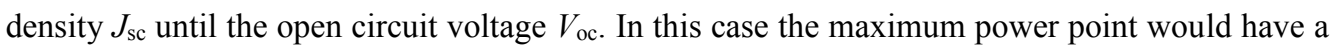
current density of $J_{\mathrm{sc}}$ and voltage of $V_{\mathrm{oc}}$. The fill factor (FF) has been invented to measure how close a given characteristic is to conforming to the idea rectangular $\mathrm{J}-\mathrm{V}$ shape.

$$
F F=\frac{J_{m p} * V_{m p}}{J_{s c} * V_{o c}},(6.2)
$$

According to the definition of the FF, it should also be the ratio between the area of rectangle A and the area of rectangle B in the Figure 6.2

After introducing FF, combining equation 6.1 and equation 6.2 , the power conversion efficiency can be rewritten as

$$
P C E=\frac{F F * J_{s c} * V_{o c}}{P_{i n}}
$$

\subsubsection{Working principle of BHJOSCs}

The working process of BHJOSCs from photon absorption to charge extraction can be described by the following six steps that are also shown in Figure 6.3, and efficiency of each step are represented by $\eta$.

a. a light absorption process which causes a transition in a material (the absorber) from a ground state to an excited state, $\left(\eta_{\text {Generat. }}^{\text {Exciton }} \eta_{\mathrm{A}}\right)$

b. Diffusion of excitons to D/A interfaces. $\left(\eta_{\text {Diff. }}^{\text {Exiton }}\right)$

c. Exciton dissociation and charge transfer $(\mathrm{CT})$ exciton formation at D/A interfaces $\left(\eta_{\text {Diss. }}^{\text {Exiton }}\right.$ )

d. CT exciton dissociation and charge separation at the D/A interfaces ( $\left.\eta_{\text {Diss. }}^{\mathrm{CT}}\right)$

e. Free charge transport $\left(\eta_{\text {Trans. }}^{\text {Charge }}\right)$

f. Charge carrier collection at the electrodes and combing with an arriving positive-charge carrier and returning the absorber to the ground state. $\left(\eta_{\text {coll. }}^{\text {charge }}\right)$ 


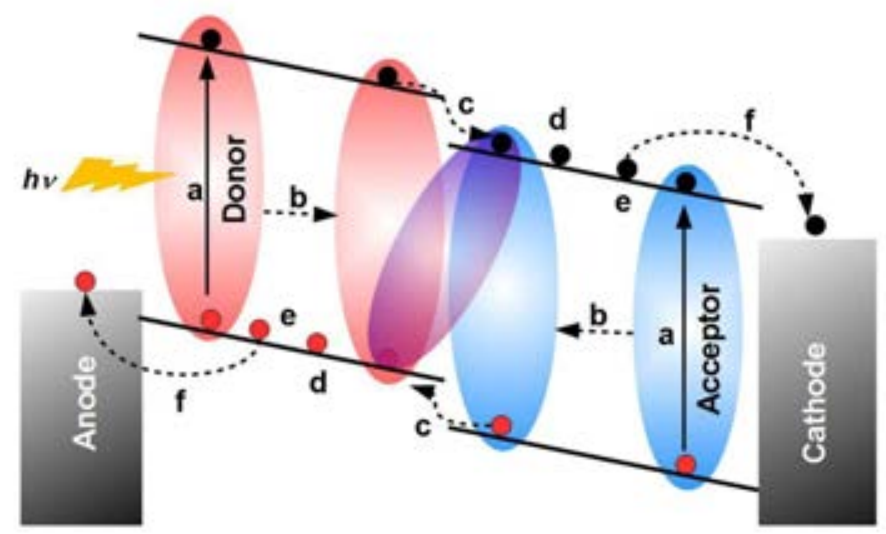

Figure 6.3 Schematic working principle of BHJOSCs.

\subsection{Efficiency of Organic Solar Cell}

There are three approaches to express the efficiency of the organic solar cell. They are power conversion efficiency, external quantum efficiency and internal quantum efficiency respectively.

\subsubsection{Power conversion efficiency}

As discussed at the beginning of this chapter, the power conversion efficiency is defined as the ratio between maximum output power and incident power of the sun, and can be expressed as formula 6.4 after introduction of the fill factor.

$$
P C E=\frac{F F * J_{s c} * V_{o c}}{P_{i n}},(6.4)
$$

\subsubsection{External Quantum Efficiency}

The externally measured ratio of the number of collected charges $\left(N_{\text {charge }}^{\text {out }}\right)$ to the number of incident photons $\left(N_{\text {photon }}^{\mathrm{n}}\right)$ of a particular wavelength is referred to as the external quantum efficiency (EQE) of photovoltaic devices, also referred to as incident photon to converted electron efficiency ( $\eta_{\mathrm{IPCE}}$ ) and can be expressed by formula 6.5 . 


$$
\operatorname{EQE}(\lambda)=\frac{N_{\text {charge }}^{\text {out }}(\lambda)}{N_{\text {Photon }}^{\text {in }}(\lambda)}
$$

EQE is usually lower than $100 \%$ because of various external and internal losses. The external losses mainly optical losses means that the photons with the required energy can't be absorbed by the active layer completely due to the reflection and transition in addition of the parasitic absorption of the electrodes. The internal losses means that not all the absorbed photons by active layer can be converted to extracted charges due to various recombination process. All of these losses can be distributed to each step of the working process and EQE should be the multiplication of quantum efficiency of each step as shown in formula 6.6.

$$
E Q E=\eta_{\text {Generat. }}^{\text {Exciton }} * \eta_{\text {Diff. }}^{\text {Exciton }} * \eta_{\text {Diss. }}^{\text {Exiton }} * \eta_{\text {Diss. }}^{\text {CT }} * \eta_{\text {Trans. }}^{\text {Charge }} * \eta_{\text {Coll. }}^{\text {Charge }},(6.6)
$$

\subsubsection{Internal Quantum Efficiency}

Internal quantum efficiency is defined as the ratio of the number of collected charges to the number of photons absorbed by the active layer $\left(N_{\text {Photon }}^{\text {absod }}\right)$.

$$
\operatorname{IQE}(\lambda)=\frac{N_{\text {charge }}^{\text {out }}(\lambda)}{N_{\text {Photon }}^{\text {absorbed }}(\lambda)},(6.7)
$$

The IQE represents the solar cell response normalized by the actually absorbed photo numbers via active layer. So the value of the IQE is determined by each process after absorption of the photons and contains the information about charge generation, recombination and extraction. The interdependency of the EQE and IQE could expressed by formula $(6.8) .{ }^{[62,63]}$

$$
I Q E=\frac{E Q E}{\eta_{A}},(6.8)
$$

Where $\eta_{\mathrm{A}}$ represents the efficiency of incident light that is absorbed by the active layer. 


\subsection{Charge generation in organic solar cell}

\subsubsection{Exciton generation, diffusion and dissociation}

In organic photovoltaics, the photons with the energy $(h v)$ larger than the band gap $(E \mathrm{~g})$ of donor/acceptor can be absorbed and equal number electron-hole pairs with the number of absorbed photos are generated. The initial photo excited electron-hole pairs are bounded together in the form of Frenkel excitons due to the low dielectric constant of organic semiconductors. These excitons can be dissociated into free charge carriers assisted by D/A interfaces, so they should diffuse to the $\mathrm{D} / \mathrm{A}$ interface within the exciton infinite lifetime. In that case, the phase separation between donor and acceptor plays a key role in determining the diffusion efficiency. The desired nanostructure of the active layer is to form continuous interpenetrating networks and separated donor and acceptor phases with average domain sizes on the order of tens of nanometers that is comparable with the diffusion length. ${ }^{[64,65,66]}$

When the strongly bound excitons arrive at $\mathrm{D} / \mathrm{A}$ interface, they can be converted into more delocalized charge transfer (CT) states ${ }^{[67]}$ assistant by the energetic offset between donor and acceptor. So the optimization of the donor and acceptor materials with appropriate energetic offset plays a key role in designing of the organic solar cell with efficient exciton dissociation. A rule of thumb is that the difference between LUMO of donors and acceptors should be or larger than 0.3 $\mathrm{eV} \cdot{ }^{[16]}$

The energy difference between bounded Frenkel excitons $\left(E_{\mathrm{D}^{*}}\right)$ and charge transfer states $\left(E_{\mathrm{CT}}\right)$ is defined as the driving force ${ }^{[68,69,70]}$ The value of the driving force could be minimized to $0-0.1 \mathrm{eV}$ in optimized recipe. ${ }^{[68,71]}$ Too large driving force would result low open circuit voltage, while insufficient driving force will obstruct exciton dissociation, which lead to low short circuit current. The convenient way of identifying if there are enough driving force is to carry out the photoluminescence (PL) measurement. The PL emitting from Frenkel excitons could be quenched efficiently in the blend indicating that the driving force is enough for exciton dissociation, otherwise there could be not enough driving force for exciton dissociation at the $\mathrm{D} / \mathrm{A}$ interface or the excitons could not diffuse to the $\mathrm{D} / \mathrm{A}$ interface before recombination. ${ }^{[68,71]}$ Whether inefficient exciton diffusion or insufficient driving force is limiting the eventually exciton dissociation can be distinguished by PL measurement under bias in combination of morphology measurements like 
AFM, TEM or XRD. The Frenkel exciton diffusion is not affected by an electric field, while the exciton dissociation can be enhanced via facilitated CT exciton dissociation and inhibited exciton regeneration from $\mathrm{CT}$ excitons under bias. ${ }^{[71,72]}$

\subsubsection{Charge transfer excitons formation and dissociation}

CT excitons are formed following the dissociation of the Frenkel exciton and the CT excitons need to be further dissociated into free charge carriers that can be transported to and collected by the electrodes. The process is showing in Figure 6.3 and Figure 6.4.

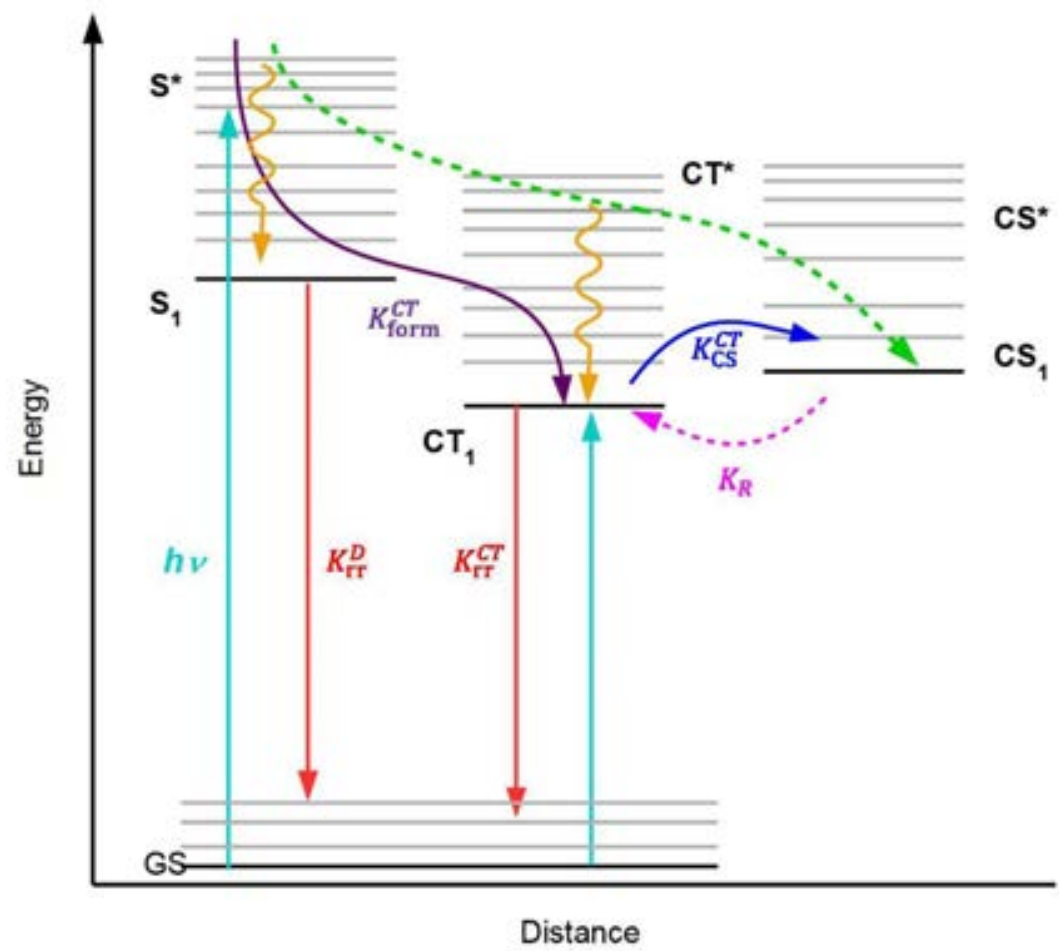

Figure 6.4 Energetics of the relevant states at BHJOSCs. The figure is adapted from reference. ${ }^{[73]}$ Charge transfer excitons can also be formed via direct optical excitation besides formation via charge transfer process. As shown in Figure 6.4, the electrons in the valence band of donor can be excited directly to the conduction band (LUMO) of the acceptor at the D/A interface and form CT excitons. The transition process from the ground state to excited state is visible in the low energy 
region of photovoltaic external quantum efficiency spectrum. ${ }^{[74]}$ The existence of the CT excitons can also be proved by the radiative decay of the $\mathrm{CT}$ excitons detected via PL or electroluminescence (EL) measurement in some D/A blend. ${ }^{[75]}$ The energy of the CT state can be calculated by fitting the measured photovoltaic EQE spectrum (Figure 6.4) using formula 6.9. ${ }^{[76]}$

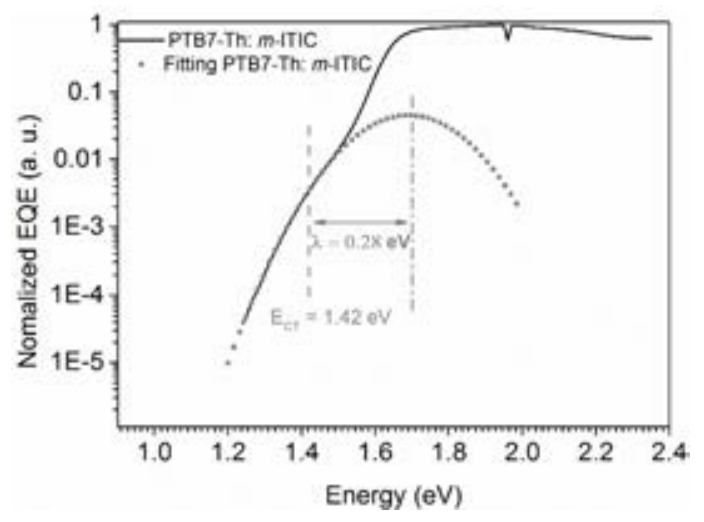

Figure 6.4 Normalized FTPS-EQE of PTB7-Th: $m$-ITIC.

$$
E Q E_{P V}=\frac{f}{E \sqrt{4 \pi \lambda k T}} \exp \left(\frac{-\left(E_{C T}+\lambda-E\right)^{2}}{4 \lambda k T}\right)
$$

CT excitons should dissociate into free charge carriers instead of recombining to the ground state in order to generate current. The dissociation of the $\mathrm{CT}$ excitons can be easily affected by electric fields, and the existence of interface dipole generated by the ICT state at the D/A interface can also facilitate the dissociation of CT excitons. ${ }^{[40,44]}$ Furthermore, the existence of ICT states will populate the most easily oxidized chains in the donors and the most reduced chain in the acceptors. In this way, the most tightly bound sites where charge transfer electron-hole pairs could be created at the interface are already occupied by interfacial dipoles in the dark ground state and they are consequently not available to participate in the exciton dissociation process, which ensures that the charge transfer excitons upon dissociation are "hotter" than otherwise would be the case. ${ }^{[77,78]}$ 


\subsubsection{Charge carrier transportation and Charge collection}

The efficient photoinduced charge generation should be followed by efficient charge extraction processes. The charge carrier collection efficiency is determined by the competition between charge carrier extraction and recombination. The charge extraction length could be defined as

$$
l=\mu \tau E(6.10)
$$

Where $\tau$ represent the lifetime of a charge carrier, $\mu$ is the charge carrier mobility and $\mathrm{E}$ is the electric filed. Due to the low carrier mobility in organic solar cells, the thickness of active layer is always limited and the optimized thickness is around $100 \mathrm{~nm}$ in most of the devices.

\subsection{Recombination in organic solar cells}

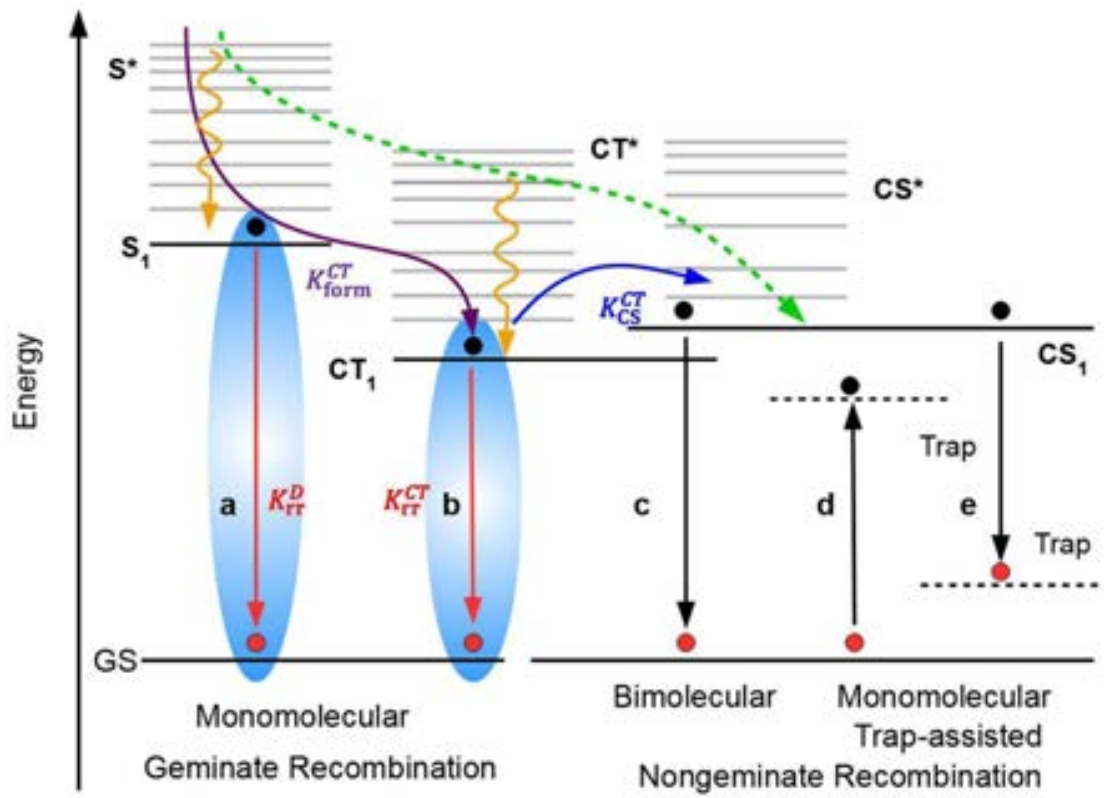

Figure 6.5 Energetics of the relevant states at BHJOSCs: An overview of the four most encountered recombination mechanisms. (a), Frenkel exciton recombination, (b), CT exciton recombination, (c), recombination of free charges via CT states. (d) and (e), trap assisted recombination. The figure is adapted from reference. ${ }^{[73,79]}$ 
The ideally scenario is that every absorbed photon is successfully converted into the free charge carriers and collected at electrodes. While the reality is that each step described above from photo absorption to charge collection is wrought with potential loss mechanism limiting the power conversion efficiency of the organic solar cells. The involved different kinds of recombination in the photovoltaic process are summarized in Figure 6.5.

\subsubsection{Geminate recombination}

Geminate recombination means that the recombination involving an electron-hole pair originates from a single photon event. The geminate recombination include the losses of excitons that relax to the ground state before they dissociate to CT excitons at D/A interface and the losses of CT excitons relaxation before dissociating to free charge carriers. Both of these two kinds of geminate recombination are considered as monomolecular recombination.

\subsubsection{Non-geminate recombination}

During the extraction process of free charge carriers, the free charge carriers could be eliminated via non-geminate recombination. Non-geminate recombination includes three different kinds of mechanisms. They are bimolecular recombination, trap-assistant recombination and auger.

\section{Bimolecular recombination}

Bimolecular recombination also named Langevin recombination means the recombination of free holes and free electrons originating from different excitons. The recombination rate of Langevin recombination follows the formula

$$
R_{L}=\zeta \frac{q}{\varepsilon}\left(\mu_{n}+\mu_{p}\right)\left(n p-n_{i}^{2}\right),(6.11)
$$

Where $\zeta$ is Langvin-reduction factor for the net recombination, $\mathrm{q}$ the elementary charge, $\varepsilon$ the dielectric constant, and $\mu_{\mathrm{n}}$ and $\mu_{\mathrm{p}}$ are the mobility of electrons and holes respectively. $\mathrm{n}$ and $\mathrm{p}$ represent the electron and hole charge density respectively and $n_{\mathrm{i}}$ is the intrinsic carrier concentration. Bimolecular recombination mainly happens at the D/A interface via CT state, confirmed by EL from injected charges at low voltage radiative decay through CT state in some 
system. So decreasing of D/A interface area would reduce the probability of opposing charge carriers finding one another thereby suppressing bimolecular recombination.

\section{Trap assisted recombination}

Trap assisted recombination, processes $\mathrm{d}$ and $\mathrm{e}$ in Figure 6.5, is a process where free carriers recombine with the trapped opposite carriers resident in trap states. Trap assisted recombination includes two steps, typically one carrier first is captured by a trap state and then the second opposite free charge carrier recombines with trapped carriers. Although two charge carriers are involved in trap assisted recombination, it is monomolecular recombination because just one carrier is involved at a time. The Shockley-Read-Hall recombination model describing trap assisted recombination in inorganic semiconductors can be applied to organic solar cell and the recombination rate is then expressed by the formula ${ }^{[80]}$

$$
R_{S R H}=\frac{C_{n} C_{p} N_{t r}\left(n p-n_{i}^{2}\right)}{\left[C_{n}\left(n+n_{1}\right) C_{p}\left(P-P_{1}\right)\right.}
$$

Trap assisted recombination usually originates from impurities in organic semiconductors, creating energy levels inside the forbidden band gap. In this thesis, one kind of trap assisted recombination is caused by ICT states formed at the interface of donor and acceptor. ${ }^{[9,43,72]}$

\subsubsection{Distinguishing of bimolecular recombination and monomolecular recombination.}

Generally speaking, under open-circuit conditions, the dominant recombination can be distinguished from the dependence of $V_{\mathrm{oc}}$ on the natural logarithm of the light intensity. Monomolecular dominant recombination has a slope of $2.0 \mathrm{kT} / \mathrm{e}$, while bimolecular dominant recombination has a slope of $k T / e$.

\subsubsection{Voltage losses in organic solar cell}

Two definitions of the voltage losses are used in this thesis, both commonly used in literature. One way is to relate the measured Voc to the electrical (transport) gap, and the other way is to compare the measured Voc with the optical gap. ${ }^{[81]}$ The electrical gap is defined as the difference in energies 
of the states that are occupied by free electrons and free holes. The optical gap of the devices is defined as the minimum of the optical gaps of the donor and acceptor materials.

An empirical estimate of the Voc in terms of the HOMO of the donor and the LUMO of the acceptor was proposed without considering vacuum level misalignment as shown in equation $6.13^{[16]}$

$$
V_{\text {oc }}=\left(-\left|E_{\text {Hомо }}^{D}\right|+\left|E_{\text {LUMO }}^{A}\right|\right) q^{-1}-0.3 V,(6.13)
$$

Where $0.3 \mathrm{~V}$ is an empirical value, representing losses of Voc compared to the electrical gap, i.e. differences between HOMO of the donor and LUMO of the acceptor $\left(\mathrm{E}_{\mathrm{LUMO}}^{\mathrm{A}}-\mathrm{E}_{\text {номо }}^{\mathrm{D}}\right)$. The value of the HOMO and LUMO are estimated from the oxidation/reduction potential measured by electrochemical method.

As discussed in chapter 4, The IP and EA can be measured via UPS and IPES respectively, so the electrical gap can be expressed as

$$
\Delta E_{g}^{D A}=I P_{D}-E A_{A},(6.14)
$$

There can be spontaneous integer charge transfer when organic materials are brought into contact and the integer charge transfer energy can be used to predict the organic/organic interface interaction and energy-level alignment as we discussed in chapter $4 .{ }^{[2,34,41,42]}$ In organic solar cell, when the $E_{\mathrm{ICT}}$ of the acceptor is larger than the $E_{\mathrm{ICT}+}$ of the donor, there should be charge transfer between donor and acceptor in the dark ground state and formation of the dipole at the interface, creating a vacuum level misalignment. In that case, the effective electrical gap can be reformulated as

$$
\Delta E_{g, e f f}^{D A}=I P_{D}-E A_{A}+\Delta,(6.15)
$$

Where $\Delta$ represents interface potential step obtained from difference between acceptor $E_{\text {ICT- }}$ and donor $E_{\mathrm{ICT}+}$

$$
\Delta=\left|E_{I C T+, D}-E_{I C T-, A}\right|,(6
$$

At open circuit voltage, the generation rate of the free charge carriers should equal to the recombination rate. The recombination occurs mainly through direct bimolecular recombination and trap assisted recombination in the good contact devices. The occupied ICT states can act as 
sites for trap assisted recombination. Two extreme situations is sole bimolecular recombination and sole trap assisted recombination, respectively. The Voc under each situation can be expressed as equation 6.17 and 6.18 .

$$
\begin{gathered}
e V_{o c}=E_{g, e f f}^{D A}-k_{B} T \ln \frac{N_{c} N_{v}}{G / \beta},(6.17) \\
e V_{o c}=E_{g, e f f}^{D A}-2 k_{B} T \ln \frac{\beta_{R S H} N_{I C T} \sqrt{N_{C} N_{V}}}{G},
\end{gathered}
$$

Where $\mathrm{G}$ is the generation rate, and $\mathrm{N}_{\mathrm{C}} / \mathrm{N}_{\mathrm{V}}$ is the effective states. $\beta / \beta_{\mathrm{RSH}}$ represents bimolecular/trap assisted recombination coefficient respectively. More general equation can be reformed to equation 6.19 .

$$
\begin{aligned}
e V_{o c} & =E_{g, e f f}^{D A}-n_{s} k_{B} T \ln \frac{\beta N_{c} N_{v}+\beta_{R S H} N_{I C T} \sqrt{N_{C} N_{V} \exp \left(\frac{\Delta E_{g, e f f}^{D A}-e V_{O C}}{2 k T}\right)}}{G} \\
& \approx E_{g, e f f}^{D A}-n_{s} k_{B} T \ln \left(\frac{C_{0}(\Delta)}{G}\right)(6.19)
\end{aligned}
$$

$V_{\text {oc loss }}$ is here defined as the deviation from the effective electrical gap $\left(\Delta \mathrm{E}_{\mathrm{g} \text {, eff }}^{\mathrm{DA}}\right)$, i.e. ideal $V_{\mathrm{oc}}$, in the measured $V_{\mathrm{oc}}$, which can be formulated as

$$
V_{o c ~ l o s s}=\Delta E_{g, e f f}^{D A} q^{-1}-V_{o c},(6.20)
$$

Insert equation 6.20 to equation 6.17 and 6.18 , Voc loss can be expressed as equation 6.21 and $6.22 .^{[43]}$

$$
\begin{gathered}
e V_{o c \text { loss }}=k_{B} T \ln \frac{N_{c} N_{v}}{G / \beta}, E_{I C T+}>E_{I C T-},(6.21) \\
e V_{\text {oc loss }}=n_{s} k_{B} T \ln \left(\frac{C_{0}(\Delta)}{G}\right), E_{I C T+}<E_{I C T-},(6.22)
\end{gathered}
$$


Occupied integer charge transfer states at the donor/acceptor (D/A) interface, occurring when EICT+, $\mathrm{D} \leqslant \mathrm{E}_{\mathrm{ICT}-\text {, A }}$ (Figure 1), can act as trap sites for recombination that reduce the Voc, while the generation of free charges at the $\mathrm{D} / \mathrm{A}$ interface is enhanced by the interface potential energy gradient generated by occupied integer charge transfer states. Hence, there is a trade-off in terms of occupied integer charge transfer state density and the sweet spot occurs at $\mathrm{E}_{\mathrm{ICT}+} \approx \mathrm{E}_{\mathrm{ICT}-\text { as shown }}$ in Figure 6.6.

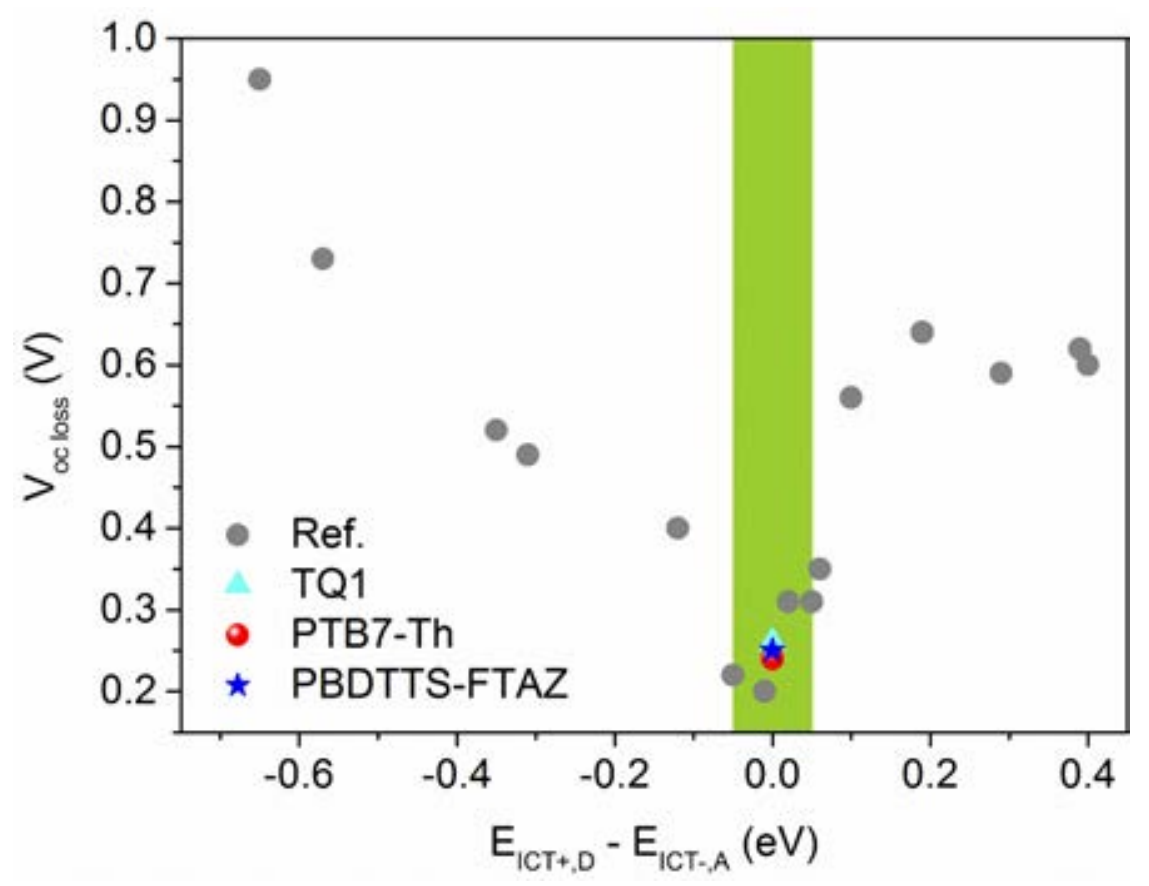

Figure6.6 $V_{\mathrm{oc}}$ loss versus $E_{\mathrm{ICT}+, \mathrm{D}}-E_{\mathrm{ICT}-\text {, A }}$ for a series of polymer: fullerene. $\mathrm{e} V_{\mathrm{oc}}$ loss $=\Delta E_{\mathrm{g}, \text { eff }}^{\mathrm{DA}}-\mathrm{e} V_{\mathrm{oc}}$. The green region contains the polymer: fullerene blends where $E_{\mathrm{ICT}+, \mathrm{D}} \approx E_{\mathrm{ICT}-}$, A within the error bar of the measurement. The figure is adapted from reference. ${ }^{[15]}$

When the measured Voc is compared to optical gap, the $V_{\mathrm{oc}, \text { loss }}$ can be expressed by the formula

$$
V_{o c, l o s s}=E_{D *} q^{-1}-V_{o c}(6.23)
$$

Where $E_{\mathrm{D}^{*}}$ is the optical gap that could be determined from the cross point of the normalized absorption and emission spectra as shown in Figure A1 or usually extracted directly from the onset of the absorption spectra. ${ }^{[69,72,82]}$ Before charge generation, the strongly bound excitons in the neat 
donor/acceptor materials need convert into delocalized charge transfer states. The voltage losses can be divided into two parts, charge transfer losses and recombination losses, and the equation 6.23 can be rewritten as

$$
V_{o c, l o s s}=\left(E_{D *}-E_{\mathrm{CT}}\right) q^{-1}+\left(E_{\mathrm{CT}} q^{-1}-V_{o c}\right),(6.24)
$$

Where $\left(E_{D^{*}}-E_{C T}\right)$ is defined as driving force. The generation rate of the free charge carriers should be equal to the recombination rate at open circuit condition. In other words, at Voc, the recombination current balances with the photogenerated current and Voc is given by equation (6.25). Starting from which, the Voc could be related to the $E_{\mathrm{CT}}$ as shown in equation (6.28). The detailed process can be found in the literature.

$$
V_{o c}=\frac{k T}{q} \ln \left(\frac{J_{P h}}{J_{0}}+1\right)
$$

Where $\mathrm{J}_{0}$ is related to electro-optical properties by formula (6.26)

$$
J_{0}=\frac{q}{E Q E_{E L}} \int E Q E_{P V}(E) \emptyset_{B B}^{T} d E(6.26)
$$

Here, $\mathrm{EQE}_{\mathrm{EL}}$ is the electroluminescence $\mathrm{EQE}$ and $\phi_{\mathrm{BB}}^{\mathrm{T}}$ is the black body photon flux at temperature $\mathrm{T}$ that can be expressed as

$$
\emptyset_{B B}^{T}=\frac{2 \pi}{h^{3} c^{2}} E^{2} \exp \left(-\frac{E}{k T}\right)
$$

The $\phi_{\mathrm{BB}}^{\mathrm{T}}$ is strongly decreasing with increasing of photo energy, so only low energy CT part of the EQEPV spectra contributes to $J_{0}$. Combining formula 6.9, 6.25, 6.26, and 6.27, the Voc can be expressed as in equation 6.28 .

$$
V_{o c}=\frac{E_{C T}}{q}+\frac{k T}{q} \ln \left(\frac{J_{S c} c^{2} h^{3}}{f q 2 \pi\left(E_{C T}-\lambda\right)}\right)+\frac{k T}{q} \ln \left(E Q E_{E L}\right),(6.28)
$$

When the $E_{\mathrm{CT}}$ is considered as the effective optical bandgap, the $\mathrm{V}_{\text {oc losses }}$ compared to $E_{\mathrm{CT}}$ can be reformulated as equation (6.29) 


$$
\begin{aligned}
V_{\text {oc }, \text { losse }} & =\left(E_{\mathrm{CT}} q^{-1}-V_{o c}\right) \\
& =\frac{-k T}{q} \ln \left(\frac{J_{s c} c^{2} h^{3}}{f q 2 \pi\left(E_{C T}-\lambda\right)}\right)+\frac{-k T}{q} \ln \left(E Q E_{E L}\right) \\
& =\Delta V_{\text {rad }}+\Delta V_{\text {nrad }}(6.29)
\end{aligned}
$$

Where voltage losses are divided into radiative $\left(\Delta V_{\text {rad }}\right)$ and non-radiative $\left(\Delta V_{\text {nonrad }}\right)$ recombination. The radiative energy losses are in principle unavoidable, since any light absorber should also emit light. If caused by defects and impurities, non-radiative recombination is avoidable, resulting in a maximum Voc if the electroluminescence external quantum efficiency ( $\mathrm{EQEEL}$ ) is close to 1. When there is only radiative recombination, the $\mathrm{V}_{\text {oc,rad }}$ could be expressed as equation 6.30

$$
V_{o c, r a d}=\frac{E_{C T}}{q}+\frac{k T}{q} \ln \left(\frac{J_{s c} c^{2} h^{3}}{f q 2 \pi\left(E_{C T}-\lambda\right)}\right)
$$

The relationship of the recombination current and voltage in equation 6.25 can be reformulated as equation 6.31 if there are only radiative recombination.

$$
V_{o c, r a d}=\frac{k T}{q} \ln \left(\frac{J_{P h}}{J_{0, r a d}}+1\right)
$$

Where $J_{0, \text { rad }}$ can be got from equation 6.32

$$
\begin{gathered}
J_{0, \text { rad }}=q \int_{0}^{\infty} \emptyset_{e m}(E, V=0) d E=\int_{0}^{\infty} E Q E_{P V}(E) \emptyset_{B B}(E) d E(6.32) \\
\Delta V_{o c, n r}=V_{o c, r a d}-V_{o c}=-\frac{k T}{q} \ln E Q E_{E L}(6.33)
\end{gathered}
$$

Minimizing the non-radiative recombination loss can significantly improve the Voc and performance of the organic solar cell. $\mathrm{EQE}_{\mathrm{EL}}$ for organic solar cell is typically around $10^{-6}$ to $10^{-9}$, which counts for a high voltage loss around $0.3-0.6 \mathrm{~V}$ compared to inorganic solar cell and perovskite solar cells. The inorganic solar cells have the lowest $\Delta V_{\mathrm{nr}}$ in the range of $0.04-0.21 \mathrm{~V} .^{[83]}$ For Perovskite solar cells, it is around $0.2-0.5 \mathrm{~V} \cdot{ }^{[83]}$ It has been proved recently that the $\Delta \mathrm{V}_{\mathrm{oc}} \mathrm{nr}$ can 
be decreased to around $0.24 \mathrm{~V}$ in both fullerene (Figure 6.7$)^{[72]}$ and non-fullerene system that contribute significantly to enhance the open circuit voltage in organic solar cells. ${ }^{[84]}$
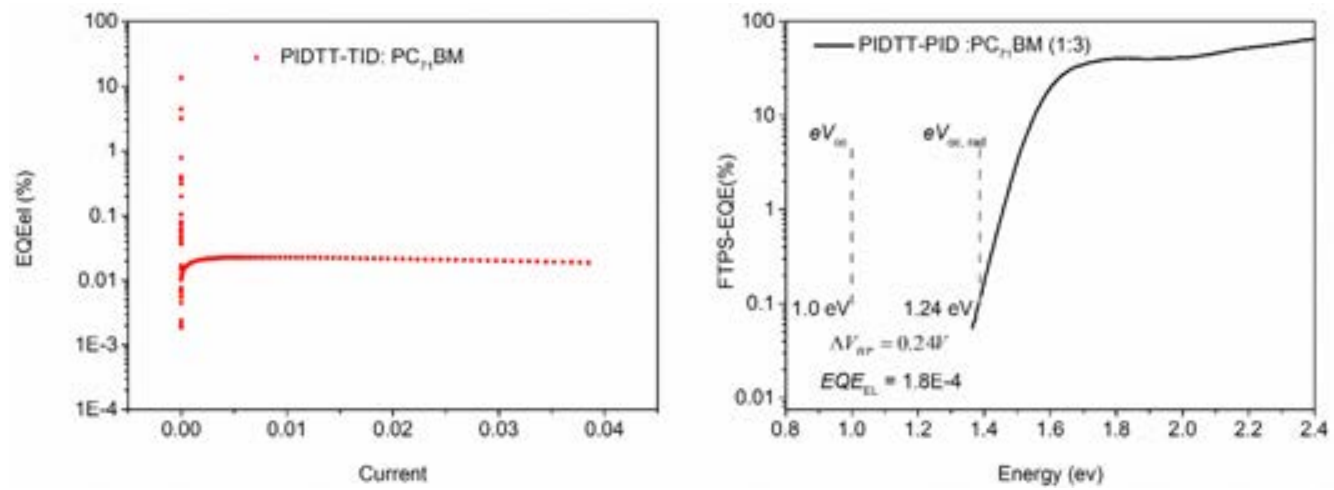

Figure 6.7 (a) EQEEL spectra and (b) FTPS-EQE spectra of the PIDTT-TID: PC ${ }_{71} B M$ (1:3) blend. The figures were adapted from reference. ${ }^{[72]}$ 


\section{Chapter 7 Ternary Organic Solar Cell}

\subsection{Advantages of ternary organic solar cells}

Improvement of any steps involved in working process of organic solar cells from photo absorption to charge collection would afford probability of improving the performance of organic solar cells. New donor materials, non-fullerene acceptors and developments in electrode design have pushed the power conversion efficiency (PCE) of the binary donor/acceptor (D/A) BHJOSC to over $12 \%$ by improving photon harvesting ability, charge generation, charge transport and/or charge extraction. So-called tandem and ternary device structures also have been deployed to enhance PCE. Both concepts use an additional absorbing material (donor or acceptor) to extend the spectral range of light absorption, but the tandem approach uses two stacked binary sub-cells that covers different parts of the solar spectrum, which is significantly harder to fabricate in a printing process and requires current matching between the two sub-cells, in practice limiting the device to the lower-current sub-cell, whereas the ternary approach uses a single absorbing layer compromising three organic semiconductors: two donors and one acceptor (D1/D2/A) or two acceptors and one donor (D/A1/A2) to achieve improved coverage of the solar spectrum that retains the simplicity of printing process from the binary D/A bulk-heterojunction solar cells. Besides of the expanded coverage of the solar spectrum and access to easy solution processing mentioned above, ternary organic solar cells can improve the charge dissociation and transportation, and as we now show in this thesis, the Voc can also be enhanced.

Although there are various advantages for ternary organic solar cells, the introduction of the third component making the working mechanism complicate and different from binary solar cells instead of simple superposition of the working process of referenced binary solar cells. There are mainly three working mechanisms in a ternary solar cell: charge transfer, energy transfer and parallel-linkage. The determining factors of working principles are the energy level alignment of the three components and the distribution of the third component in the active layer. The third component could be locate at the D/A interface, or embedded in donor or acceptor, or form their own channels as shown in Figure7.1. 

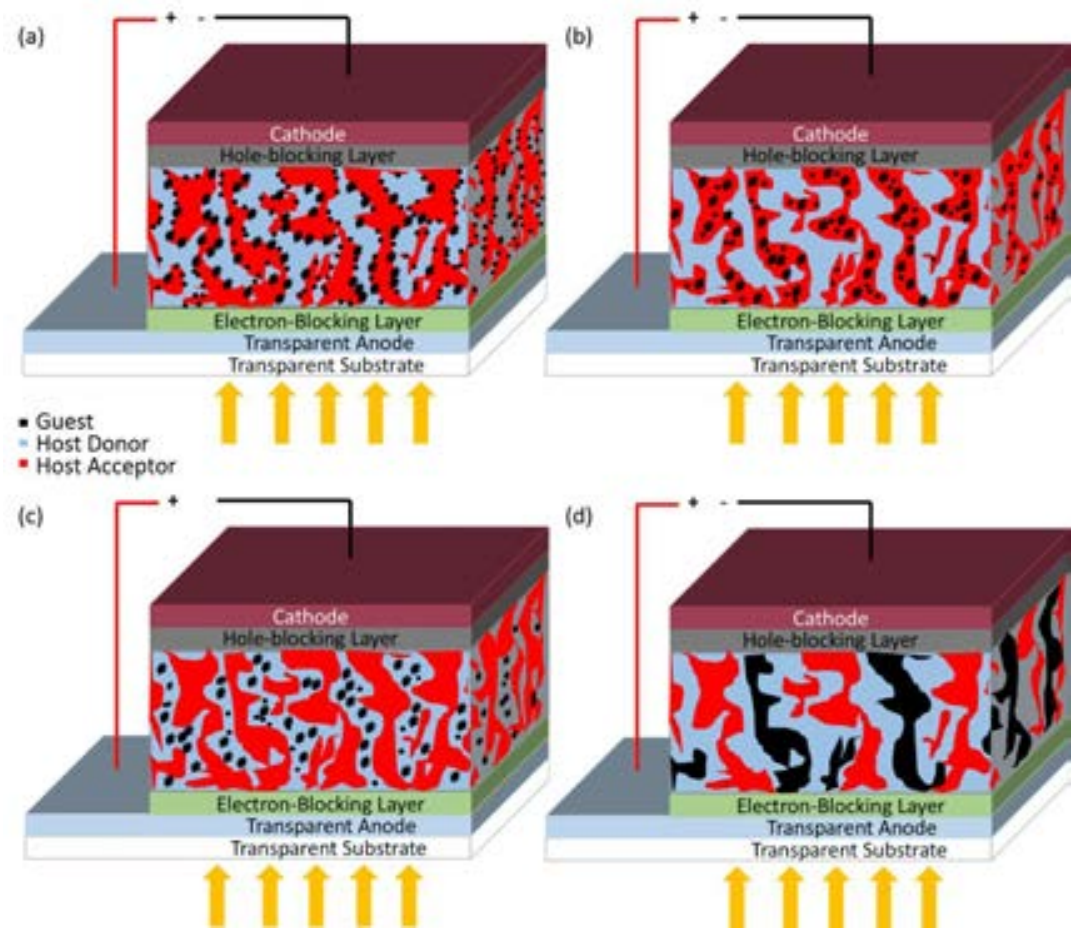

Figure7.1 Working mechanism of ternary organic solar cell. The third component (a) locates at the interface of the host donor and acceptor, and (b) and (c) embeds in host acceptor or donor, and (d) forms its own channel.

\subsection{Distribution of the third component and identification methods}

Distribution of the third component in ternary blend includes two aspects. One is the vertical distribution of the third component, and another is the location of the third component relative to host binary blend in ternary blend films, both of which are important for ternary solar cells. The energy levels and energy level alignment can be determined via CV or UPS measurement as we discussed earlier. The vertical distribution can be measured by e.g. photoelectron spectroscopy (UPS and XPS) and both of the vertical distribution and the location of the third component in the ternary blend can be identified via contact angle measurements. 
The frontier electronic structure is unique for a specific material so the UPS spectra will be different from each other, especially in the region of the frontier orbitals. The UPS spectra of the neat film and the blend film then can be measured to identify the vertical distribution according to the shape of the valence band as shown in Figure7.2. The major component at the surface can be identified by comparing the properties of frontier orbital of pure and blend film in UPS spectra, and the ratio of each component can be obtained by fitting the UPS spectra. More accurate quantitative measurement can be done via XPS measurements. The ratio of each component can be deduced via calculating the ratio of the featured elements in each material. ${ }^{[85]}$

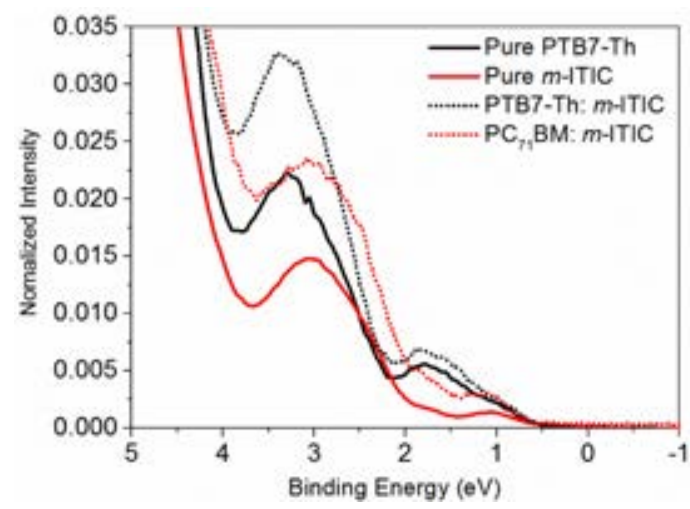

Figure 7.2 Valence band structure of neat PTB7-Th, $m$-ITIC and blends obtained from UPS spectra. Adapted from reference. ${ }^{[9]}$

Another simple method is the contact angle measurement as shown in Figure 7.3. The surface energy here can be deduced from the contact angle. The materials with the lower surface energy (large contact angle) will tend to be segregated into the air/film interface while the material with higher surface energy (small contact angle) typically is going to be segregated to the film/electrode interface.
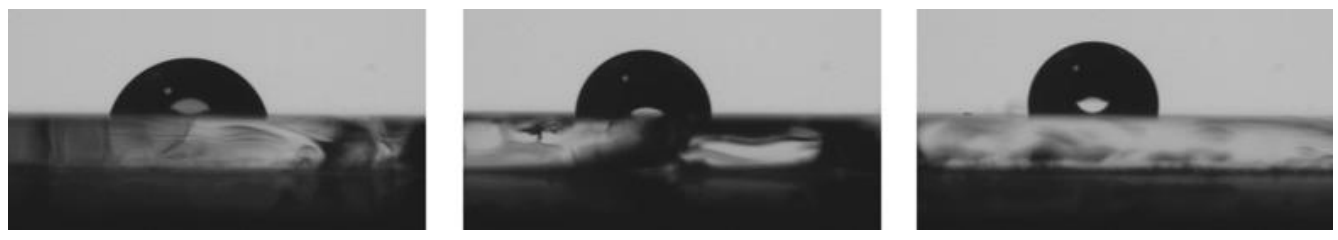

Figure7.3 Water contact angle of three different films, $\mathrm{PC}_{71} \mathrm{BM}$ (left), $m$-ITIC (middle), PTB7Th (right). Adapted from reference. ${ }^{[9]}$ 
As to the location of the third component in the blend, it can be determined via wetting coefficient calculation of each component according to the measured contact angle. The wetting coefficient of the third component in blends of materials donor $\mathrm{A}$ and acceptor $\mathrm{C}$ can be calculated according to Equation 7.1 (Young's equation according), where $\omega_{\mathrm{s}(\mathrm{c})}$ represents the wetting coefficient and $\Upsilon_{\mathrm{s}(\mathrm{X}) \mathrm{s}(\mathrm{Y})}$ represents the interface surface energy between solid $\mathrm{X}$ and solid $\mathrm{Y}$, which can be deduced from Equation 7.2 (Neumann's equation). $\Upsilon_{\mathrm{sv}}$ represent surface tension energy between solid(s) and vapor (v), which can be deduced from Equation 7.3 and $Y_{\text {lv }}$ represent liquid-vapor surface tension. $\theta$ represents the water contact angle of the film. $\beta$ is $0.000115 \mathrm{~m}^{4} \mathrm{mj}^{-2}$ in Equation 7.2 and 7.6. The physical meaning and detail derivation process of each equation can be found in literature. When $\omega_{\mathrm{s}(\mathrm{C})}<-1$, the third component $\mathrm{C}$ will tend to embed in the domain of material Acceptor $\mathrm{C}$.

$\omega_{\mathrm{s}(\mathrm{C})}>1$, the third component will tend to embed in the domain of material Donor A.

$-1<\omega_{\mathrm{s}(\mathrm{C})}<1$, the third component will tend to distribute at the interface of Donor A and acceptor C.

$$
\begin{gathered}
\omega_{s(C)}=\frac{\gamma_{s(C) s(B)}-\gamma_{s(C) s(A)}}{\gamma_{s(A) s(B)}},(7.1) \\
\gamma_{s(X) s(Y)}=\gamma_{s(X) v}-\gamma_{s(Y) v}-\sqrt{\left(\gamma_{s(X) v} \gamma_{s(Y) v}\right)} * \exp \left(-\beta\left(\gamma_{s(X) v} \gamma_{S(Y) v}\right)^{2}\right),(7.2) \\
\gamma_{s v}=\gamma_{l v} x_{n+1}^{2},(7.3) \\
x_{n+1}=x_{n}-\frac{x_{n}-a e^{b\left(1-x_{n}^{2}\right)^{2}}}{1+4 a b x_{n}\left(1-\left(x_{n}^{2}\right) e^{\left.b\left(1-x_{n}^{2}\right)^{2}\right)}\right.}(0 \leq x \leq 1),(7.4) \\
\alpha=\frac{\cos \theta+1}{2},(7.5) \\
b=\beta \gamma_{l v}^{2},(7.6)
\end{gathered}
$$




\subsection{Working mechanisms of ternary organic solar cells}

There are mainly three kinds of working mechanisms in ternary solar cells, as mentioned, which is determined by the relative energy levels and the distribution of each component. They are charge transfer, energy transfer and parallel linkage respectively. In many ternary solar cells, all these mechanisms usually coexist with one dominate process. ${ }^{[86,87]}$ Different kinds of working mechanisms could be identified via PL and J-V curve measurement.

\subsubsection{Cascade exciton dissociation and charge transfer}
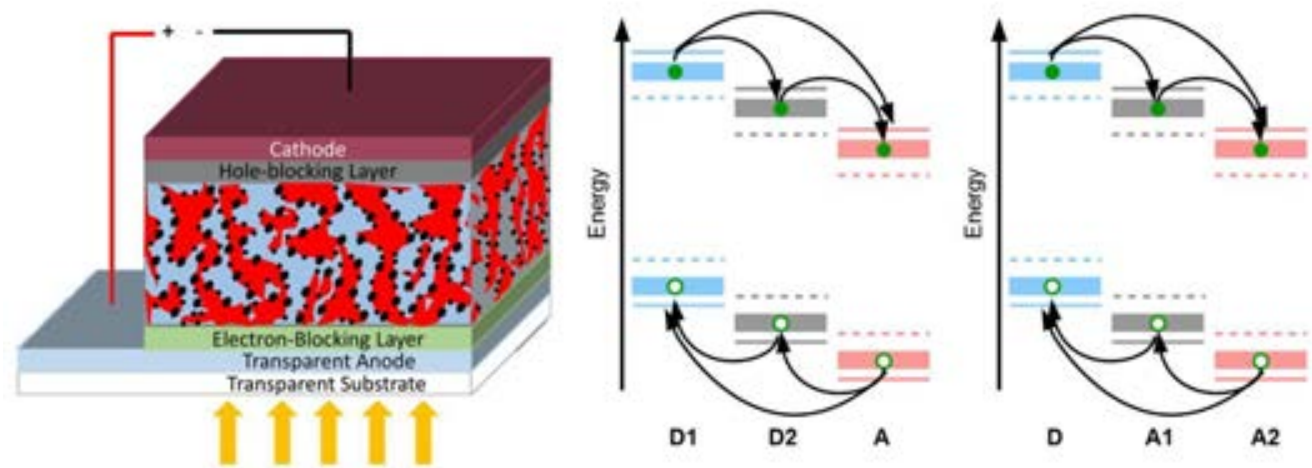

Figure 7.4 Cascade charge transfer mechanism

During design process of ternary solar cells with charge transfer and transport as dominate mechanisms, the selection of the third component should meet the two main requirements. The first one is that the third component should locate at the interface of the dominant donor and acceptor so as to form a percolating pathway for charge transfer and transportation, and the second one is that the energy levels of the third component should locate between the energy levels of the host donor and acceptor, as shown in Figure7.4, forming a "cascade junction". The charge transfer mechanism is that there is exciton dissociation and charge transfer between two donors (D1/D2) or two acceptors (A1/A2) in addition of the exciton dissociation and charge transfer at the interface of donor and acceptor (D/A) similar to that in binary solar cell. In double donor ternary, the excitons generated in donor D1 can transfer electrons to either acceptor A or donor D2. In the latter case, the D2 subsequently transfers electrons to the acceptor A. While the excitons generated in D2 can 
transfer the electron to acceptor and in parallel the hole to D1. Following the charge transfer, the electrons are transported to cathode through the channel formed by the acceptor domains and the holes are transported to anode through the channel formed by the host donor. Similar process can occur in double acceptor ternary system, the excitons generated in acceptor A2 can transfer a hole either to donor D or acceptor A1. In the latter case, the acceptor A1 subsequently transfers a hole to the donor D. Alternatively the excitons generated in acceptor A1 could transfer a hole to donor $\mathrm{D}$ and in parallel the electron to A2. The electrons are transported to the cathode through the channel formed by host acceptor A2 and the holes are transported to anode through the channel formed by donor. The charge transfer between two donors or two acceptors can be measured by $J$ $V$ curves. If there is charge transfer between two donors or two acceptors, composing a solar cell device, the blend device usually shows larger $J_{\mathrm{sc}}$ and medium Voc compared to the corresponding neat film devices as shown in Figure 7.4. Another convenient method is the PL measurement. If there is charge transfer between two donors (or two acceptors), the PL emission intensity of one donor (acceptor) would be reduced without increasing PL intensity of other donor (acceptor). TRPL combined with the optical gap can also afford proof of charge transfer.

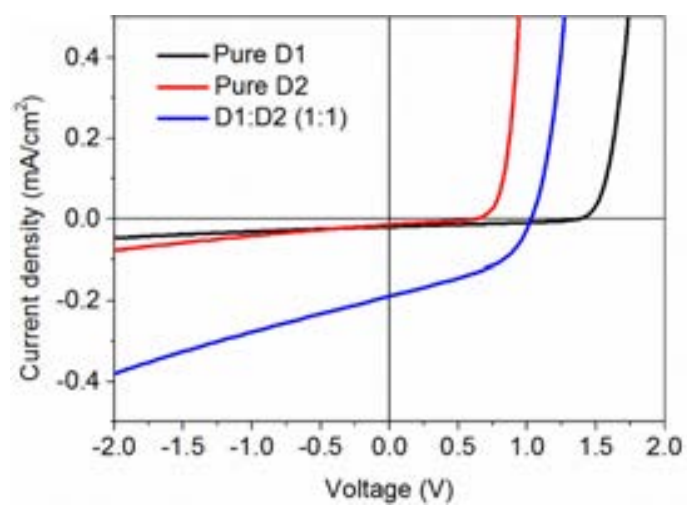

Figure7.4 J-V curves of two donor polymers and their blend with the ration of 1:1.

The electrons and holes are mainly transported to the electrodes through the channels formed by the host acceptor and donor, respectively, so the loading of the third component at the interface of the host donor and acceptor would decrease the probability that electrons and holes to meet and recombine, so the voltage losses due to CT state recombination can be decreased. ${ }^{[88,89]}$ The trap 
assisted recombination via ICT states can also be tuned by addition of the third component at the interface of the host donor and acceptor. ${ }^{[9]}$

\subsubsection{Energy transfer}
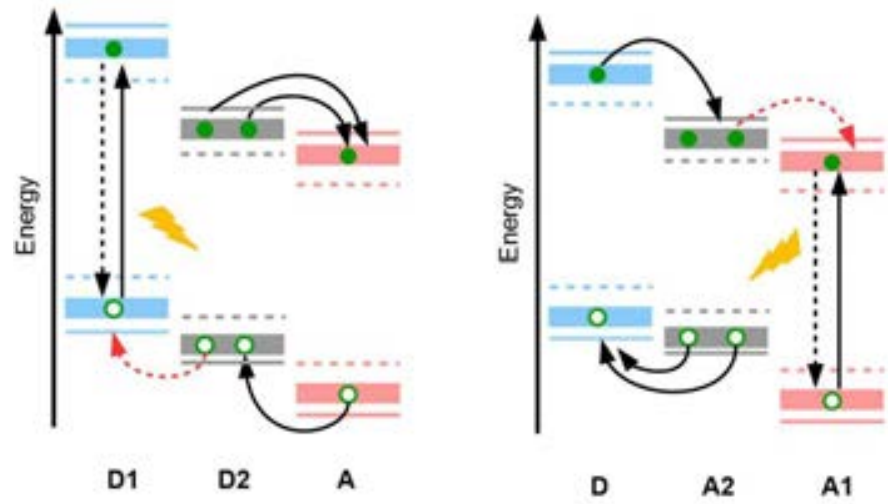

Figure 7.5 Energy level diagram in ternary blend with energy transfer mechanism.

Energy transfer between two donors or two acceptors is a competing process compared with charge transfer in ternary blend films as shown in Figure 7.5. In addition to the advantages of the ternary solar cell we mentioned, the energy transfer has the potential to improve the efficiency of the solar cell, even surpassing the Shockley-Queisser (S-Q) limit of a single p-n junction. Two strategies in conjugation with the energy transfer mechanism are singlet fission and upconversion. ${ }^{\text {90, } 91,92]}$ During energy transfer, an exciton can be relocated from excited energy donor to an energy acceptor via non-radiative process. The non-radiative energy transfer process requires that the energy of the energy donor excited state must be higher than that of the energy acceptor excited state and the energy transfer rate must he faster than the intrinsic decay rate of the excited energy donor. At the end of energy transfer process, the energy donor is in the ground state and the energy acceptor is in the excited state. The energy transfer mechanisms include two types of mechanisms: Förster energy transfer and Dexter energy transfer. Förster energy transfer is based on a dipoledipole electromagnetic interaction and requires that the absorption spectrum of energy acceptor should overlap with the emission spectrum of energy donor completely or partially at least as shown in Figure 7.6. Förster energy transfer occurs through space via electromagnetic interaction and can therefore occur over long distance, typically around 1-5 nm. The efficiency of the Förster 
energy transfer decreases with the distance between energy donor and energy acceptor as $\mathrm{r}^{-6}$ (equation 7.7)

$$
K_{E T}=\frac{1}{\tau_{D}}\left(\frac{R_{c}}{r}\right)^{6}
$$

Where $\tau_{\mathrm{D}}$ is the life time of the excited states of the energy donor, and $\mathrm{r}$ is the distance between energy donor and energy acceptor. Rc is the critical radius and represent the distance at which the energy transfer rate is equal to the intrinsic decay rate of the donor.

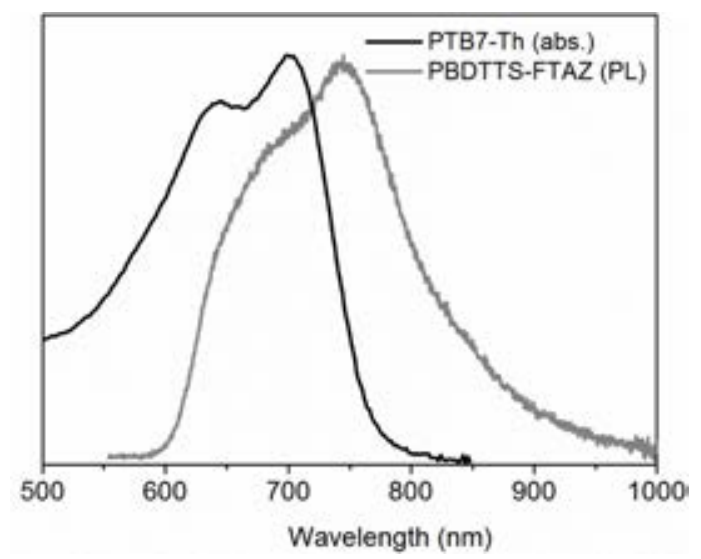

Figure 7.6 Normalized emission spectrum of energy donor and absorption spectrum of energy acceptor. Adapted from the reference. ${ }^{[15]}$

Dexter energy transfer needs an overlap of the wavefunctions between energy donor and energy acceptor so as to allow electron exchange. Hence it just can take place over short distances, typically around $1.0 \mathrm{~nm}$. The rate of Dexter energy transfer exponentially decreases with the distance between energy donor and energy acceptor (equation 7.8).

$$
K_{E T}=K J \exp \left(\frac{-2 r}{L}\right)
$$

Where $\mathrm{k}$ is related to the specific orbital interactions and $\mathrm{r}$ is the donor acceptor separation. $\mathrm{L}$ is the sum of the van der Vaals radii and $\mathrm{J}$ is the normalized spectral overlap integral. 
In a ternary system, when the third component act as energy acceptor, D2 in double donor system and A2 in double acceptor system as shown in Figure 7.5, it should be adjacent both to the energy donor D1 or A1 and host acceptor D or host donor A. When the third component act as energy donor, D1 in double donor system and A1 in double acceptor system as shown in Figure 7.5, the third component just need but have to adjacent to the energy acceptor D2 or A2 due to the limited radius of energy transfer. In a double donor ternary system involving energy transfer, the exciton energy in D1 can be transferred to D2 and the excitons generated in D2 dissociated at the D2/A interface. The hole would be transported to the anode directly or transferred to D1 then transported to the anode, while the electrons are transported to cathode (mainly) via the acceptor. In double acceptor system, the excitons generated in A1 can be energy transferred to A2 and then dissociated at the D/A2 interface. The hole can be transferred to the anode via D and the electrons are transported to the cathode directly or transferred to A1 then transported to the cathode. The energy transfer can be identified by PL measurements. The PL intensity quenching of the energy donor will increase the PL intensity of the energy acceptor as shown in the Figure 7.6.

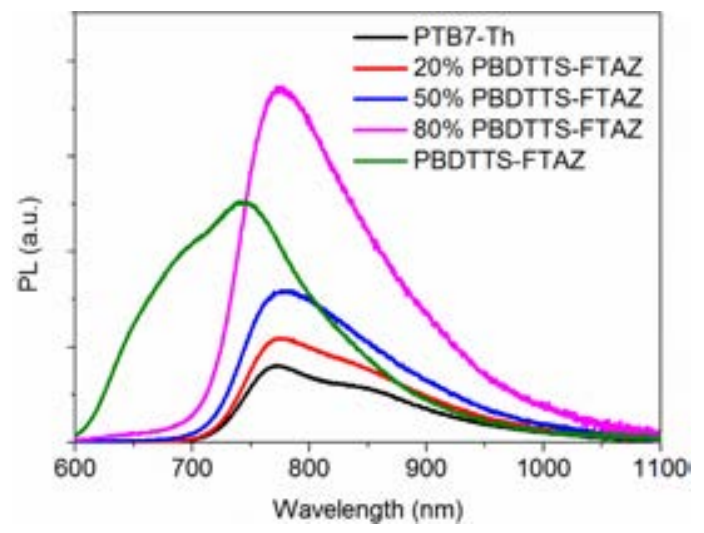

Figure7.6 PL spectra involving energy transfer. PTB7-Th act as energy acceptor and PBDTTSFTAZ act as energy donor. The figure is adapted from reference. ${ }^{[15]}$ 


\subsubsection{Parallel linkage}
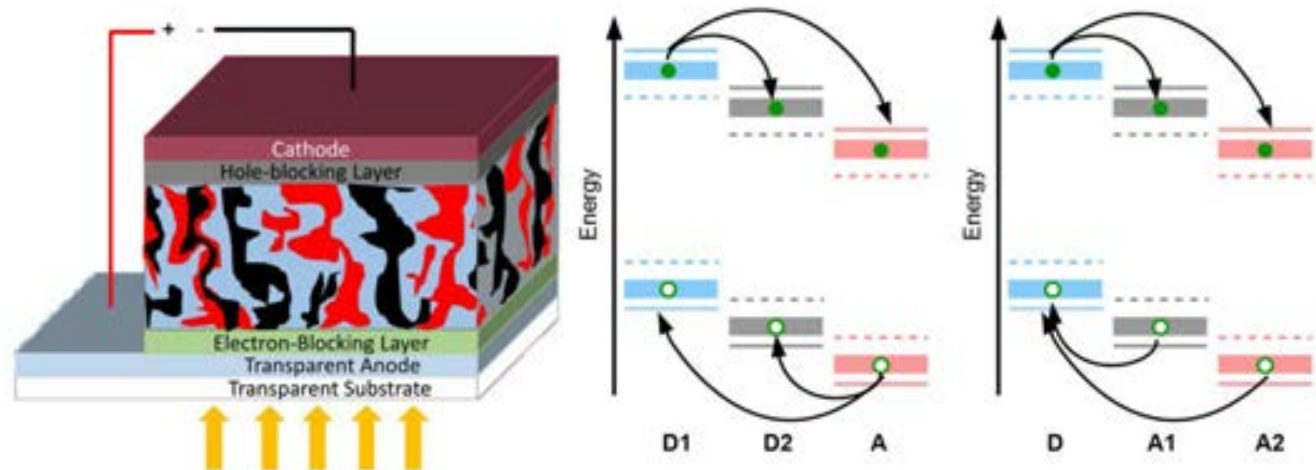

Figure 7.7 Energy level diagram in ternary blend with parallel linkage mechanism.

If only parallel linkage mechanisms occurs in the ternary system, there are no interaction between double donors or double acceptors, neither charge transfer nor energy transfer. In double donor system, both of the two donors, D1 and D2 in Figure 7.7, should be adjacent to the acceptor A, so as to form the $\mathrm{D} / \mathrm{A}$ interface with the acceptor. In double acceptor system, the two acceptor A1 and A2 in Figure 7.7, should be adjacent to the donor D. In this double donor ternary system, the excitons generated in the two donors or acceptor diffuse to the corresponding D1/A or D2/A interface and dissociate into free charge carriers. Then the hole is transported to the anode via the corresponding donor and the electron is transported to the cathode via the acceptor. In the equivalent double acceptor system, the excitons generated in the donor or two acceptors diffuse to and dissociate at the corresponding D/A1 or D/A2 interfaces, then the hole is transported to the anode and the electron is transported to the cathode via the corresponding acceptor. The PL spectrum combined with the J-V curve can be used to identify the parallel linkage mechanism. ${ }^{[87]}$

The working mechanisms mentioned above usually co-exist in a ternary system with one or two mechanisms dominating as shown in Figure7.8. The ratio between different mechanisms can be turned by turning the energy levels and location of the third component. 


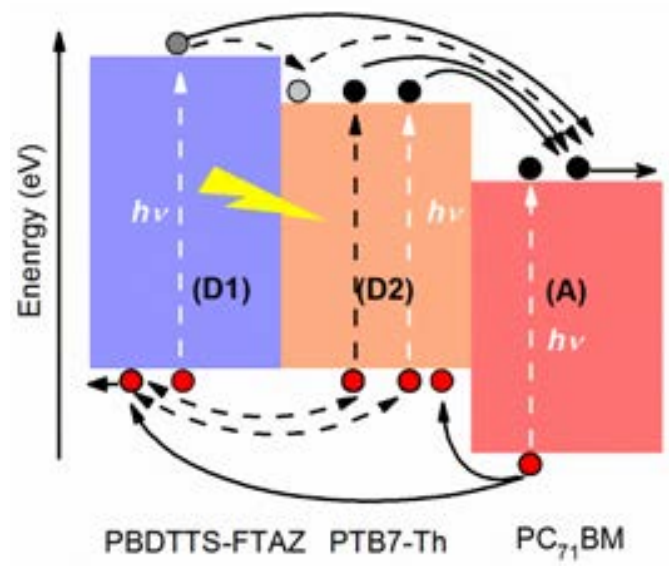

Figure7.8 co-existed working mechanisms of the ternary solar cell. Adapted from reference ${ }^{[15]}$ 


\section{Chapter 8 Stability of Organic Solar Cell}

\subsection{Parameters impacting the stability of organic solar cells}

Solution processing of organic molecules/polymers allows for low-temperature manufacturing of organic photovoltaics on flexible substrates using common printing techniques, which affords a promising route for the realization of low-cost, large area, flexible and light weight organic solar cells with shorter energy payback time. On the other hand, the relative low efficiency compared to inorganic solar cell and inferior stability are so far hindering the commercialization of the organic solar cell. The efficiency of the organic solar cell has been pushed to over $12 \%$ in recent years by various strategies, such as designing and synthesizing new active layer and interface layer materials, designing and fabricating ternary and tandem solar cells, etc. The overall stability of an organic solar cell is affected by the stability of each component, such as the stability of the electrode, interface layer and active layer.

The active layer containing the conjugated molecules/polymers is the key component of an organic solar cell, but these molecules/polymers generally suffer from poor air stability and require an inert atmosphere processing environment, which increases manufacturing complexity and cost. Thus, understanding of the stability and degradation mechanism is another key issue. The factors leading to degradation of the conjugated molecules/polymers mainly include oxygen, water, heating, illumination and diffusion of the interface layer and electrodes. All these factors are often coupled with each other at the same time and the degradation of conjugated molecules/polymers typically follow many complicated pathways. Therefore, it's necessary to figure out the effect of each parameter responsible for the degradation so as to find out the corresponding strategies to prevent the degradation of the active layer and increase the stability of the organic solar cell. Photoelectron spectroscopy provides a convenient in-situ method of studying the degradation of conjugated molecules/polymers by controlling exposure of oxygen and water vapor separately.

\subsection{In-situ method of studying degradation}

Photo electron spectroscopy is a powerful technique to measure the frontier electronic structure and interface properties of thin films. ${ }^{[2,93,94]}$ The detrimental changes in the frontier electronic 
structure and interface properties caused by various factors such as oxygen, water, heating and illumination can be probed. ${ }^{[95,96,97,98]}$ An advantage of this method is that the exposure of oxygen and water can be separately monitored quantitatively. The active layer of an organic solar cell is composed by both p-type donor and n-type acceptor. It has been proved that it's more difficult to develop practically useful n-type semiconductors compared to p-type semiconductors. ${ }^{[99,100]}$ Indeed, fullerene was the dominant acceptors in organic solar cells until the recent rapid development of the non-fullerene acceptors. Thus, in this thesis, the attention is focused on the degradation of the n-type acceptors.

It is revealed by the in-situ method that both oxygen and water tend to interact with the fullerene part of the PCBM. The interaction between oxygen and fullerene is a weak interaction, because the frontier electronic structure cannot be affected except of the whole spectra shifting toward the high binding energy and this shifting is reversible when the sample is treated by thermal annealing in vacuum. ${ }^{[97]}$ Water exposure, on the other hand, leads to significant chemical interaction as revealed by PES where the frontier orbital in the UPS spectra are irreversibly broadened and bleached, and new features appear in the XPS spectra. ${ }^{[97]}$ The rapid development of non-fullerene acceptors in the last two years now affords more recipes for designing both efficient and stabile OSC, as discussed in this thesis where non-fullerene acceptors are successfully used to design ternary solar cells with both enhanced efficiency and thermal stability. Besides improving the efficiency of the devices, understanding of the stability and degradation mechanism of the non-fullerene acceptors exposed to water and oxygen is obviously a key issue. Three n-type non-fullerene small molecular acceptors are investigated in this thesis. All of them are exposed to oxygen and water vapor separately. The experiment results reveal that the degradation mechanism of non-fullerene acceptors is different from the fullerene acceptors, and that the non-fullerene acceptors show more tolerance to both of water vapor and oxygen, a promising development for the technology.

\subsection{Thermal stability of the active layer containing non-fullerene acceptors}

Thermal stability is also crucial for organic solar cell because the working temperature of the organic solar cell is often high due to continuous illumination during the day. It is well known that thermal annealing of the device can lead to diffusion of metal ions from the electrodes into the active layer and create leakage current. ${ }^{[101,102]}$ Furthermore, the high temperature can induce 
chemical reactions at the metal/organic interface and alter the interface (morphology) properties. ${ }^{[103 \text {, }}$ 104] In order to investigate the thermal stability of the active layer, the device structure of ITO/PEDOT:PSS/active layer/ZnO/Al could be adopted because it has been proved that the interface between active layer and electron/hole transportation layer are electronically stable during thermal stress, which allows exclusion of thermal degradation of the interfacial layers during the annealing of the device. ${ }^{[105]}$ The experiment results in this thesis proved that incorporation of the non-fullerene acceptor into the ternary blend strongly improves thermal stability of the solar cell under industrial relevant thermal stress. The J-V curve in Figure 8.1 present the comparison of the thermal stability of fullerene containing binary and non-fullerene containing ternary solar cell.
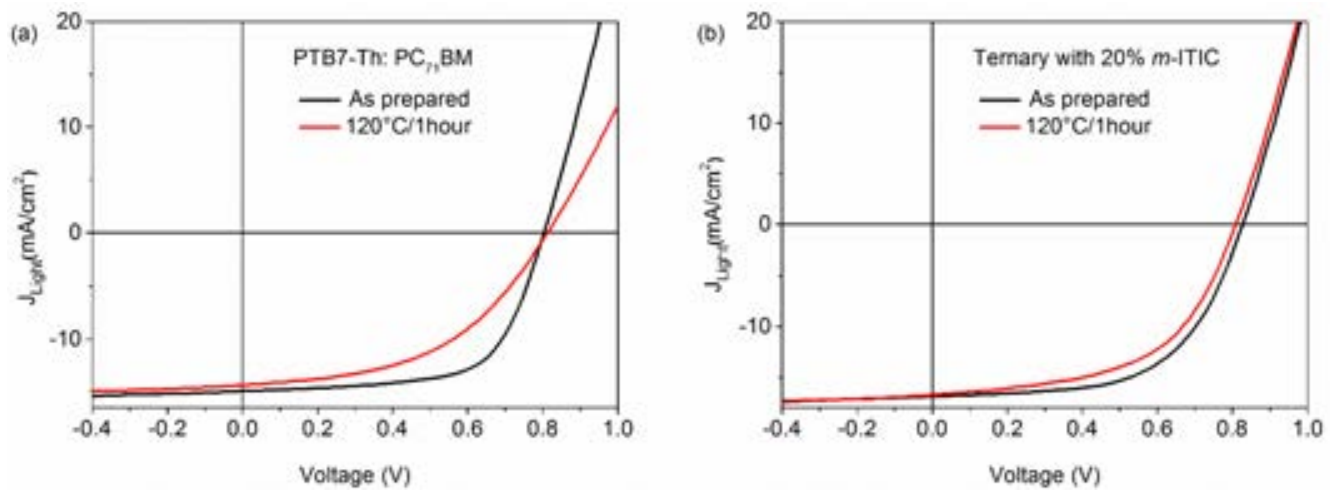

Figure 8.1 $J-V$ curves of fresh and degraded devices for a binary solar cell and b) ternary solar cell under simulated AM $1.5 \mathrm{G}$ irradiation $\left(100 \mathrm{~mW} \mathrm{~cm}^{-2}\right)$. Adapted from reference. ${ }^{[9]}$ 


\section{Chapter 9 Summary of Papers and Further Outlook}

\subsection{Summary of papers}

\subsubsection{Paper 1}

\section{Relationship of Vertical Ionization Potential and Oxidation potential of $\pi$-conjugated molecules/polymers}

Chuanfei Wang, Liangqi Ouyang, Slawomir Braun, Xianjie Liu, Mats Fahlman

(Manuscript)

A series of conjugated molecules/polymers typically used in organic solar cells were deposited in Platinum substrates or Platinum electrode to form thin film. Then the vertical ionization potential and oxidation potential were measured respectively by photoelectron spectroscopy and electrochemical method. It was found that there is a linear relationship between $I P$ and $E_{\mathrm{ox}}$ with the slop equal to unity (Figure 9.1). The relationship can be expressed as

$$
-I P=-(1.03 \pm 0.14) q E \mathrm{ox}+(4.45 \pm 0.09) \mathrm{eV}
$$

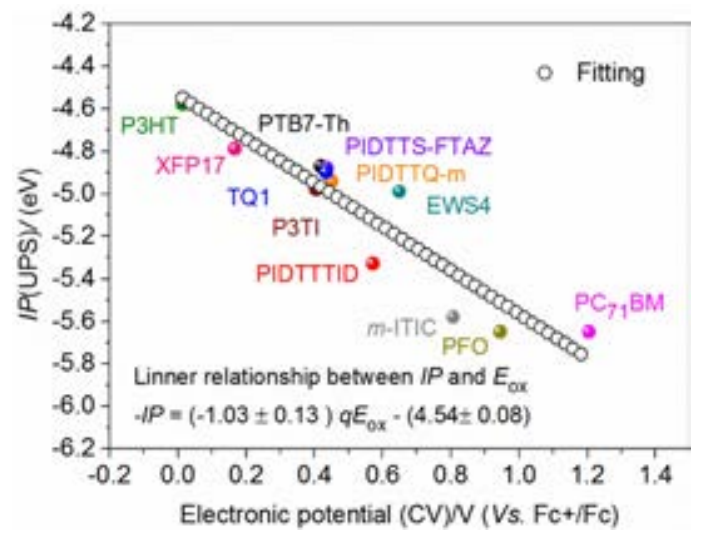

Figure 9.1 The relationship between oxidation potential and vertical ionization potential. 
Although the linear relationship with a slope of 1.0 presented is obtained from a set of $\pi$ conjugated organic molecules/polymers typically used for organic solar cells. We expect this relationship to hold also for other non-metal organic semiconductors. 


\subsubsection{Paper 2}

\section{Low Band Gap Polymer Solar Cells with Minimal Voltage Losses}

Chuanfei Wang, Xiaofeng Xu, Wei Zhang, Jonas Bergqvist, Yuxin Xia, Xiangyi Meng, Kim Bini, Wei Ma, Arkady Yartsev, Koen Vandewal, Mats R Andersson, Olle Inganäs, Mats Fahlman, Ergang Wang

Advanced Energy Materials, 2016, 6, 1600148

The relative higher voltage losses compared to optical gap is one of the main factors that limits the performance of organic solar cells. The total voltage losses could be divided into two parts. They are recombination losses including radiative and non-radiative recombination, and electron transfer losses due to the conversion of the bonded excitons in neat materials into delocalized charge transfer states at the interface. Compared to electron transfer losses and radiative recombination losses, the non-radiative voltage losses constitute the largest part of the total voltage losses. In organic solar cell, the non-radiative voltage losses is typically around $350 \mathrm{mV}$ that corresponds to an $\mathrm{EQE}_{\mathrm{EL}}$ of $10^{-6}$.

In paper 2, In order to obtain a solar cell with low voltage loss but high exciton dissociation efficiency, PIDTT-TID was used as the donor to be blended with acceptor of the $\mathrm{PC}_{71} \mathrm{BM}$ because the donor has a broad absorption but the deep HOMO level and the difference between the LUMO of the donor and acceptor is around the $0.3 \mathrm{eV}$, which should afford enough driving force for exciton dissociation. The results proved that the voltage loss could be decreased to $490 \mathrm{mV}$ by decreasing non-radiative recombination to $240 \mathrm{mV}$ in the low band gap polymer solar cell, while maintaining the voltage as high as $1.0 \mathrm{~V}$ as shown in Figure9.2. The non-radiative voltage loss is comparable with that of a perovskite solar cell. 


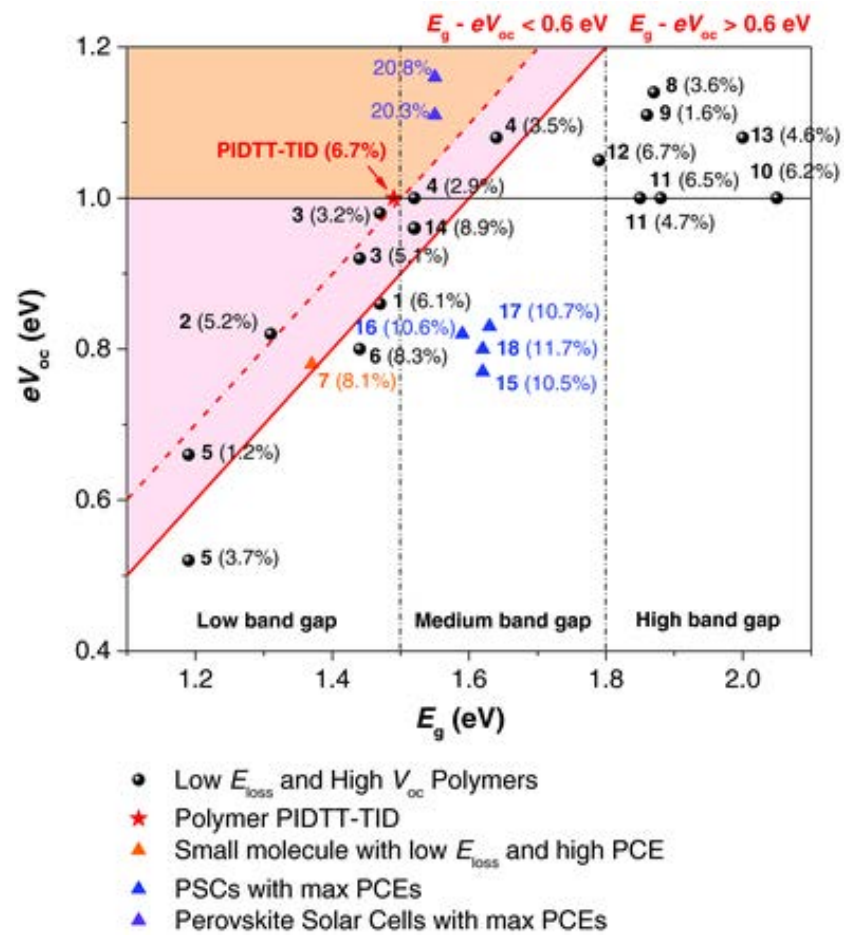

Figure9.2 Plots of eVoc against Eg for Perovskite and organic solar cells with low Eloss or high Voc. Eg is determined from the absorption onset. The black solid line is the eVoc of $1.0 \mathrm{eV}$, the red dashed line is the $\mathrm{eVoc}=\mathrm{Eg}-0.5$, and the red solid line is the $\mathrm{eVoc}=\mathrm{Eg}-0.6$. 


\subsubsection{Paper 3}

\section{Ternary organic solar cells with enhanced open circuit voltage}

Chuanfei Wang, Xiaofeng Xu, Wei Zhang, Sadok Ben Dkhil, Xiangyi Meng, Xianjie Liu, Olivier Margeat, Arkady Yartsev, Wei Ma, Jörg Ackermann, Ergang Wang, Mats Fahlman

Nano Energy, 2017, 37, 24

Ternary organic solar cell combined the advantages of broad absorption of tandem solar cells and simplicity of single bulk heterojunction solar cell, making it a promising strategy of improving the performance of organic solar cell. The short circuit current density is usually improved in efficient ternary system, while the $V_{\text {oc }}$ either assumes a value in between those obtained by the respective binary solar cells or pins to the smaller value of the two.

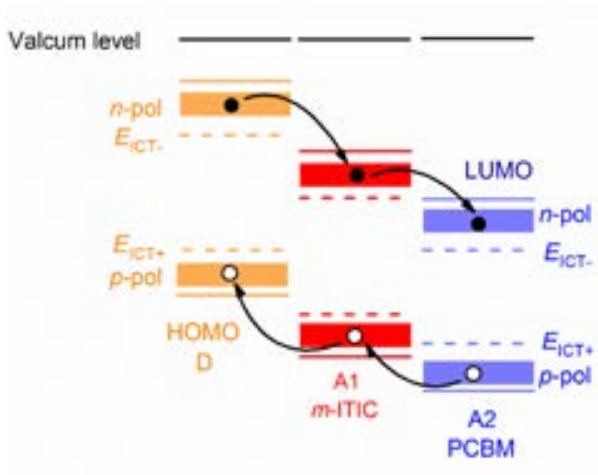

Sest-organized cascade energy level

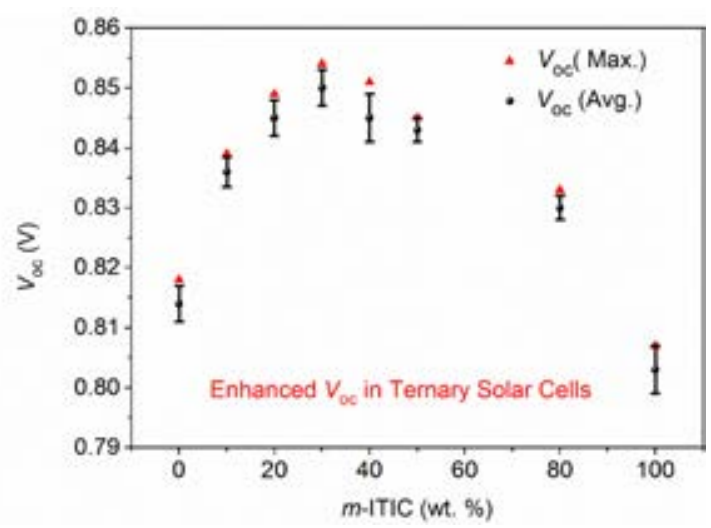

Figure 9.3 Self-organized cascade junction of Donor/Acceptor1/Accepter (left panel) and enhanced Voc of ternary solar cell (right panel).

In paper 3, the polymer donor of PTB7-Th and acceptor $\mathrm{PC}_{71} \mathrm{BM}$ were employed as the host system of the ternary solar cell. Because the $E_{\mathrm{ICT}+}$ of PTB7-Th is equal to the $E_{\mathrm{ICT}-}$ of the $\mathrm{PC}_{71} \mathrm{BM}$, which

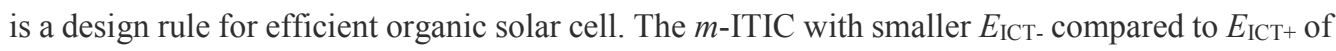
PTB7-Th was added to the host system. The surface tension and energy levels of $m$-ITIC make it self-organize at the interface of the host donor and acceptor to form a cascade-type energy level alignment (Figure 9.3). For the first time, the ternary solar cell with enhanced open circuit voltage was designed and demonstarted (Figure 9.3). Both performance and thermal stability were 
enhanced in the ternary solar cell. The enhanced open circuit voltage could be contributed to decreased radiative bimolecular recombination and trap assisted recombination via integer charge transfer state. We also show that this strategy can be generally used in other system. 


\subsubsection{Paper 4}

\section{Ternary Organic Solar Cells with Minimum Voltage Losses}

Chuanfei Wang, Wei Zhang, Xiangyi Meng, Jonas Bergqvist, Xianjie Liu, Zewdneh Genene, Xiaofeng Xu, Arkady Yartsev, Olle Inganäs, Wei Ma, Ergang Wang, Mats Fahlman

Advanced Energy Materials, 2017, 6, 1700390

According to integer charge transfer model, the appearance of integer charge transfer states in organic solar cell could be the site of trap assistant recombination and increase the voltage losses of organic solar cell, while the charge generation would be enhanced because of the existence of the ICT state. The trade-off between charge generation and charge recombination by ICT state will

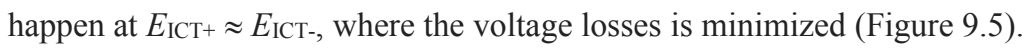
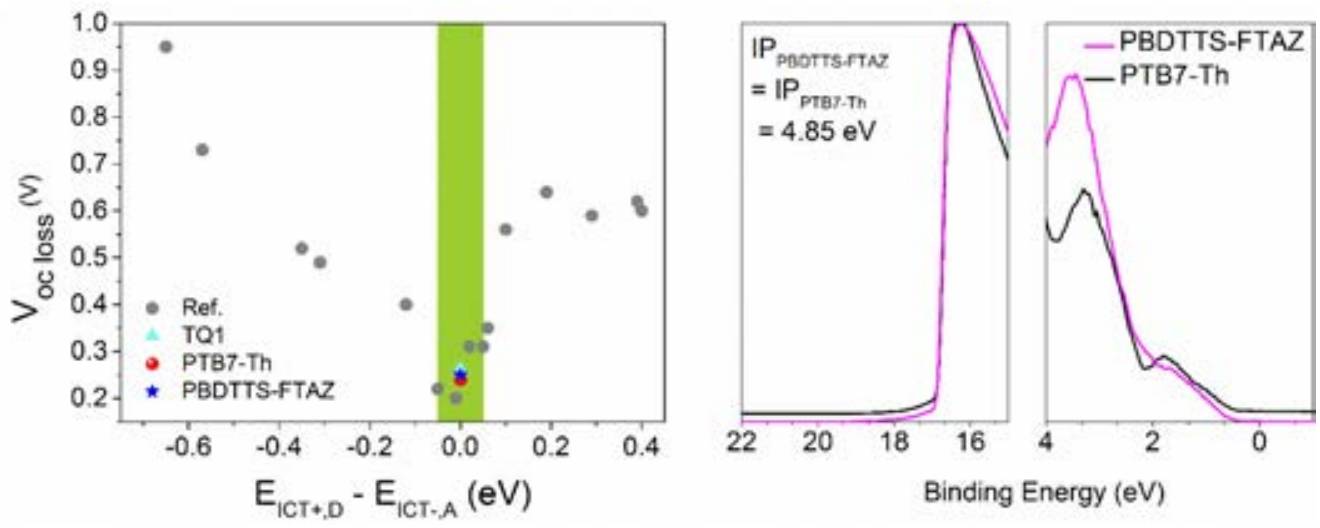

Figure 9.5 (a) $V_{\text {oc loss }}$ versus $E_{\mathrm{ICT}+\text {, D }}-E_{\mathrm{ICT}-}$, A for a series of polymer: fullerene. (b) UPS spectra of pure PTB7-Th and pure PBDTTS-FTAZ film on the substrate of ITO/PEDOT: PSS.

In paper 4, low-bandgap polymer PTB7-Th and a high-bandgap polymer PBDTTS-FTAZ sharing the same bulk ionization potential and interface positive integer charge transfer energy while featuring complementary absorption spectra are selected as two donors to fabricate efficient ternary solar cells (Figure 9.4b). At the same times, the fullerene acceptor was chosen so that $E_{\mathrm{ICT}+}$ of the two donor polymers is equal to $E_{\text {ICT- }}$ of the fullerene, enabling enhanced dissociation of all polymer donor and fullerene acceptor excitons and suppressed bimolecular and trap assisted recombination. 
It also proved that efficient energy transfer and charge transfer could coexist between the two donor polymers with same ionization potential and positive pinning energy.

\subsubsection{Paper 5}

Pyrrolo [3,4-g] quinoxaline-6, 8-dione-based conjugated copolymers for bulk heterojunction solar cells with high photovoltages

Xiaofeng Xu, Chuanfei Wang, Olof Bäcke, David I James, Kim Bini, Eva Olsson, Mats R Andersson, Mats Fahlman, Ergang Wang

Polymer Chemistry, 2015, 6, 4624

The maximum attainable voltage of the bulk heterojunction organic solar cell is determined by the alignment of the energy levels of the donor and acceptor, i.e. the HOMO of the donor and the LUMO of the acceptor. In order to obtain high voltage, in paper 5, four deep HOMO and medium band gap polymers synthesized by combining electron-deficient unit PQD and electron efficient unite PBDT and PT were used as donor in fullerene based binary organic solar cell. The experiment shows that all of the obtained voltages for the four deep HOMO medium band gap polymers could reach $1.0 \mathrm{~V}$. The highest value is $1.08 \mathrm{~V}$, which is rarely observed in medium band gap polymer. 


\subsubsection{Paper 6}

\section{Degradation of n-type non-fullerene small molecules}

Chuanfei Wang, Shaofei Ni, Slawomir Braun, Xianjie Liu, Mats Fahlman

\section{Manuscript}

Solution processing of organic molecules/polymers affords a promising route for the realization of low-cost, large area, flexible and light weight organic solar cells with shorter energy payback time. The relative low efficiency and inferior stability are hindering the commercialization of the organic solar cell, however. The rapid development of the fullerene-free small molecular acceptors push the efficiency of the organic solar cell to a higher level that if accompanied by an increased stability may provide the needed breakthrough. So understanding the stability and degradation mechanism of these kind of acceptors is a key issue.

In paper 6 , the stability and degradation of three n-type non-fullerene small molecules, named $p$ ITIC, $m$-ITIC and $o$-IDTBR, are explored via an in-situ method, employing the photoelectron spectroscopy technique. The materials are deposited on substrates of aluminum to form thin films and subsequently the thin films are exposed in-situ to oxygen and water respectively. The experiment results reveal that all of the films show enhanced resistance to oxygen and water vapor compared to fullerene small molecules. Furthermore, the evolution of the frontier orbital properties of the non-fullerene molecules is different from the evaluation trend of the fullerene when they are exposed to oxygen. The frontier orbital of the non-fullerene molecules are broaden and bleached slowly with the increase of the exposure time, and the binding energy also increased slowly, while the frontier orbital properties of fullerene in UPS spectra show no change but the binding energy decreased quickly. More importantly, the p/m-ITIC show little degradation when exposed to water vapor, while there is significant chemical interaction between water vapor and fullerene. 


\subsection{Further outlook}

The experiment results in this thesis raise a lot of additional questions that need studying and clarifying.

Besides of the IP, the determination of the EA is also an important task especially for acceptors in organic solar cell. The usually used method in the community is electrochemical method. It is expected that there is a liner relationship between the reduction potential $\mathrm{E}_{\text {red }}$ and the EA with the slope equal to unit. With the rapid development of the new fullerene free acceptor materials, it's also urgent to determine the EA of the typically used fullerene free acceptors and extend the relationship between the open circuit voltage losses and the pinning energy based on the established model in fullerene solar cell.

The working mechanism of the ternary solar cell is complicated and still need to be investigated in detail, especially the open circuit voltage of the ternary solar cell. Such as how the open circuit voltage can be turned in ternary blend, alloy charge transfer state model or two charge transfer state model. The alloy charge transfer model proposes that the evolution of the $E_{\mathrm{CT}}$ is due to an alloy formation when two miscible donors or acceptors are used and that the CT state can partially delocalize. The two charge transfer state model, on the other hand, proposes that the ternary solar cell can be viewed as comprising two separate binary solar cells and that the electrons and holes are transported via three separated percolating networks. It should be interesting to explore how the third component affect the open circuit voltage loss in ternary blend and a quantitative study about the voltage loss should be conducted.

The development of polymer acceptor and fullerene-free small molecules afford more chance to improve the performance and stability of the organic solar cell. The new acceptor materials are to be used in ternary solar cells, such as all-polymer ternary solar cells and the ternary solar cell with fullerene free small molecules as acceptor. The strategies used in this thesis should be tried extending to other non-fullerene ternary systems.

One of the advantages of ternary organic solar cell is that it can be mass produced by roll to roll methods. In the lab scale, the devices are deposited on the ITO substrate. In order to employ the printing process and reduce the energy payback time, the ITO-free plastic substrate should be tried to be used in the ternary devices fabrication in following research. 
The electrode modifier, i.e. interface layer, can improve the charge extraction and stability of the organic solar cell and different kinds of the buffer layer can be used in both binary and ternary solar cell to figure out the selection principles.

The stability of the pure materials was investigated in the thesis and it is also important to figure out the stability and the degradation mechanisms of the corresponding devices in the near future. 


\section{Appendix}

VR: vibration relaxation. IC: internal conversion. ISC: intersystem crosing. F: fluorescence. P: phosphorescence, Q: qunching.

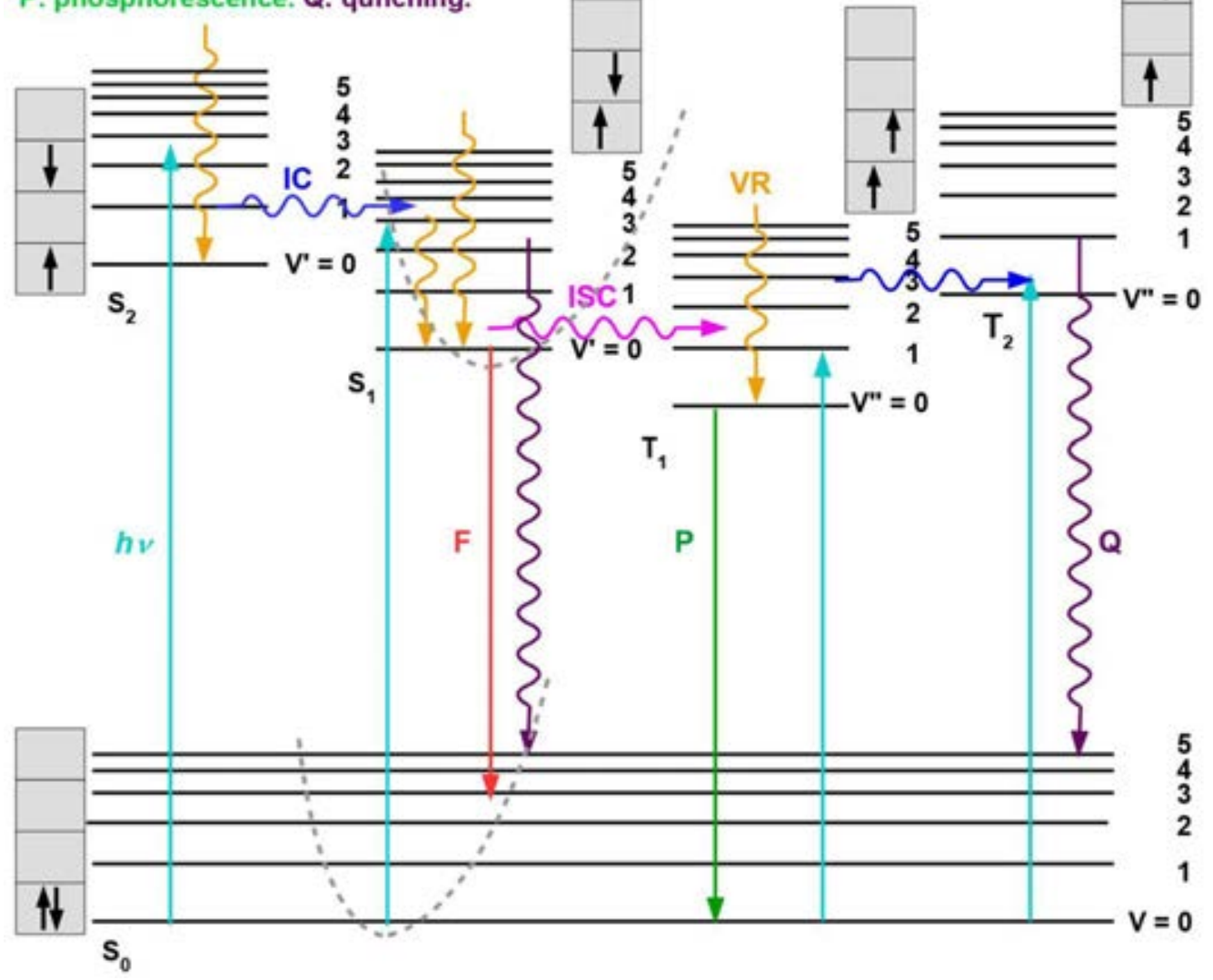

Figure A1 Jablonski diagram 


\section{Reference}

[1] C. W. Tang, S. A. Vanslyke, Appl. Phys. Lett. 1987, 51, 913.

[2] S. Braun, W. R. Salaneck, M. Fahlman, Adv. Mater. 2009, 21, 1450.

[3] W. N. Hansen, G. J. Hansen, Phys. Rev. A 1987, 36, 1396.

[4] R. Gomer, G. Tryson, J. Chem. Phys. 1977, 66, 4413.

[5] Y. Y. Liang, Y. Wu, D. Q. Feng, S. T. Tsai, H. J. Son, G. Li, L. P. Yu, J. Am. Chem. Soc. 2009, 131, 56.

[6] C. M. Cardona, W. Li, A. E. Kaifer, D. Stockdale, G. C. Bazan, Adv. Mater. 2011, 23, 2367.

[7] Y. B. Cheng, A. Pascoe, F. Huang, Y. Peng, Nature 2016, 539, 488.

[8] http://www.ren21.net.

[9] C. F. Wang, X. F. Xu, W. Zhang, S. Ben Dkhil, X. Y. Meng, X. J. Liu, O. Margeat, A. Yartsev, W. Ma, J. Ackermann, E. G. Wang, M. Fahlman, Nano Energy 2017, 37, 24.

[10] www.ise.fraunhofer.de.

[11] S. Kato, Theor. Chem. Acc. 2000, 103, 219.

[12] W. R. Salaneck, Phys. Rev. Lett. 1978, 40, 60.

[13] M. Campoy-Quiles, T. Ferenczi, T. Agostinelli, P. G. Etchegoin, Y. Kim, T. D. Anthopoulos, P. N. Stavrinou, D. D. C. Bradley, J. Nelson, Nat. Mater. 2008, 7, 158.

[14] A. Atxabal, S. Braun, T. Arnold, X. N. Sun, S. Parui, X. J. Liu, C. Gozalvez, R. Llopis, A. Mateo-Alonso, F. Casanova, F. Ortmann, M. Fahlman, L. E. Hueso, Adv. Mater. 2017, 29, 1606901.

[15] C. Wang, W. Zhang, X. Meng, J. Bergqvist, X. Liu, Z. Genene, X. Xu, A. Yartsev, O. Inganäs, W. Ma, E. Wang, M. Fahlman, Adv. Energy Mater. 2017, 1700390.

[16] M. C. Scharber, D. Wuhlbacher, M. Koppe, P. Denk, C. Waldauf, A. J. Heeger, C. L. Brabec, Adv. Mater. 2006, 18, 789.

[17] H. Ishii, K. Sugiyama, E. Ito, K. Seki, Adv. Mater. 1999, 11, 605.

[18] B. A. Jones, A. Facchetti, M. R. Wasielewski, T. J. Marks, J. Am. Chem. Soc. 2007, 129, 15259.

[19] H. T. Nicolai, M. Kuik, G. A. H. Wetzelaer, B. de Boer, C. Campbell, C. Risko, J. L. Bredas, P. W. M. Blom, Nat. Mater. 2012, 11, 882.

[20] D. Abbaszadeh, A. Kunz, G. A. H. Wetzelaer, J. J. Michels, N. I. Craciun, K. Koynov, I. Lieberwirth, P. W. M. Blom, Nat. Mater. 2016, 15, 628.

[21] A. Pron, P. Gawrys, M. Zagorska, D. Djurado, R. Demadrille, Chem. Soc. Rev. 2010, 39, 2577.

[22] P. I. Djurovich, E. I. Mayo, S. R. Forrest, M. E. Thompson, Org. Electron. 2009, 10, 515.

[23] I. G. Hill, A. Kahn, Z. G. Soos, R. A. Pascal, Chem. Phys. Lett. 2000, 327, 181.

[24] S. J. Yang, P. Olishevski, M. Kertesz, Synth. Met. 2004, 141, 171.

[25] S. van Reenen, S. Kouijzer, R. A. J. Janssen, M. M. Wienk, M. Kemerink, Adv. Mater. Interfaces 2014, 1, 1400189.

[26] C. Arantes, M. Scholz, R. Schmidt, V. Dehm, M. L. M. Rocco, A. Scholl, F. Reinert, F. Wurthner, Appl. Phys. A-Mater. Sci. Process. 2012, 108, 629.

[27] N. D. Lang, W. Kohn, Phys. Rev. B 1971, 3, 1215.

[28] N. D. Lang, W. Kohn, Phys. Rev. B 1973, 7, 3541.

[29] N. D. Lang, Phys. Rev. Lett. 1981, 46, 842.

[30] Y. C. Chen, J. E. Cunningham, C. P. Flynn, Phys. Rev. B 1984, 30, 7317.

[31] C. Tengstedt, W. Osikowicz, W. R. Salaneck, I. D. Parker, C. H. Hsu, M. Fahlman, Appl. Phys. Lett. 2006, 88, 053502. 
[32] M. Fahlman, A. Crispin, X. Crispin, S. K. M. Henze, M. P. de Jong, W. Osikowicz, C. Tengstedt, W. R. Salaneck, J. Phys.-Condes. Matter 2007, 19, 183202.

[33] H. Vazquez, F. Flores, A. Kahn, Org. Electron. 2007, 8, 241.

[34] S. Braun, M. P. de Jong, W. Osikowicz, W. R. Salaneck, Appl. Phys. Lett. 2007, 91, 202108.

[35] X. Crispin, V. Geskin, A. Crispin, J. Cornil, R. Lazzaroni, W. R. Salaneck, J. L. Bredas, J. Am. Chem. Soc. 2002, 124, 8131 .

[36] J. Chen, M. A. Reed, A. M. Rawlett, J. M. Tour, Science 1999, 286, 1550.

[37] G. Heimel, L. Romaner, E. Zojer, J. L. Bredas, Accounts Chem. Res. 2008, 41, 721.

[38] M. Fahlman, P. Sehati, W. Osikowicz, S. Braun, M. P. de Jong, G. Brocks, J. Electron Spectrosc. Relat. 2013, 190, 33.

[39] M. Bokdam, D. Cakir, G. Brocks, Appl. Phys. Lett. 2011, 98, 113303.

[40] H. Aarnio, P. Sehati, S. Braun, M. Nyman, M. P. de Jong, M. Fahlman, R. Osterbacka, Adv. Energy Mater. 2011, 1, 792.

[41] W. Osikowicz, M. P. de Jong, W. R. Salaneck, Adv. Mater. 2007, 19, 4213.

[42] R. J. Murdey, W. R. Salaneck, Jpn. J. Appl. Phys. 2005, 44, 3751.

[43] Q. Y. Bao, O. Sandberg, D. Dagnelund, S. Sanden, S. Braun, H. Aarnio, X. J. Liu, W. M. M. Chen, R. Osterbacka, M. Fahlman, Adv. Funct. Mater. 2014, 24, 6309.

[44] V. I. Arkhipov, P. Heremans, H. Bassler, Appl. Phys. Lett. 2003, 82, 4605.

[45] J. Isaksson, C. Tengstedt, M. Fahlman, N. Robinson, M. Berggren, Adv. Mater. 2004, 16,316 .

[46] Z. Tang, W. Tress, Q. Y. Bao, M. J. Jafari, J. Bergqvist, T. Ederth, M. R. Andersson, O. Inganas, Adv. Energy Mater. 2014, 4, 1400643.

[47] Z. F. Ma, Z. Tang, E. G. Wang, M. R. Andersson, O. Inganas, F. L. Zhang, J. Phys. Chem. C 2012, 116, 24462.

[48] A. Orimo, K. Masuda, S. Honda, H. Benten, S. Ito, H. Ohkita, H. Tsuji, Appl. Phys. Lett. 2010, 96, 043305.

[49] D. S. Germack, C. K. Chan, R. J. Kline, D. A. Fischer, D. J. Gundlach, M. F. Toney, L. J. Richter, D. M. DeLongchamp, Macromolecules 2010, 43, 3828.

[50] S. Honda, H. Ohkita, H. Benten, S. Ito, Adv. Energy Mater. 2011, 1, 588.

[51] T. W. Cheng, H. Keskkula, D. R. Paul, Polymer 1992, 33, 1606.

[52] D. Li, A. W. Neumann, J. Colloid Interface Sci. 1990, 137, 304.

[53] A. D. B. C. R. Brundle, Electron Spectroscopy: Theory, Techniques and Applications; Academic Press: New York 1978.

[54] W. R. Salaneck, S. Stafstrom, and Jean Luc Brédas., Conjugated polymer surfaces and interfaces; Cambridge University Press, 2003.

[55] T. Johansson, W. Mammo, M. Svensson, M. R. Andersson, O. Inganas, J. Mater. Chem. 2003, 13, 1316.

[56] J. L. Bredas, R. Silbey, D. S. Boudreaux, R. R. Chance, J. Am. Chem. Soc. 1983, 105, 6555.

[57] G. Gritzner, J. Kůta, Electrochim. Acta 1984, $29,869$.

[58] G. Yu, J. Gao, J. C. Hummelen, F. Wudl, A. J. Heeger, Science 1995, 270, 1789.

[59] H. Kallmann, M. Pope, J. Chem. Phys. 1959, 30, 585.

[60] C. W. Tang, Appl. Phys. Lett. 1986, 48, 183.

[61] S. J. Fonash, Solar Cells Device Physics; Academic Press: San Diego 1981, P4.

[62] S. R. Forrest, MRS Bull. 2005, 30, 28.

[63] A. Armin, M. Velusamy, P. Wolfer, Y. L. Zhang, P. L. Burn, P. Meredith, A. Pivrikas, Acs Photonics 2014, 1, 173.

[64] O. V. Mikhnenko, H. Azimi, M. Scharber, M. Morana, P. W. M. Blom, M. A. Loi, Energ Environ. Sci. 2012, 5, 6960. 
[65] R. R. Lunt, N. C. Giebink, A. A. Belak, J. B. Benziger, S. R. Forrest, J. Appl. Phys. 2009, 105, 053711.

[66] B. Siegmund, M. T. Sajjad, J. Widmer, D. Ray, C. Koerner, M. Riede, K. Leo, I. D. W. Samuel, K. Vandewal, Adv. Mater. 2017, 29, 1604224.

[67] M. A. Loi, S. Toffanin, M. Muccini, M. Forster, U. Scherf, M. Scharber, Adv. Funct. Mater. 2007, 17, 2111.

[68] K. Vandewal, Z. F. Ma, J. Bergqvist, Z. Tang, E. G. Wang, P. Henriksson, K. Tvingstedt, M. R. Andersson, F. L. Zhang, O. Inganas, Adv. Funct. Mater. 2012, 22, 3480.

[69] D. Veldman, S. C. J. Meskers, R. A. J. Janssen, Adv. Funct. Mater. 2009, 19, 1939.

[70] M. A. Faist, T. Kirchartz, W. Gong, R. S. Ashraf, I. McCulloch, J. C. de Mello, N. J. Ekins-Daukes, D. D. C. Bradley, J. Nelson, J. Am. Chem. Soc. 2012, 134, 685.

[71] Z. F. Ma, W. J. Sun, S. Himmelberger, K. Vandewal, Z. Tang, J. Bergqvist, A. Salleo, J. W. Andreasen, O. Inganas, M. R. Andersson, C. Muller, F. L. Zhang, E. R. Wang, Energ Environ. Sci. 2014, 7, 361.

[72] C. F. Wang, X. F. Xu, W. Zhang, J. Bergqvist, Y. X. Xia, X. Y. Meng, K. Bini, W. Ma, A. Yartsev, K. Vandewal, M. R. Andersson, O. Inganas, M. Fahlman, E. G. Wang, Adv. Energy Mater. 2016, 6.

[73] K. Vandewal, S. Albrecht, E. T. Hoke, K. R. Graham, J. Widmer, J. D. Douglas, M. Schubert, W. R. Mateker, J. T. Bloking, G. F. Burkhard, A. Sellinger, J. M. J. Frechet, A. Amassian, M. K. Riede, M. D. McGehee, D. Neher, A. Salleo, Nat. Mater. 2014, 13, 63.

[74] K. Vandewal, A. Gadisa, W. D. Oosterbaan, S. Bertho, F. Banishoeib, I. Van Severen, L. Lutsen, T. J. Cleij, D. Vanderzande, J. V. Manca, Adv. Funct. Mater. 2008, 18, 2064.

[75] K. Tvingstedt, K. Vandewal, A. Gadisa, F. L. Zhang, J. Manca, O. Inganas, J. Am. Chem. Soc. 2009, 131, 11819.

[76] K. Vandewal, K. Tvingstedt, A. Gadisa, O. Inganas, J. V. Manca, Phys. Rev. B 2010, $81,125204$.

[77] F. Deschler, E. Da Como, T. Limmer, R. Tautz, T. Godde, M. Bayer, E. von Hauff, S. Yilmaz, S. Allard, U. Scherf, J. Feldmann, Phys. Rev. Lett. 2011, 107, 127402.

[78] P. Sehati, S. Braun, L. Lindell, X. J. Liu, L. M. Andersson, M. Fahlman, IEEE J. Sel. Top. Quantum Electron. 2010, 16, 1718.

[79] C. M. Proctor, M. Kuik, T. Q. Nguyen, Prog. Polym. Sci. 2013, 38, 1941.

[80] M. Kuik, L. J. A. Koster, G. A. H. Wetzelaer, P. W. M. Blom, Phys. Rev. Lett. 2011, 107, 256805.

[81] R. A. J. Janssen, J. Nelson, Adv. Mater. 2013, 25, 1847.

[82] W. W. Li, K. H. Hendriks, A. Furlan, M. M. Wienk, R. A. J. Janssen, J. Am. Chem. Soc. 2015, 137, 2231.

[83] J. Z. Yao, T. Kirchartz, M. S. Vezie, M. A. Faist, W. Gong, Z. C. He, H. B. Wu, J. Troughton, T. Watson, D. Bryant, J. Nelson, Phys. Rev. Appl. 2015, 4, 014020.

[84] J. Liu, S. S. Chen, D. P. Qian, B. Gautam, G. F. Yang, J. B. Zhao, J. Bergqvist, F. L. Zhang, W. Ma, H. Ade, O. Inganas, K. Gundogdu, F. Gao, H. Yan, Nat. Energy 2016, $1,16089$.

[85] Z. Xu, L. M. Chen, G. W. Yang, C. H. Huang, J. H. Hou, Y. Wu, G. Li, C. S. Hsu, Y. Yang, Adv. Funct. Mater. 2009, 19, 1227.

[86] T. Ameri, P. Khoram, J. Min, C. J. Brabec, Adv. Mater. 2013, 25, 4245.

[87] Q. S. An, F. J. Zhang, J. Zhang, W. H. Tang, Z. B. Deng, B. Hu, Energ Environ. Sci. 2016, 9, 281.

[88] K. Vandewal, J. Widmer, T. Heumueller, C. J. Brabec, M. D. McGehee, K. Leo, M. Riede, A. Salleo, Adv. Mater. 2014, 26, 3839. 
[89] J. Benduhn, K. Tvingstedt, F. Piersimoni, S. Ullbrich, Y. L. Fan, M. Tropiano, K. A. McGarry, O. Zeika, M. K. Riede, C. J. Douglas, S. Barlow, S. R. Marder, D. Neher, D. Spoltore, K. Vandewal, Nat. Energy 2017, 2, 17053.

[90] L. Q. Yang, L. Yan, W. You, J. Phys. Chem. Lett. 2013, 4, 1802.

[91] P. J. Jadhav, A. Mohanty, J. Sussman, J. Lee, M. A. Baldo, Nano Lett. 2011, 11, 1495.

[92] H. Q. Wang, T. Stubhan, A. Osvet, I. Litzov, C. J. Brabec, Sol. Energy Mater. Sol. Cells 2012, 105, 196.

[93] W. R. Salaneck, M. Logdlund, M. Fahlman, G. Greczynski, T. Kugler, Mater. Sci. Eng. R-Rep. 2001, 34, 121.

[94] W. R. Salaneck, Rep. Prog. Phys. 1991, 54, 1215.

[95] K. Z. Xing, M. Fahlman, M. Logdlund, D. A. dosSantos, V. Parente, R. Lazzaroni, J. L. Bredas, R. W. Gymer, W. R. Salaneck, Adv. Mater. 1996, 8, 971.

[96] K. Z. Xing, N. Johansson, Adv. Mater. 1997, 9, 1027.

[97] Q. Y. Bao, X. J. Liu, S. Braun, M. Fahlman, Adv. Energy Mater. 2014, 4, 1301272.

[98] Y. Wang, S. Di Motta, F. Negri, R. Friedlein, J. Am. Chem. Soc. 2011, 133, 10054.

[99] H. E. Katz, A. J. Lovinger, J. Johnson, C. Kloc, T. Siegrist, W. Li, Y. Y. Lin, A. Dodabalapur, Nature 2000, 404, 478.

[100] W. J. Li, H. E. Katz, A. J. Lovinger, J. G. Laquindanum, Chem. Mater. 1999, 11, 458.

[101] Y. Zhang, H. L. Yip, O. Acton, S. K. Hau, F. Huang, A. K. Y. Jen, Chem. Mater. 2009, 21,2598 .

[102] R. C. Mulherin, S. Jung, S. Huettner, K. Johnson, P. Kohn, M. Sommer, S. Allard, U. Scherf, N. C. Greenham, Nano Lett. 2011, 11, 4846.

[103] Y. Lin, J. A. Lim, Q. S. Wei, S. C. B. Mannsfeld, A. L. Briseno, J. J. Watkins, Chem. Mater. 2012, 24, 622.

[104] M. H. Liao, C. E. Tsai, Y. Y. Lai, F. Y. Cao, J. S. Wu, C. L. Wang, C. S. Hsu, I. Liau, Y. J. Cheng, Adv. Funct. Mater. 2014, 24, 1418.

[105] S. Ben Dkhil, M. Pfannmoller, M. I. Saba, M. Gaceur, H. Heidari, C. VidelotAckermann, O. Margeat, A. Guerrero, J. Bisquert, G. Garcia-Belmonte, A. Mattoni, S. Bals, J. Ackermann, Adv. Energy Mater. 2017, 7, 1601486. 


\section{Papers}

The papers associated with this thesis have been removed for copyright reasons. For more details about these see:

http:// urn.kb.se/ resolve?urn=urn:nbn:se:liu:diva-143025 